MILD

CONDUSTIVE

DRVING

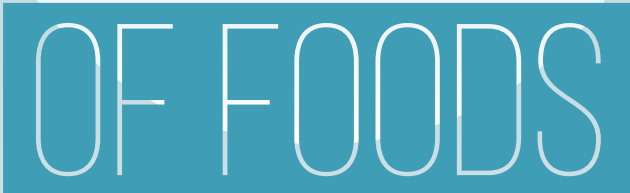

Jun Qiu 



\section{Propositions}

1. Conductive drying at lower temperature is not necessarily milder. (this thesis)

2. Understanding material-specific drying behaviour enables more generic energy efficient drying.

(this thesis)

3. Big data analyses can extract high value information from data sets having low value density.

4. The complexity of food systems cannot be captured with models that only consider part of the system.

5. Planning for flexibility gives more flexibility in planning.

6. Writing scientific propositions is more an art than a science.

Propositions belonging to the thesis, entitled

"Mild conductive drying of foods"

$$
\text { Jun Qiu }
$$

Wageningen, 17th April 2019 



\title{
Mild conductive drying of foods
}

\author{
Jun Qiu
}




\section{Thesis committee}

\section{Promotors}

Dr M.A.I. Schutyser

Associate Professor, Laboratory of Food Process Engineering

Wageningen University \& Research

Prof. Dr R.M. Boom

Professor of Food Process Engineering

Wageningen University \& Research

\section{Other members}

Prof. Dr V. Fogliano, Wageningen University \& Research

Dr A.J.B. van Boxtel, Wageningen University \& Research

Prof. Dr S. Khalouffi, Université Laval, Québec, Canada

Prof. Dr C.W.M. van der Geld, Eindhoven University of Technology

This research was conducted under the auspices of the Graduate School VLAG (Advanced studies in Food Technology, Agrobiotechnology, Nutrition and Health Sciences). 


\title{
Mild conductive drying of foods
}

\author{
Jun Qiu
}

Thesis

submitted in fulfilment of the requirements for the degree of doctor

at Wageningen University

by the authority of the Rector Magnificus,

Prof. Dr A.P.J. Mol,

in the presence of the

Thesis Committee appointed by the Academic Board

to be defended in public

on Wednesday 17 April 2019

at 4 p.m. in the Aula. 
Jun Qiu

Mild conductive drying of foods

170 pages

PhD thesis, Wageningen University, Wageningen, the Netherlands (2019)

With references, with summary in English

ISBN: 978-94-6343-579-6

DOI: https://doi.org/10.18174/469413 


\section{Table of contents}

$\begin{array}{lll}\text { Chapter } 1 \text { General introduction } & 1\end{array}$

Chapter 2 Formation and degradation kinetics of organic acids during heating and drying of concentrated tomato juice

Chapter 3 Conductive thin film drying kinetics relevant to drum drying

Chapter 4 Model development for conductive thin film drying 65 processes

Chapter 5 Agitated thin-film drying of foods

Chapter 6 A systematic analysis on tomato powder quality 105 prepared by four conductive drying technologies

Chapter 7 General discussion

Summary

Acknowledgements 



\section{CHAPTER 1}

\section{General introduction}




\subsection{Introduction}

Drying is employed in the food industry to preserve and extend the shelf-lives of foods, since at very low water content, microbial spoilage and many chemical reactions are slowed down or even halted. Moreover, drying decreases the product volume and its weight, which benefits handling and transportation costs ${ }^{1,2}$. There is a growing market of dried food ingredients with high added value, such as thickeners, emulsifiers, flavouring, and pigments, which requires increasing drying capacity and further optimisation of the quality of the final dried product ${ }^{3}$.

Optimal design and control of drying operations are highly relevant to the food industry. During drying, food formulations are transformed from a liquid or semi-solid moist product into a dry product. During this transformation various physical and chemical reactions occur that generally affect the product quality including flavour, colour, nutritional properties, etc. ${ }^{4}$. Drying also creates specific functional properties in foods and ingredients such as rehydration properties, solubility, hygroscopicity, etc., which are crucial to their application.

In addition to product quality, drying impacts the total environmental footprint and costs of food production. It is estimated that drying operations account for $9 \%$ to $25 \%$ of the total industrial energy consumption in developed countries 3, 5, 6. Given the limited available resources and global warming, continuous efforts should be made to radically increase the efficiency in drying operations. However, such efforts should not only focus on the development of more energy efficient dryer designs or operation strategies, but also on the understanding of the transformation of products during drying, which is critical to the success or failure of drying processes with respect to product quality.

Therefore, this thesis focuses on obtaining better insights in more energyefficient conductive drying technologies, and providing better scientific support for successful drying of foods. 


\subsection{Classification of drying technologies}

According to open literature, there are more than 400 different dryer designs, amongst which 100 distinct designs are applied more or less commonly ${ }^{5}$. Most drying technologies are based on either convective or conductive heat transfer.

More than $85 \%$ of the industrial dryers are convective dryers ${ }^{7-9}$. During convective drying, usually hot air is used, which is in direct contact with the product (Figure 1-1). Examples are belt dryers, spray dryers, and (batch or continuous) tray dryers. In the food industry, spray drying is one of the most commonly used drying methods to produce dried powder ingredients. It is a relatively mild drying method, since fast evaporation prevents excessive heating of the sprayed droplets and the particle temperature increases only gradually towards the outlet air temperature ${ }^{\mathbf{1 0}}$. A disadvantage of spray drying is the relatively poor energy efficiency, which is due to the energy loss via the warm and moist exhaust gas.

(A)

\section{Convective drying}

Wet product

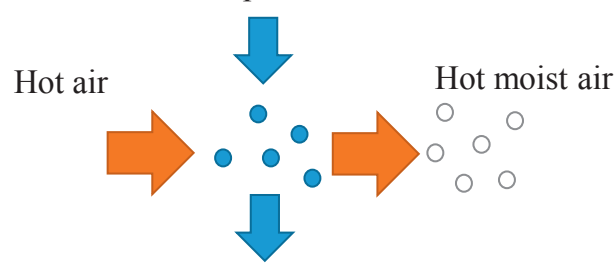

(B)

\section{Conductive drying}

Water vapour

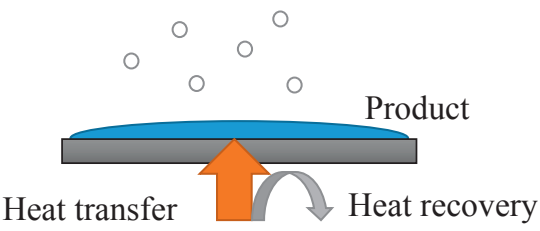

Dried product

Figure 1-1 Schematic representation of drying mechanisms of (A) convective (direct) drying and (B) conductive (indirect or contact) drying.

The second largest category of dryers relies on conductive drying. Heat is here transferred from condensed steam or hot water to the product via conduction through a (metal) wall (Figure 1-1) ${ }^{5}$. The product is applied as a thin film (stagnant or agitated) on the heated surface to minimise the drying time. A disadvantage of conductive drying is the relatively high product temperature, which is equal to the boiling temperature and can negatively affect the product quality. Therefore, some conductive dryers operate at reduced pressure, which 
allows milder drying at lower temperature, albeit at the cost of larger equipment complexity. Typical conductive dryers are (vacuum) drum dryers, agitated thin film dryers and refractance window dryers ${ }^{11}$. Table 1-1 provides a more extensive comparison between convective (direct) and conductive (indirect) drying technologies ${ }^{9,12}$.

Table 1-1 Comparison of direct and indirect drying ${ }^{\text {9, }}$.

\begin{tabular}{|c|c|c|}
\hline Aspects & Convective drying & Conductive drying \\
\hline Heat medium & $\begin{array}{l}\text { Heating medium can be air } \\
\text { (most common), inert gas (i.e. } \\
\mathrm{N}_{2} \text { for drying materials with } \\
\text { organic solvent), and } \\
\text { superheated steam. } \\
\text { Heat medium has direct contact } \\
\text { with the surface of the material } \\
\text { to be dried. } \\
\text { Heat for evaporation is supplied } \\
\text { by convection. }\end{array}$ & $\begin{array}{l}\text { Heating medium can be } \\
\text { saturated steam, hot water or } \\
\text { electricity. } \\
\text { Heating medium is separated } \\
\text { from the material by a wall. } \\
\text { Heat for evaporation is supplied } \\
\text { by conduction through the wall. }\end{array}$ \\
\hline Moisture removal & $\begin{array}{l}\text { The evaporated moisture is } \\
\text { carried away by the heating } \\
\text { medium. }\end{array}$ & $\begin{array}{l}\text { Only low gas flow or vacuum is } \\
\text { needed to carry away the } \\
\text { evaporated moisture }\end{array}$ \\
\hline $\begin{array}{l}\text { Application under } \\
\text { vacuum }\end{array}$ & Not possible. & $\begin{array}{l}\text { Possible. But it is difficult to be } \\
\text { operated in a continuous mode } \\
\text { under vacuum. }\end{array}$ \\
\hline Energy efficiency & $\begin{array}{l}\text { Low due to the energy loss via } \\
\text { exhaust gas. }\end{array}$ & $\begin{array}{l}\text { High due to the limited exhaust } \\
\text { gas. }\end{array}$ \\
\hline $\begin{array}{l}\text { Production } \\
\text { capacity }\end{array}$ & $\begin{array}{l}\text { Generally higher than } \\
\text { conductive dryers }\end{array}$ & $\begin{array}{l}\text { Lower production capacity due } \\
\text { to the limited availability of the } \\
\text { heat transfer areas. }\end{array}$ \\
\hline Cost & High & $\begin{array}{l}\text { Higher capital cost. } \\
\text { Difficult to design, fabricate and } \\
\text { maintain }\end{array}$ \\
\hline $\begin{array}{l}\text { Cross } \\
\text { contamination }\end{array}$ & Remains & $\begin{array}{l}\text { Avoided as the heat medium } \\
\text { does not contact the product }\end{array}$ \\
\hline Dusting & High & $\begin{array}{l}\text { Minimal cleaning of exhaust gas } \\
\text { is need. Additional benefit is the } \\
\text { low emission of fines and } \\
\text { particles. }\end{array}$ \\
\hline Solvent recovery & $\begin{array}{l}\text { Difficult because a large volume } \\
\text { of gas needs to be cooled to } \\
\text { recover the solvent. }\end{array}$ & $\begin{array}{l}\text { Easier as vapour released can be } \\
\text { easily condensed. }\end{array}$ \\
\hline $\begin{array}{l}\text { Suitability for toxic } \\
\text { materials }\end{array}$ & Not suitable. & $\begin{array}{l}\text { Suitable as limited exhaust gas } \\
\text { needed. }\end{array}$ \\
\hline
\end{tabular}




\subsection{Conductive drying}

Conductive drying is less thoroughly understood compared to convective drying ${ }^{9}$. The kinetics of conductive drying is a complex function of both the operation conditions and the material properties. Compared to convective drying, the hydrodynamics of the drying phase is much more complex, often accompanied by boiling, inducing local turbulence and chaotic flow. Direct analysis of conductive drying kinetics in situ therefore remains a great challenge. To ultimately enhance the application of the more energy efficient conductive drying methods for food production, more insights should thus be generated on a better understanding of the conductive drying principle. This will allow systematic comparison of different conductive thin film drying technologies, such as (vacuum) drum drying, refractance window drying, and agitated thin film drying, which are all promising alternatives to conventional convective drying. Whereas drum drying employs a large heat load to products, vacuum drum drying and refractance window drying allow milder film drying conditions which may be suitable for heat sensitive foods. Agitated thin film drying applies high shear to disrupt a drying film and is generally operated under mildly reduced pressure conditions.

\subsection{1 (Vacuum) drum drying}

Drum drying is extensively used for industrial drying of viscous pasty or pureed foods, such as pre-gelatinized starches, mashed potatoes, caseinate and fruit purees ${ }^{13-15}$. Drum dryers can be classified as single, double and twin drum dryers ${ }^{16}$. Figure 1-2 (A) shows a schematic representation of a double drum dryer. It has two counter-rotating hollow steel drums of equal diameter. The gap between the two drums can be adjusted. During operation, the feed is supplied to the feeding pool and heats up to the boiling point, leading to fast initial vapour release. Due to drum rotation and gravity, the material then flows through the gap and adheres to the outer surface of the two drums as a semisolid film. The film is relatively thin $(<0.5 \mathrm{~mm})$, which makes the drying fast (10-30 s) ${ }^{12}$. At the opposite side of the drum, the dried product is scraped off by blades and the hot surface is reused. Drum drying is reported as one of the most energy efficient drying methods, consuming on average $40 \%$ less energy 
compared to spray drying ${ }^{10}$. Although most drum dryers are operated at atmospheric pressure, vacuum drum dryers are available that can operate at reduced boiling temperature. The capital costs of vacuum drum dryers are however higher than those of regular drum dryers.

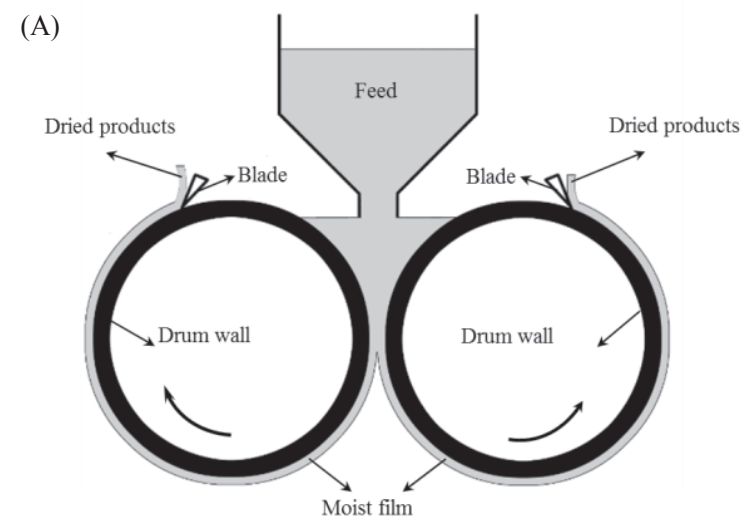

(B)

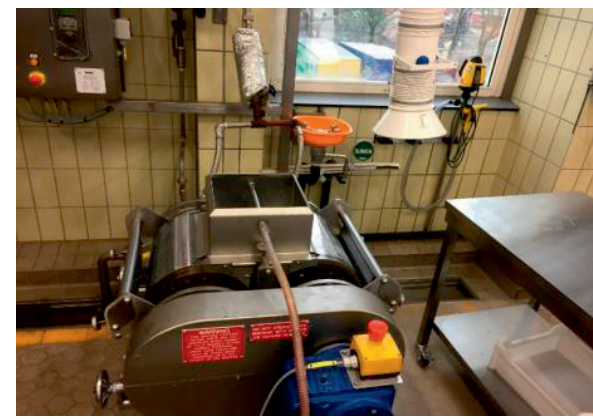

(C)

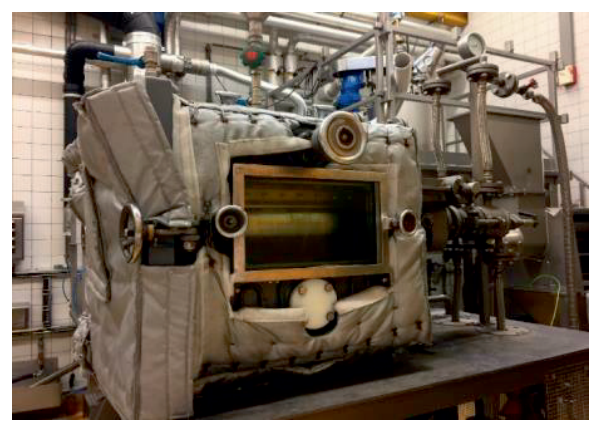

Figure 1-2 (A) Schematic representation of a double drum dryer, and pictures of (B) a regular drum dryer in Unilever (Tummers Machinebouw B.V., Hoogerheide, The Netherlands) and (C) a vacuum drum dryer in ANDRITZ Gouda (Waddinxveen, the Netherlands).

\subsubsection{Agitated thin film drying (ATFD)}

Agitated thin film drying (ATFD) is a relatively novel and mild conductive drying method as it is generally operated under reduced pressure. The drying takes place in a scraped heat exchanger, consisting of a drying chamber with a heated jacket and a rotor with fixed blades (Figure 1-3). During ATFD, the feed is supplied to the top of the drying chamber and flows down mainly due to gravity. It is distributed by the rotating action of the blades as a thin film across 
the heated surface. Vapour is released from the drying chamber and subsequently condensed in a separate chamber. The product film is progressively dried, transforming from a liquid, into a paste and finally into a brittle solid state. The brittle solid film is fragmented into small particles by the rotating blade. ATFD is suitable for heat and oxygen sensitive products as it can be operated under reduced pressure ${ }^{17}$. A major challenge for the application of ATFD is that its operation is sensitive to the dried material properties, which makes it applicable only to specific products.

(A)

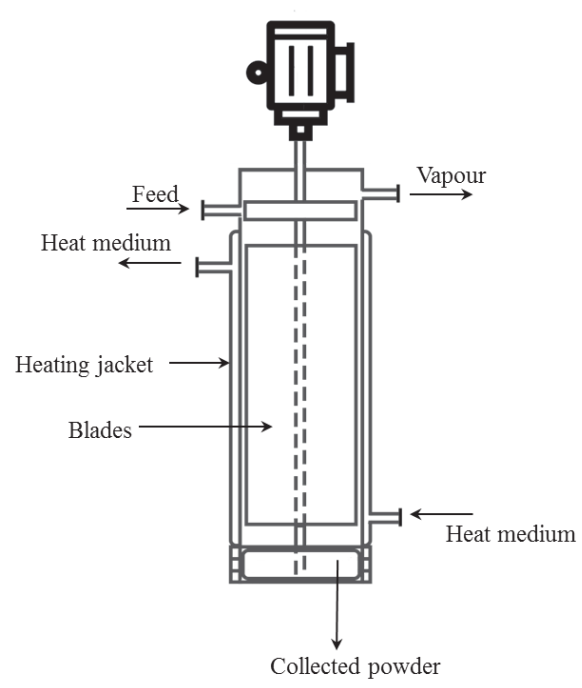

(B)

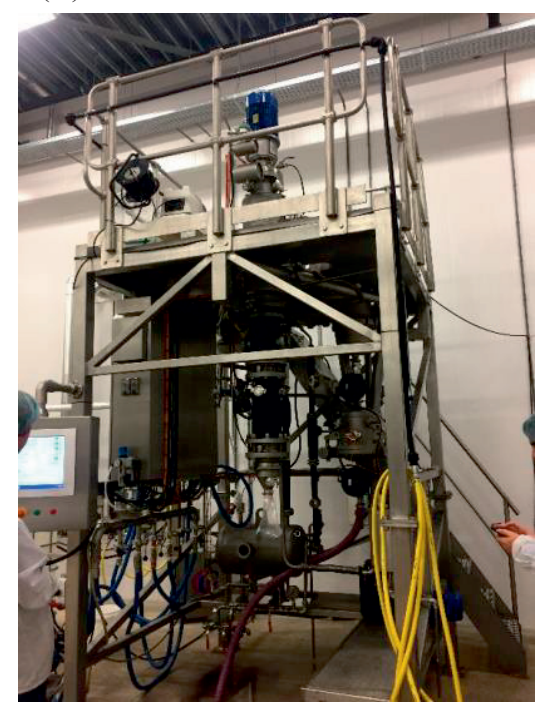

Figure 1-3 (A) Schematic representation and (B) picture of a pilot-scale agitated thin film dryer in Bodec (Helmond, the Netherlands).

\subsubsection{Refractance window drying (RWD)}

Refractance window drying (RWD) is another mild conductive drying method, which is especially investigated for drying various pureed or sliced fruits and vegetables, e.g. tomato, carrot, strawberry, asparagus, mango, kiwi, etc. ${ }^{6}{ }^{\mathbf{1 8 - 2 1}}$. The wet product is spread as a thin film and dried on a transparent polyethylene conveyor belt moving over circulating hot water (Figure 1-4). The plastic belt was originally aimed to allow mostly radiative heat transfer. However, it has been shown that radiative heat transfer contributes only $\sim 3 \%$ of the total heat transfer and most heat is transferred by conduction ${ }^{18}$. In contrast to drum 
drying and ATFD, no boiling occurs as the whole process is operated below the boiling temperature $\left(<95{ }^{\circ} \mathrm{C}\right)$ at atmospheric pressure. The driving force for mass transfer is the difference in relative humidity between the air and the film. At the final stage of the process, the dried product is conveyed over a cold water bath and cools down below the glass transition temperature. In this way, a brittle film is obtained, which can be scraped off and fragmented into flakes or particles. RWD is considered as a mild technology, applicable to especially heat sensitive products. At the same time, RWD is limited in capacity and scalability, as very thin films need to be applied to accommodate the slow drying.

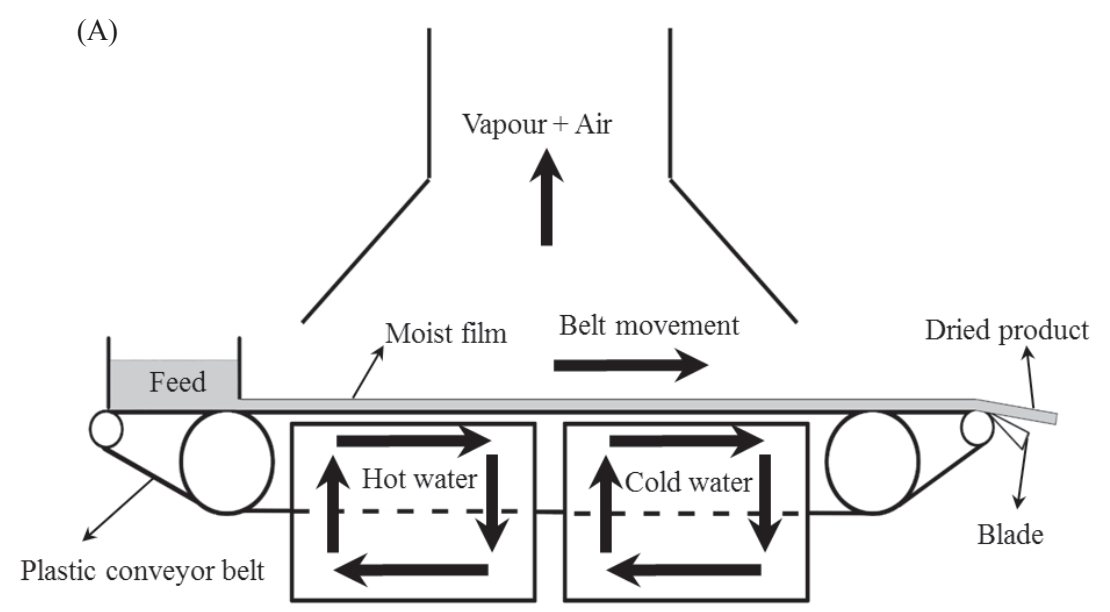

(B)

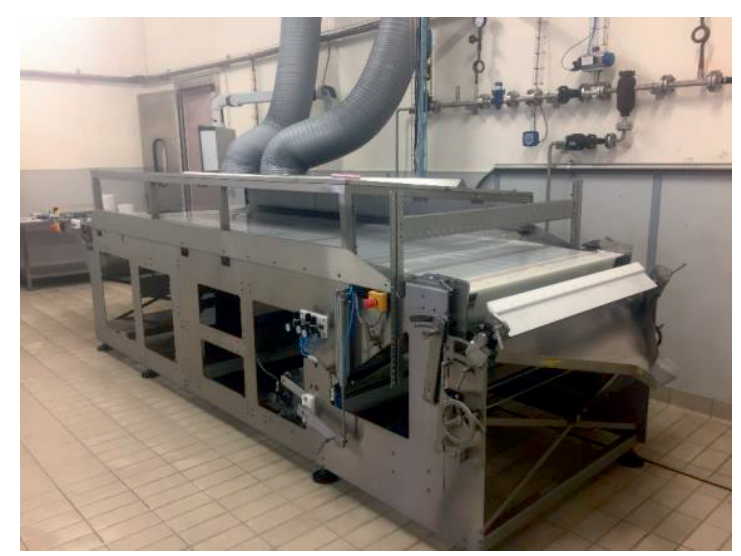

Figure 1-4 (A) Schematic representation and (B) picture of the refractance window dryer at ILVO (Melle, Belgium). 


\subsection{Research aim}

This thesis is part of a project entitled "Exploration on mild film drying technologies for more efficient dehydration of liquid concentrated foods". The overall project aimed at obtaining better insight in conductive drying and systematically comparing different conductive dryers in terms of product quality, energy consumption and costs. A techno-economic assessment was carried out at the Energy Research Centre of the Netherlands (ECN) ${ }^{22}$.

The objective of the study reported in this thesis was to investigate the principle of conductive drying of foods and to translate the insights generated to the operation of different mild conductive drying technologies. The main hypothesis behind this objective is that lower drying temperatures and faster drying to lower moisture content lead to higher product quality. Therefore, conductive drying processes that can operate at lower temperature (e.g. VDD, ATFD and RWD) are expected to provide milder drying conditions and thus better product quality. An added hypothesis is that RWD may be less mild than VDD and ATFD, since its drying time is longer.

The product quality is here defined as the level of micronutrients and taste components that are sensitive to heat, such as non-volatiles and volatiles. The principle of conductive drying is assessed in custom-built laboratory-scale drying systems designed to mimic non-agitated (e.g. drum drying) and agitated conductive thin film drying (e.g. ATFD), allowing better analysis of the drying behaviour and the impact of drying on the product quality.

The influence of material properties and operating conditions on drying behaviour and product quality were studied via experimental analyses and kinetic modelling. Finally, ATFD and RWD were compared at pilot scale to regular and vacuum drum drying, investigating the effect of the drying procedures and operating conditions applied on the powder quality. 


\subsection{Outline of this thesis}

The research results reported in this thesis can be divided into two aspects, namely processing and product quality. Figure 1-5 shows the schematic outline of the thesis.

Chapter 2 focuses on the influence of thermal processing and drying on the presence of tomato taste markers, i.e. citric, malic, ascorbic and pyroglutamic acids (PCA). The levels of the four markers in the processed tomato juice were experimentally assessed. In addition, kinetic models were developed to predict ascorbic acid degradation and PCA formation considering the coupled effect of temperature and moisture content.

Chapter 3 explores the transient drying kinetics of conductive thin film drying, relevant to drum drying. The drying kinetics was characterised by using a novel custom-built experimental system, allowing simultaneous on-line monitoring of both mass and temperatures in the process. The impact of different processing parameters, such as material properties, film thickness and feed concentration, on the drying kinetics was studied.

Chapter 4 proposes a heat-transfer governed model to describe the drying process in a lab-scale conductive thin film dryer. The model calculations were compared with the experimental data reported in Chapter 3. Subsequently, the model was modified to describe the industrial drum drying process.

Chapter 5 reports on the drying behaviour of foods using the ATFD process and investigates the influence of process parameters on the final product properties. A customized laboratory-scale ATFD dryer was applied to different food formulations: solutions of whey protein isolate and sucrose, and juices of bell pepper, tomato and spinach. The drying behaviour of each food was compared. Specifically, spinach juice was selected as a model system to study the influence of drying parameters.

Chapter $\mathbf{6}$ compares the organoleptic quality of tomato powders prepared with four conductive drying technologies, i.e. regular and vacuum drum drying, agitated thin film drying and refractance window drying. Pilot-scale 
experiments were carried out and the flavour quality of the resulting powders was evaluated by quantitatively determining the concentrations of key volatile and non-volatile compounds that contribute to tomato flavour. Principal component analysis (PCA) and partial least-square discriminant analysis (PLSDA) were performed to study the relationship between powder quality and conductive drying methods.

Chapter 7 provides a general discussion, verifying the earlier results with and extending these to conductive drying of milk powders and a primary economic assessment of different conductive dryers. In addition, a perspective on the future research and an insight-based guideline for conductive drying of foods are discussed.

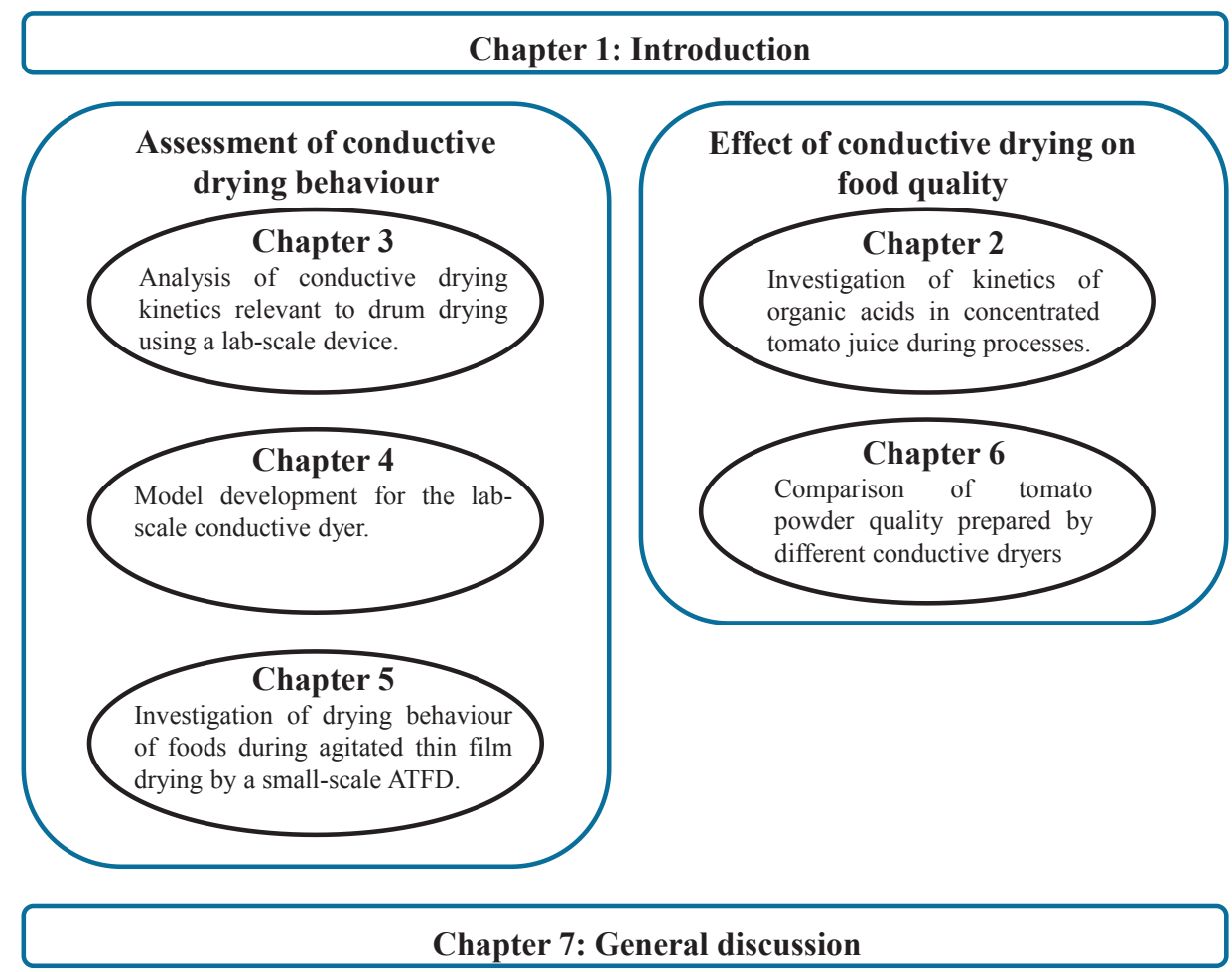

Figure 1-5 Schematic outline of the content in this thesis. 


\section{References}

[1]. Qiu, J., Khalloufi, S., Martynenko, A., Van Dalen, G., Schutyser, M. and Almeida-Rivera, C. (2015). Porosity, bulk density, and volume reduction during drying: review of measurement methods and coefficient determinations. Drying Technology, 33(14), 1681-1699.

[2]. Schuck, P., le Floch-Fouere, C. and Jeantet, R. (2013). Changes in functional properties of milk protein powders: effects of vacuum concentration and drying. Drying Technology, 31(13-14), 1578-1591.

[3]. Mujumdar, A. S. and Huang, L. (2007). Global R\&D needs in drying. Drying Technology, 25(4), 647-658.

[4]. Henríquez, M., Almonacid, S., Lutz, M., Simpson, R. and Valdenegro, M. (2013). Comparison of three drying processes to obtain an apple peel food ingredient. CyTA-Journal of Food, 11(2), 127-135.

[5]. Mujumdar, A. S. (2006). Principles, classification, and selection of dryers. Handbook of Industrial Drying, Fourth Edition (pp. 4-31). Boca Raton: CRC Press.

[6]. Raghavi, L., Moses, J. and Anandharamakrishnan, C. (2018). Refractance window drying of foods: A review. Journal of Food Engineering, 222, 267-275.

[7]. Zarein, M., Samadi, S. H. and Ghobadian, B. (2015). Investigation of microwave dryer effect on energy efficiency during drying of apple slices. Journal of the Saudi Society of Agricultural Sciences, 14(1), 41-47.

[8]. Moses, J., Norton, T., Alagusundaram, K. and Tiwari, B. (2014). Novel drying techniques for the food industry. Food Engineering Reviews, 6(3), 43-55.

[9]. Sahni, E. K. and Chaudhuri, B. (2012). Contact drying: A review of experimental and mechanistic modeling approaches. International Journal of Pharmacentics, 434(1), 334-348.

[10]. Nindo, C. and Tang, J. (2007). Refractance window dehydration technology: a novel contact drying method. Drying Technology, 25(1), 37-48. 
[11]. Caparino, O. A., Tang, J., Nindo, C. I., Sablani, S. S., Powers, J. R. and Fellman, J. K. (2012). Effect of drying methods on the physical properties and microstructures of mango (Philippine 'Carabao' var.) powder. Journal of Food Engineering, 111(1), 135-148.

[12]. Devahastin, S. and Mujumdar, A. S. (2006). Indirect dryers. Handbook of Industrial Drying, Fourth Edition (pp. 137-149). Boca Raton: CRC Press.

[13]. Trystram, G. and Vasseur, J. (1992). The modeling and simulation of a drum-drying process. International Chemical Engineering, 32, 689-689.

[14]. Kalogianni, E., Xynogalos, V., Karapantsios, T. and Kostoglou, M. (2002). Effect of feed concentration on the production of pregelatinized starch in a double drum dryer. LWT-Food Science and Technology, 35(8), 703-714.

[15]. Rodriguez, G., Vasseur, J. and Courtois, F. (1996). Design and control of drum dryers for the food industry. Part 1. Set-up of a moisture sensor and an inductive heater. Journal of Food Engineering, 28(3), 271-282.

[16]. Daud, W. R. W. (2006). Drum dryers. Handbook of Industrial Drying, Fourth Edition. Boca Raton: CRC Press.

[17]. Pawar, S. B., Patil, R., Mujumdar, A. and Thorat, B. (2011). Mathematical modeling of agitated thin-film dryer. Drying Technology, 29(6), 719-728.

[18]. Zotarelli, M. F., Carciofi, B. A. M. and Laurindo, J. B. (2015). Effect of process variables on the drying rate of mango pulp by Refractance Window. Food Research International, 69, 410-417.

[19]. Abonyi, B., Feng, H., Tang, J., Edwards, C., Chew, B., Mattinson, D. and Fellman, J. (2002). Quality retention in strawberry and carrot purees dried with Refractance Window ${ }^{\mathrm{TM}}$ system. Journal of Food Science, 67(3), 1051-1056.

[20]. Azizi, D., Jafari, S. M., Mirzaei, H. and Dehnad, D. (2017). The influence of refractance window drying on qualitative properties of kiwifruit slices. International Journal of Food Engineering, 13(2). 
[21]. Nindo, C. I., Sun, T., Wang, S., Tang, J. and Powers, J. (2003). Evaluation of drying technologies for retention of physical quality and antioxidants in asparagus (Asparagus officinalis, L.). LWT-Food Science and Technology, 36(5), 507-516.

[22]. Smidt de, R. P., Wemmers, A. K. and Spoelstra, S. (2017). Thin film drying pocesses 'Energy and economic aspects compared to spray drying': Report ECN-E--17084, Energy Research Centre of the Netherlands (ECN). 


\section{CHAPTER 2}

\section{Formation and degradation kinetics of organic acids during heating and drying of concentrated tomato juice}

This chapter has been published as: Qiu, J., Vuist, J.-E., Boom, R. M., \& Schutyser, M. A. I. (2018). Formation and degradation kinetics of organic acids during heating and drying of concentrated tomato juice. LWT - Food Science and Technology, 87(C), 112-121. 


\section{Abstract}

Tomato products are often thermally processed or concentrated to obtain their desired shelf life and to facilitate transport. However, processing negatively affects the quality of tomato products. This study focused on the influence of processing on the presence of important tomato taste markers, i.e. citric, malic, ascorbic and pyroglutamic acids (PCA). Isothermal heat treatment of tomato juice was experimentally assessed at varying moisture content (0.18 to 0.95 $\mathrm{kg} / \mathrm{kg}$ total), temperature $\left(60\right.$ to $100{ }^{\circ} \mathrm{C}$ ) and time (0 to $18 \mathrm{~h}$ ) combinations. Increasing ascorbic acid degradation (up to $70 \%$ ) and PCA formation (up to $0.032 \mathrm{mmol} / \mathrm{g}$ FT) were measured, while citric and malic acids were unaffected. First order reaction kinetics described the degradation and formation of ascorbic acid $\left(\mathrm{R}^{2}=0.76\right)$ and PCA $\left(\mathrm{R}^{2}=0.98\right)$, where the coupled effect of both moisture content and temperature on the reaction rates was modelled with an Arrhenius-type equation. Higher temperature enhanced both reaction rates with factors of 4.2 and 5.1 for ascorbic acid and PCA, respectively (from 60 to $100{ }^{\circ} \mathrm{C}$ at $95 \mathrm{w} / \mathrm{w}$ ), while at lower moisture content the rate of the ascorbic acid degradation decreased with a factor of 3.5 and the rate of the PCA formation increased with a factor of 3.5 (both from 95 down to $5 \mathrm{w} / \mathrm{w}$ at $90{ }^{\circ} \mathrm{C}$ ). Finally, by implementation of the kinetic models in a process model, it was estimated that $25 \%$ of ascorbic acid degrades during co-current drying while after counter-current drying only $21 \%$ degrades. Similarly, during co-current drying $0.021 \mathrm{mmol} / \mathrm{g}$ FT PCA is formed, which is more than during counter-current drying $(0.008 \mathrm{mmol} / \mathrm{g}$ FT). This approach yields an interesting insight on the effect of processing on the presence of ascorbic acid and PCA and thus offers opportunities for process optimisation. 


\subsection{Introduction}

The main purpose of thermal processing and drying in the food industry is preservation. During thermal treatment, microbial and enzymatic activities are reduced, while drying aims at reductions in water activity preventing the growth of microbes and the occurrence of undesired chemical reactions during storage. In addition, dried products have reduced volume and are easier to handle during storage and transportation. However, during processing various physical and chemical reactions may occur that negatively affect the product quality including the decline of the nutritional properties, aroma loss, as well as changes in taste and colour ${ }^{\mathbf{1}}$. The impact of processing on product quality can be minimised by the optimisation of the process conditions, for example by a short time - high temperature heat treatment. Minimally processed foods are perceived more fresh by consumers while having extended shelf-life ${ }^{2}$.

The focus in this study is the thermal processing and drying of (concentrated) tomato juice. Tomato (Lycopersicum esculentum) is amongst the most popular fruits globally ${ }^{3}$. Tomato is considered as a useful source of fibres, proteins, minerals, vitamins, lycopene and antioxidants and thus fits in a healthy diet $\mathbf{4 , 5}$. Tomatoes are consumed fresh and incorporated in processed foods, e.g. juice, puree, sauce, canned varieties and dried products ${ }^{6}$. Annually, over 40 million tons of tomatoes are processed worldwide into a large variety of foods ${ }^{7}$.

As discussed above, it is desired that the processing of tomato should have minimum effect on the perceived freshness and nutritional properties of the final product. Numerous studies reported the impact of processing on tomato quality specifically in terms of nutritional quality decline and colour retention. Only a few studies focused on the retention of non-volatile taste characteristics, such as sour taste. The sour taste of tomato is an important organoleptic quality attribute connected to the perceived freshness and is related to the presence of specific organic acids ${ }^{\mathbf{8}-10}$. Organic acids comprise over $0.15 \mathrm{~kg} / \mathrm{kg}$ dry weight of tomatoes. The most abundantly present organic acids in tomatoes are citric, malic, and ascorbic acids ${ }^{\mathbf{9}, \mathbf{1 1}}$. Specifically, ascorbic acid, also known as vitamin 
C, is well known for its sensitivity towards heat and the presence of oxygen and thus degrades during processing and storage ${ }^{\mathbf{1 2}, \mathbf{1 3}}$.

During thermal processing some organic acids are formed as well, which results in an overall increase of the total amount of organic acid. An important organic acid with a large influence on the taste of tomato products is 5-oxopyrrolidine2-carboxylic acid, or pyroglutamic acid (PCA). PCA is the degradation product of glutamine or glutamic acid $\mathbf{1 1 , 1 4 , 1 5}$. The formation route of PCA in tomato juice can be catalysed both enzymatically and non-enzymatically. The enzymatic reaction is facilitated by $\gamma$-glutamylcysteine synthetase $(\gamma$-GCS) and Glutamate5-Kinase $(\mathrm{G} 5 \mathrm{~K})$, with optimum reaction conditions of $35^{\circ} \mathrm{C}$ at $\mathrm{pH} 7.9$ and $83^{\circ} \mathrm{C}$ at $\mathrm{pH}$ 6.0, respectively ${ }^{\mathbf{1 6}-19}$. The non-enzymatic reaction is catalysed by weak acids and is enhanced at elevated temperatures (Figure 2-1) ${ }^{\mathbf{2 0}, \mathbf{2 1}}$. The formation of PCA contributes to the perceived loss of freshness and gives the product a bitter and undesirable sour taste, and leads to the off-flavour of processed tomato $9, \mathbf{1 0}$. Quantitative understanding of the changing levels of citric acid, malic acid, ascorbic acid and PCA in tomato products could provide a better control to retain taste during processing.

(A)<smiles>[R]C(=O)O[C@H](N)CCC([R])NC(=O)O</smiles>

(B)

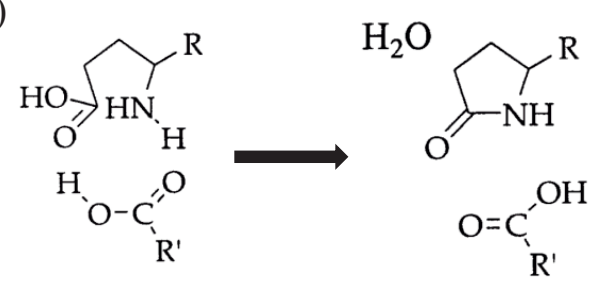

Figure 2-1 Schematic conversion of (A) glutamine and (B) glutamic into pyroglutamic acid (PCA) catalysed by a weak acid ${ }^{\mathbf{2 1}}$. 
In the present study, we investigated the kinetic modelling of ascorbic acid degradation and PCA formation. The developed models can be applied to optimise heating and drying processes of tomato juice. In most previous studies the degradation of ascorbic acid and the formation of PCA were studied as a function of the temperature only ${ }^{\mathbf{2 2 - 2 4}}$. A major challenge here is to extend the kinetic modelling to describe the combined effect of temperature and moisture content. The combined effect on the degradation of ascorbic acid was studied when storing the kiwifruits and air drying the fruit rosehip ${ }^{\mathbf{2 3}, \mathbf{2 5}}$, but no studies on tomato processing were carried out. In terms of the PCA formation, no kinetic models considering the combined effect of temperature and moisture content have been proposed.

Therefore, the objective of this study is twofold: (1) to experimentally assess the levels of citric acid, malic acid, ascorbic acid and PCA of tomato juice after thermal processing and drying; (2) to develop kinetic models that can predict ascorbic acid degradation and PCA formation considering the effect of both temperature and moisture content.

\subsection{Mathematical models}

\subsubsection{Kinetic Modelling}

First order kinetics is applied to describe the ascorbic acid degradation ${ }^{\mathbf{2 3}}$ :

$$
-\frac{d C}{d t}=k C
$$

in which $C$ is the concentration of ascorbic acid, $t$ is time and $k$ is the reaction rate constant $\left(\right.$ time $\left.^{-1}\right)$.

Integration of Eq. 2-1 yields:

$$
\frac{C_{A A, t}}{C_{A A, 0}}=\exp \left(-k_{A A} t\right)
$$

where $C_{A A, t}$ is the concentration of ascorbic acid after a specific time and $C_{A A, O}$ is the initial concentration of ascorbic acid. 
Glutamine and glutamic acid are converted into PCA during thermal

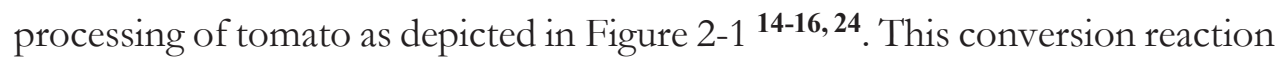
is also assumed to follow first order reaction kinetics and the total concentration of glutamine and glutamic acid can then be described as a function of time as follows ${ }^{22}$ :

$$
C_{G l u, t}=C_{G l u, 0} \exp \left(-k_{P C A} t\right) \quad \text { Eq. } 2-3
$$

Because PCA is the product of the conversion it can be described as:

$$
C_{P C A, t}=C_{G l u, 0}-C_{G l u, t}
$$

Substitution of Eq. 2-4 into Eq. 2-3 yields the following expression:

$$
C_{P C A, t}=C_{G l u, 0}\left(1-\exp \left(-k_{P C A} t\right)\right) \quad \text { Eq. } 2-5
$$

where $C_{P C A, t}$ and $C_{G \text { lu, }}$ are the concentrations of PCA and the total initial concentration of glutamic acid and glutamine in tomato, respectively.

The temperature dependency of both reactions can be described with the following modified Arrhenius equation:

$$
k=k_{\text {ref }} \exp \left[-\frac{E_{a}}{R}\left(\frac{1}{T}-\frac{1}{T_{\text {ref }}}\right)\right] \quad \text { Eq. 2-6 }
$$

where $T$ is temperature, $T_{r e}$ is a reference temperature, $k_{r e f}$ is the reaction rate constant at $T_{r e}, E a$ is the activation energy, and $R$ is the ideal gas constant.

The dependency on moisture content is incorporated in this modelling approach by making the reaction rate coefficients $\left(k_{\text {ref }}\right.$ and $\left.E a\right)$ moisture content dependent ${ }^{26}$. Perdana et al. ${ }^{27}$ investigated and extended this modelling approach to describe the inactivation of $\beta$-galactosidase during single droplet drying. The dependency of the reaction rate constant $\left(k\left(T, X_{w}\right)\right)$ on temperature and moisture content is described as follows ${ }^{27}$ :

$$
\mathrm{k}\left(\mathrm{T}, \mathrm{X}_{\mathrm{w}}\right)=\mathrm{k}_{\mathrm{w}}(\mathrm{T}) \exp \left[\ln \left(\frac{\mathrm{k}_{\mathrm{s}}(\mathrm{T})}{\mathrm{k}_{\mathrm{w}}(\mathrm{T})}\right) \cdot \exp \left(-\mathrm{p} \frac{\mathrm{X}_{\mathrm{w}}}{1-\mathrm{X}_{\mathrm{W}}}\right)\right] \quad \text { Eq. 2-7 }
$$


where $X_{w}$ is the mass fraction of water and $p$ is an empirical parameter describing the effect of moisture content on the reaction rate constant. Further, $k_{w}(T)$ and $k_{s}(T)$ are the reaction rate constants at infinite dilution $\left(X_{w}=1\right)$ and in pure solid form $\left(X_{w}=0\right)$, respectively, and can be expressed as a function of temperature:

$$
\begin{aligned}
& k_{w}(T)=k_{\text {ref,w }} \exp \left[-\frac{E_{a}}{R}\left(\frac{1}{T}-\frac{1}{T_{\text {ref }}}\right)\right] \quad \text { Eq. 2-8 } \\
& k_{S}(T)=k_{r e f, S} \exp \left[-\frac{E_{a}}{R}\left(\frac{1}{T}-\frac{1}{T_{r e f}}\right)\right] \quad \text { Eq. 2-9 }
\end{aligned}
$$

This kinetic model includes four fitting parameters, namely $k_{r e f, w}, k_{\text {ref } f, s}$ Ea and $p$. It describes the combined effect of temperature and moisture content, which is especially relevant during drying processes.

\subsubsection{Modelling of convective drying}

The developed kinetic models can be applied to evaluate the effect of drying of a tomato product on ascorbic acid and PCA levels if combined with a process model that can predict the temperature and moisture content history of a product during drying. As an example, a co- and counter-current air drying model reported by Pakowski and Mujumdar ${ }^{28}$ was implemented in the present work. The moisture removal during convective drying is driven by the difference between the moisture content of the product ( $W_{p}, \mathrm{~kg} / \mathrm{kg}$ dry solid) and the equilibrium moisture content of the air ( $W_{g}, \mathrm{~kg} / \mathrm{kg}$ dry air). When the product moisture content is higher than its critical moisture content $\left(W_{p}>W_{c}\right)$, the drying rate $J_{D}$ can be determined by:

$$
J_{D}=K\left(W_{g, e}-W_{g}\right)
$$

where $K$ is the mass transfer coefficient and $W_{g, e}$ is the equilibrium moisture content of the dry air. If $W_{p}<W_{c}, J_{D}$ can be calculated by:

$$
J_{D}=K\left(W_{g, e}-W_{g}\right)\left(\frac{W_{p}-W_{s, e}}{W_{c}-W_{s, e}}\right)^{1.5}
$$

where $W_{s, e}$ is the equilibrium moisture content of the product. 
The moisture content change in the air and the product can be expressed by Eq. 2-12 and Eq. 2-13, respectively:

$$
\begin{aligned}
& \frac{d W_{g}}{d x}=J_{D} \frac{S}{\chi F_{g}} a_{v} \\
& \frac{d W_{s}}{d x}=-J_{D} \frac{S}{F_{S}} a_{v}
\end{aligned}
$$

where $S$ is the cross-sectional area of the dryer chamber, $a_{v}$ is the contact area of the product and the air per volume of the dryer chamber, $F_{g}$ is the dry air flow rate, $F_{s}$ is the dry solid flow rate and $x$ is the position along the length of the dryer. Specially, $\chi=1$ represents co-current drying, while $\chi=-1$ represents counter-current drying.

The heat transfer rate $q$ is determined by the temperature difference between the dry air and the product:

$$
q=\alpha\left(T_{g}-T_{p}\right)
$$

where $T_{g}$ is the dry air temperature, $T_{p}$ is the product temperature and $\alpha$ is the heat transfer coefficient.

The temperature change of the dry air and the product can be expressed by Eq. 2-15 and Eq. 2-16, respectively:

$$
\begin{array}{ll}
\frac{d T_{g}}{d x}=-\frac{S}{\chi F_{g}} \frac{a_{v}}{c_{g}+c_{w v} W_{g}}\left(q+J_{D}\left(c_{w}\left(T_{g}-T_{p}\right)\right)\right) & \text { Eq. 2-15 } \\
\frac{d T_{p}}{d x}=\frac{S}{F_{s}} \frac{a_{v}}{c_{s}+c_{w} W_{p}}\left(q+J_{D}\left(\left(c_{w}-c_{w v}\right) T_{p}-h_{w}\right)\right) & \text { Eq. 2-16 }
\end{array}
$$

where $c_{g}$ is the specific heat of dry air, $c_{w}$ is the specific heat of water, $c_{w v}$ is the specific heat of water vapour, $c_{s}$ is the specific heat of the solid and $h_{w}$ is the latent heat of water.

The governing equations are solved simultaneously using MATLAB R2015b (Mathworks, Natick, USA) to obtain the product temperature and moisture content history. By combining the outcome of the drying model with the 
kinetic model, the levels of ascorbic acid and PCA could be calculated as a function of the drying time and applied conditions.

\subsection{Materials and Methods}

\subsubsection{Chemicals}

Reference chemicals for all organic acids (citric acid, malic acid, ascorbic acid and PCA), as well as phosphoric acid $\left(\mathrm{H}_{3} \mathrm{PO}_{4}\right)$ and potassium phosphate monobasic $\left(\mathrm{KH}_{2} \mathrm{PO}_{4}\right)$ used for the mobile phase, were purchased from SigmaAldrich $^{\circledR}$ (Zwijndrecht, the Netherlands). Analytical grade water (Milli-Q water) was purified by a Merck Milli-Q ${ }^{\circledR}$ water system (Amsterdam, the Netherlands).

\subsubsection{Sample preparation}

Cut and frozen tomato cubes were kindly provided by Unilever (Vlaardingen, the Netherlands). The cubes, with a volume of approximately $1 \mathrm{~cm}^{3}$, were blended with an electronic blender (Vorwerk Thermomix Tm 31, Vorwerk, Wuppertal Germany) and squeezed into a tomato juice. The moisture concentration of the juice was $0.95 \mathrm{~kg} / \mathrm{kg}$ wet basis. To vary the moisture content of the tomato juice with minimal thermal influence, the squeezed tomato juice was concentrated by freeze drying in batches of $1 \mathrm{~L}$. For this the tomato juice was first frozen and then freeze-dried at a pressure of $100 \mathrm{~Pa}$ and a shelf temperature of $-20{ }^{\circ} \mathrm{C}$ for $4 \mathrm{~h}$. Thereafter, the shelf temperature was increased to $-15{ }^{\circ} \mathrm{C}$ and maintained at this temperature for different time intervals (between 25 and $49 \mathrm{~h}$ ) to obtain tomato concentrates with moisture contents of $0.85,0.60,0.51,0.19$ and $0.13 \mathrm{~kg} / \mathrm{kg}$ wet basis. Each drying procedure was ended by increasing the temperature to $-5{ }^{\circ} \mathrm{C}$, which was maintained for $6 \mathrm{~h}$. Subsequently, the shelf temperature was further increased to $10{ }^{\circ} \mathrm{C}$ and finally to $20{ }^{\circ} \mathrm{C}$, while the pressure decreased to $0.1 \mathrm{~Pa}$. This last drying step lasted $13 \mathrm{~h}$.

\subsubsection{Isothermal heating tests}

Samples were pipetted into $5 \mathrm{~mL}$ vials, sealed and heated to a constant temperature in an Eppendorf Thermomixer ${ }^{\circledR} \mathrm{C}$ (Eppendorf, Hamburg Germany). The constant temperature was achieved within 2 min, which is very short compared to the total heat treatment time. The temperature range of the 
experiments in this study was between 60 and $100{ }^{\circ} \mathrm{C}$ and the mixing speed was fixed at $300 \mathrm{rpm}$. After heat treatment, the vial was transferred immediately into an ice bath, in order to quickly decrease the temperature. Subsequently, the sample was stored in the freezer for further analysis.

\subsubsection{Extraction and analysis of organic acids}

To prepare a sample for HPLC analysis an extraction method for organic acids from tomato juice was used as described by Selli et al. ${ }^{29}$ who developed this method for the extraction of organic acids from cherry tomato. The first step involved the addition of $25 \mathrm{~g}$ of $25 \mathrm{mmol} / \mathrm{L} \mathrm{KH}_{2} \mathrm{PO}_{4}$ buffer (adjusted to $\mathrm{pH}$ 2.5 by $\mathrm{H}_{3} \mathrm{PO}_{4}$ ) to a $5 \mathrm{~g}$ tomato sample and subsequent mixing at $300 \mathrm{rpm}$ for $10 \mathrm{~min}$ to homogenise the sample. The homogenised mixture was centrifuged at $12,000 \mathrm{~g}$ and $10{ }^{\circ} \mathrm{C}$ for $8 \mathrm{~min}$. Then the supernatant was filtered through a $0.45 \mu \mathrm{m}$ Minisart ${ }^{\circledR}$ Syringe filter (Sartorius, Goettingen, Germany) and used for HPLC analysis.

An UltiMate ${ }^{\circledR} 3000$ HPLC system equipped with a diode array detector (DAD) (Dionex, Dreieich, Germany) was used to simultaneously separate and detect the organic acids. The system was run at $1.0 \mathrm{~mL} / \mathrm{min}$ using a Prevail ${ }^{\mathrm{TM}}$ Organic Acid column with $150 \mathrm{~mm} \times 4.6 \mathrm{~mm}$ and $5 \mu \mathrm{m}$ particle size (Grace, USA). The column temperature was maintained at $30{ }^{\circ} \mathrm{C}$ and the organic acids were detected with the DAD at a wave length of $210 \mathrm{~nm}$. The injection volume was $5 \mu \mathrm{L}$. The mobile phase was $25 \mathrm{mmol} / \mathrm{L} \mathrm{KH}_{2} \mathrm{PO}_{4}$ buffer adjusted to $\mathrm{pH} 2.5$. The concentrations of organic acids were quantified by comparing the peak areas of organic acids to those of external standard references. The concentrations of organic acids are expressed as mmol per gram fresh tomato (mmol/g FT) as the moisture content of fresh tomatoes is assumed constant.

\subsubsection{Data acquisition and modelling procedures}

Isothermal heating experiments were carried out in duplicate at different time intervals. Analysis of variance (ANOVA) was applied, to evaluate if citric acid and malic acid concentrations significantly differ at different heating time within each treatment. From series of experiments at a specified temperature and moisture content, the kinetic reaction rate constants $(k)$ were calculated for 
the degradation of ascorbic acid and the formation of PCA (Eq. 2-2 and Eq. 25). Parameter optimisation was carried out using a non-linear least squares method solved by a Trust-Region Algorithm method. All the calculations were performed with the curve fitting toolbox of MATLAB R2015b (Mathworks, Natick, USA).

\subsection{Results and Discussion}

\subsubsection{Degradation and formation of organic acids during isothermal heating}

Figure 2-2 (A, B) shows the citric acid concentration during the heating for (concentrated) tomato juice with a moisture content of $0.95 \mathrm{~kg} / \mathrm{kg}$ and 0.19 $\mathrm{kg} / \mathrm{kg}$ wet basis, respectively. One-way ANOVA showed that within each treatment, the concentration of citric acid at different heating time did not significantly differ $(p>0.05)$. The citric acid concentration remains constant at different temperatures for both moisture concentrations in time. Citric acid was previously found to be very heat stable compared to other organic acids. Barbooti and Al-Sammerrai ${ }^{30}$ found that citric acid remained stable at $100{ }^{\circ} \mathrm{C}$, and decomposed only above $148{ }^{\circ} \mathrm{C}$, followed by rapid decomposition above $153{ }^{\circ} \mathrm{C}$ when melting. Similar to citric acid, ANOVA showed that the concentration of malic acid remained constant at different heating conditions ( $p>0.05)$, as can be observed in Figure 2-2 (C, D). Only for two treatments $\left(X_{w}=0.19, T=70\right.$ and $\left.100{ }^{\circ} \mathrm{C}\right)$ the $\mathrm{p}$ value was lower than 0.05 ; however, no clear trends could be observed. To confirm our observations heating experiments with model solutions of citric and malic acids at $90{ }^{\circ} \mathrm{C}$ were carried out. Both acids remained stable over long periods of heating (data not shown). Our observations are in accordance with the work done by Jeyaprakash, Frank, and Driscoll ${ }^{31}$, who reported on the stability of citric and malic acids during heat pump drying of tomatoes. Some earlier studies reported opposite results. Wiese and Dalmasso ${ }^{32}$ reported an increase in citric and malic acids after heat processing of tomato juice, while Villari et al. ${ }^{33}$ reported a decrease in citric and malic acids with increased storage temperature and time. In addition, Igual et al. 34 reported that the concentration of citric acid decreased while that of malic acid was not affected during heat treatment of grapefruit juice. 
(A)

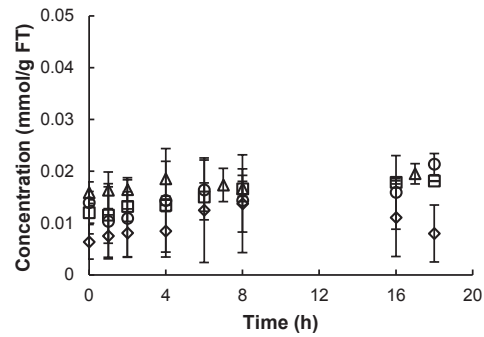

(C)

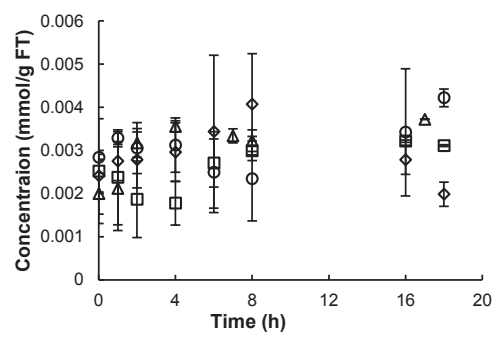

(E)

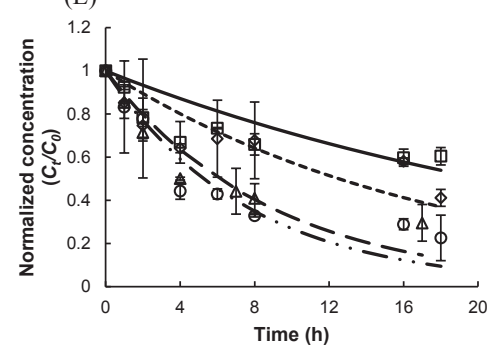

(G)

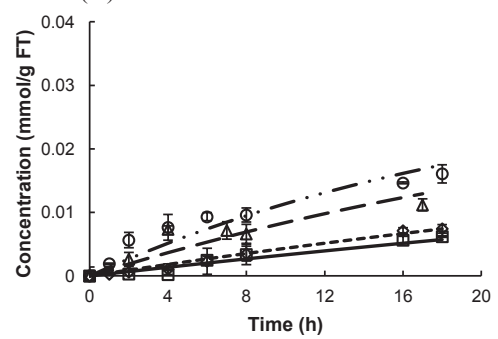

(B)

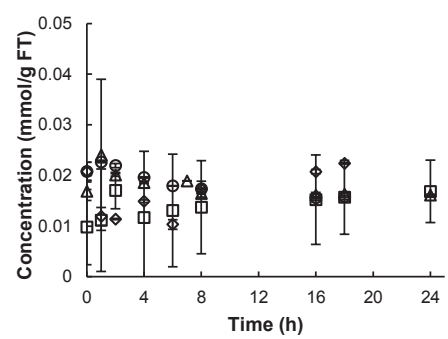

(D)

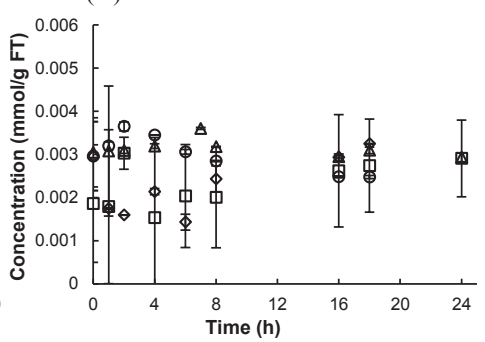

(F)

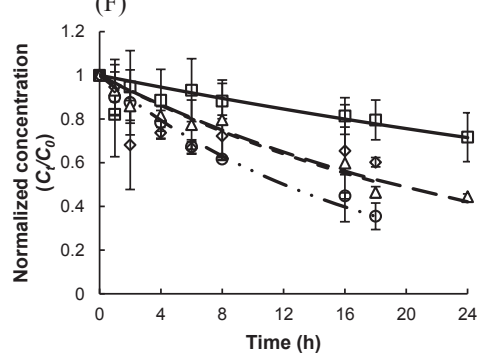

(H)

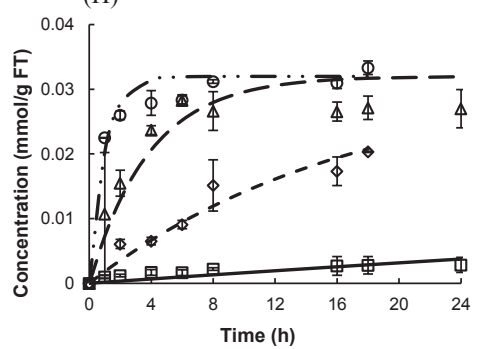

Figure 2-2 Changes in the concentrations of citric acid in tomato samples with (A) $X_{w}$ $=0.95$ and $(\mathrm{B}) X_{w}=0.19$; malic acid in tomato samples with $(\mathrm{C}) X_{w}=0.95$ and (D) $X_{w}=0.19$; ascorbic acid in tomato samples with (E) $X_{w}=0.95$ and $(\mathrm{F}) X_{w}=0.19$; and pyroglutamic acid (PCA) in tomato samples with $(\mathrm{G}) X_{w}=0.95$ and $(\mathrm{H}) X_{w}=0.19$ during the heating process. The concentrations are expressed as mmol per gram in fresh tomato $(\mathrm{mmol} / \mathrm{g} \mathrm{FT})$. The symbols represent the experimental data: $60{ }^{\circ} \mathrm{C}(\square)$, $70{ }^{\circ} \mathrm{C}(\diamond), 90{ }^{\circ} \mathrm{C}(\Delta)$, and $100{ }^{\circ} \mathrm{C}(\mathrm{O})$. The lines represent the model predictions: $60{ }^{\circ} \mathrm{C}$ (solid line), $70{ }^{\circ} \mathrm{C}$ (dotted line), $90{ }^{\circ} \mathrm{C}$ (dashed line), and $100{ }^{\circ} \mathrm{C}$ (dash-dot line). The error bars show the $95 \%$ confidence interval of the experimental data $(n=2)$. 
The concentrations of ascorbic acid and PCA during the heating were also determined. Specifically, the initial concentrations of ascorbic acid in squeezed tomato juice were found to vary between 0.36 and $0.45 \mathrm{mmol} / \mathrm{kg}$ FT. The ascorbic acid concentration was shifted for a better presentation of the results $\left(C_{A A, t} / C_{A A, 0}=1\right)$. The initial PCA concentration (between 0.001 and 0.002 $\mathrm{mmol} / \mathrm{g} \mathrm{FT}$ ) was subtracted from each measured value, to remove the originally present PCA and thus obtain the amount of PCA formed during heating. Figure 2-2 (E to $\mathrm{H}$ ) shows the normalized ascorbic acid and PCA concentrations as a function of heating time. Both organic acids exhibited a continuous change in concentration, i.e. a decreasing ascorbic acid concentration and an increasing PCA concentration. The solid lines represent the kinetic models fitted to the experimental data (Eq. 2-2 and Eq. 2-5). It can be observed that the kinetic models fit the experimental data well, indicating that a first order kinetic model is a valid approach to describe both reactions of organic acids. The calculated kinetic reaction rates are presented in Table 2-1. In the next section, the combined effect of temperature and moisture content on the reaction rate is discussed. 


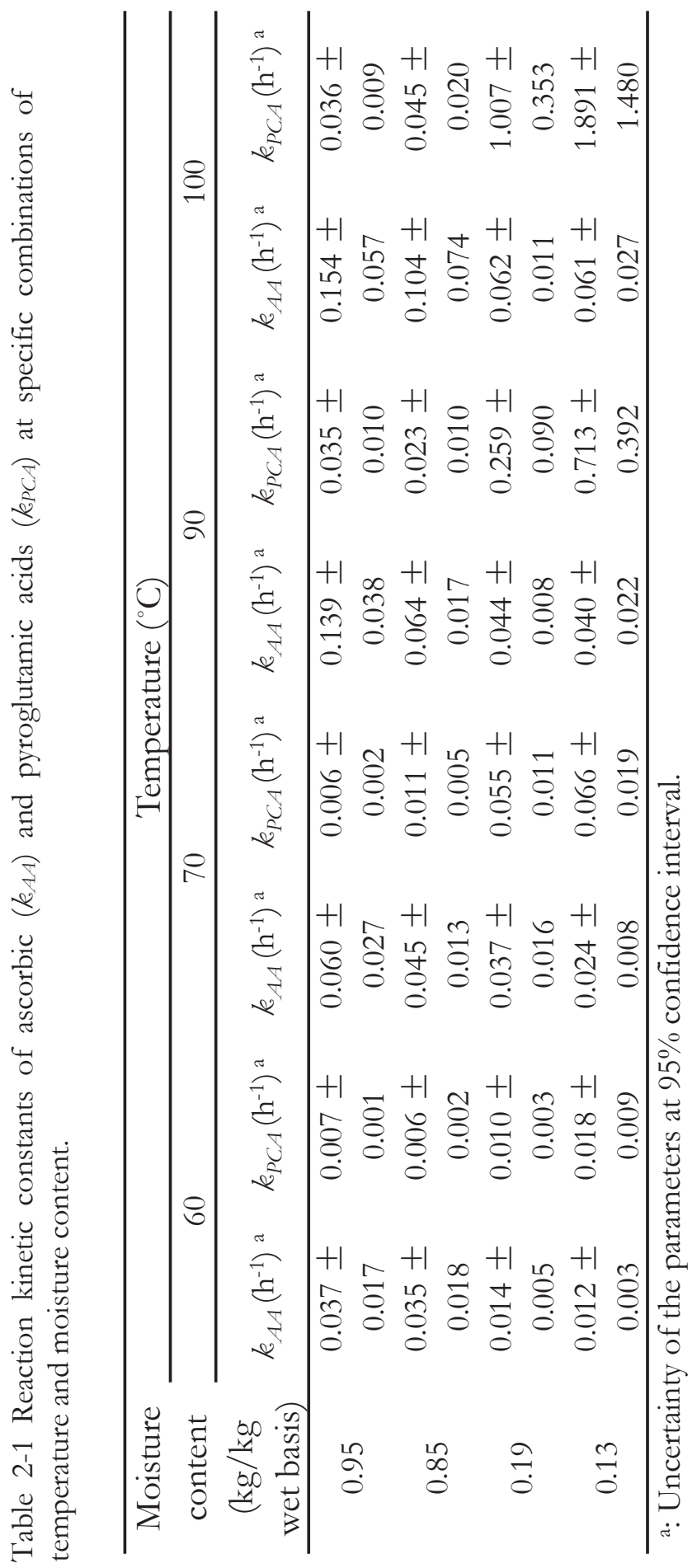




\subsubsection{Experimental and modelling results of ascorbic acid and PCA}

Table 2-1 presents the reaction rate constants of the degradation of ascorbic acid and the formation of PCA for different combinations of temperature and moisture content. The reaction rate constants of ascorbic acid and PCA were calculated by Eq. 2-2 and Eq. 2-5, respectively. The value of $C_{G l u, 0}(0.032$ $\mathrm{mmol} / \mathrm{g}$ FT) representing the total concentration of glutamic acid and glutamine in the tomato juice was taken as the average from two previous studies ${ }^{35,36}$. Specifically, this value is comparable to the maximum formation of PCA in our experimental work (between 0.030 and $0.033 \mathrm{mmol} / \mathrm{g}$ FT).

From the data in Table 2-1, it can be observed that the reaction rate constants of ascorbic acid degradation increase with increasing temperature, as expected. The stability of ascorbic acid depends also on the moisture content of the tomato juice: in Table 2-1 a positive correlation between the reaction rate and the moisture content is shown. This may be attributed to higher diffusion coefficients of ascorbic acid and oxygen at higher moisture contents ${ }^{23,37}$. Concentrated tomato samples with a lower moisture content form a denser solid matrix retarding the penetration of oxygen. This may reduce the oxygen concentration inside the product and thereby reduce the ascorbic acid oxidation degradation. Uddin et al. ${ }^{23}$ reported similar results by investigating ascorbic acid degradation in dried kiwifruits with different water activity during storage. Djendoubi Mrad et al. ${ }^{38}$ reported that during air drying of pears, ascorbic acid initially degrades slowly when the moisture content is still high, followed by a sharper decrease when the moisture content becomes low. This is because during initial drying the temperature is equal to the wet bulb temperature. When the moisture content becomes low, the temperature of the product increases; and this explains the sharp decrease in ascorbic acid.

In Table 2-1 the reaction rate constant of PCA is shown at different combinations of temperature and moisture content. Similar to the ascorbic acid degradation, the PCA formation is enhanced at high temperature. However, at higher moisture contents, the formation rate of PCA decreases. In the present study, PCA formation via the enzymatic route may be negligible, because the high temperatures (from 60 to $100{ }^{\circ} \mathrm{C}$ ) lead to low activities of $\gamma$ - 
glutamylcysteine synthetase ( $\gamma$-GCS) and Glutamate-5-Kinase (G5K) ${ }^{16-19}$. It is therefore expected that the non-enzymatic route determines the formation of PCA in our system ${ }^{39}$. In the non-enzymatic conversion, PCA formation from either glutamine or glutamic acid is a unimolecular ring-closure reaction, catalysed by weak acids (Figure 2-1). At lower moisture contents the increased concentration of substrates (either glutamine or glutamic acid) and catalysts (weak acids) is expected to promote PCA formation. Moreover, PCA formation can even occur in the dry state because the amino group and the carboxamide group of glutamine can react in the absence of water ${ }^{\mathbf{2 1}}$. Meanwhile, the effect of temperature is more significant at low moisture contents, i.e. $X_{w}=0.13$, than at high moisture contents, i.e. $X_{w}=0.95$.

Figure 2-3 (A, B) shows the reaction rate constants determined from the isothermal heating experiments at different moisture contents and the model predictions for the reaction rate constants of the ascorbic acid degradation (A) and the PCA formation (B) obtained by fitting. The model parameters for both reactions are shown in Table 2-2. The model is in good agreement with the experimental data for the PCA reaction. For ascorbic acid a reasonable agreement can be observed, but one parameter value, i.e. kerf,s, could not be accurately determined, as it has a large 95\% confidence interval. The limited agreement for ascorbic acid may be explained by the challenging HPLC analysis of this acid due to partial peak overlap with other acids present in tomato juice. This overlap especially hindered accurate analysis at low moisture content. Although one fitting parameter could not be accurately determined, the general dependency of the reaction rate constant on moisture content and temperature is well described. In Figure 2-3 (C, D), parity plots of the experimental data and model predictions are shown using logarithmic scales and show a reasonable distribution. 

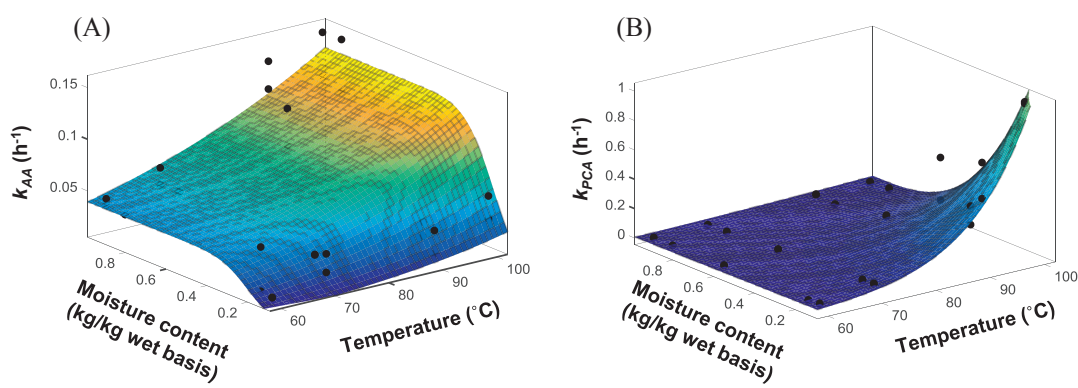

(C)
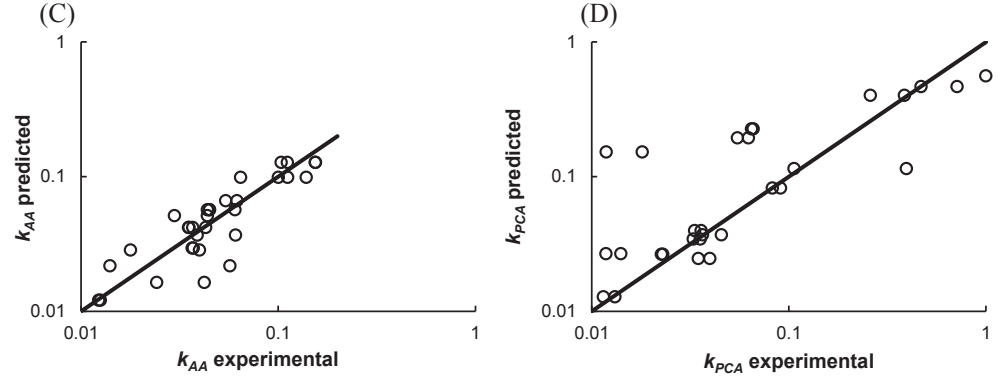

Figure 2-3 (A) and (B): Reaction kinetic constants of: (A) ascorbic acid and (B) pyroglutamic acid (PCA). The black dots represent the observed reaction kinetic constants from experimental data and the grid surfaces represent the model predictions. (C) and (D): Parity plots of the observed reaction kinetic constants of: (C) ascorbic acid and (D) PCA. The symbol ( $O$ ) represents the parity between the experimental values and the corresponding predicted value for $k$.

Table 2-2 Estimated parameter values and statistical evaluation of ascorbic acid degradation and pyroglutamic acid (PCA) formation models.

\begin{tabular}{lcccc}
\hline Estimated parameters ${ }^{2}$ & \multicolumn{2}{c}{ Ascorbic acid } & \multicolumn{2}{c}{ PCA } \\
\hline$k_{\text {ref }, w}\left(\mathrm{~h}^{-1}\right)$ & $9.9 \cdot 10^{-2}$ & $\pm 1.1 \cdot 10^{-2}$ & $2.5 \cdot 10^{-2}$ & $\pm 2.1 \cdot 10^{-2}$ \\
$k_{\text {refs, }}\left(\mathrm{h}^{-1}\right)$ & $1.5 \cdot 10^{-3}$ & $\pm 8.1 \cdot 10^{-3}$ & 0.64 & \pm 0.09 \\
$E a(\mathrm{~J} / \mathrm{mol})$ & 28750 & \pm 9100 & 37610 & \pm 4400 \\
$p$ & 8.0 & \pm 6.9 & 0.66 & \pm 0.32 \\
$T_{r e f}\left({ }^{\circ} \mathrm{C}\right) \mathrm{b}$ & 90 & & 90 & \\
$\mathrm{SSE}$ & 0.01 & & 0.04 & \\
Adjusted R ${ }^{2}$ & 0.76 & & 0.98 & \\
RMSE & $1.9 \cdot 10^{-2}$ & & $3.6 \cdot 10^{-2}$ & \\
\hline
\end{tabular}

a: Uncertainty of the parameters at $95 \%$ confidence interval.

b: Fixed value.

The model was validated using datasets of ascorbic acid and PCA concentrations in tomato samples with a moisture content of $0.51 \mathrm{~kg} / \mathrm{kg}$ wet basis. The model could reasonably well predict the ascorbic acid degradation and the PCA formation (Figure 2-4). However, it overestimated the PCA 
formation when the heating temperature was low $\left(60\right.$ and $\left.70{ }^{\circ} \mathrm{C}\right)$. The discrepancy may be explained by the high sensitivity of the reaction rate of PCA to the temperature. However, because PCA formation at low temperatures is very small, the lower discrepancy at these temperatures has less effect when evaluating a real process.

(A)

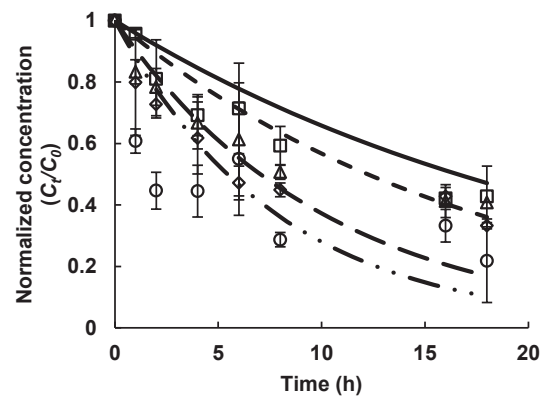

(B)

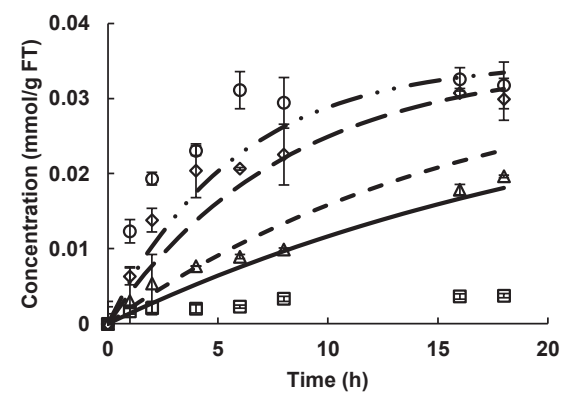

Figure 2-4 Validation of the model against data of (A) ascorbic acid and (B) pyroglutamic acid concentrations in tomato samples with $X_{w}=0.51$. The symbols represent the experimental data: $60{ }^{\circ} \mathrm{C}(\square), 70{ }^{\circ} \mathrm{C}(\diamond), 90{ }^{\circ} \mathrm{C}(\Delta)$, and $100{ }^{\circ} \mathrm{C}(\circ)$. The lines represent the model predictions: $60{ }^{\circ} \mathrm{C}$ (solid line), $70{ }^{\circ} \mathrm{C}$ (dotted line), $90{ }^{\circ} \mathrm{C}$ (dashed line), and $100{ }^{\circ} \mathrm{C}$ (dash-dot line). The error bars show the $95 \%$ confidence interval of the experimental data $(n=2)$.

\subsubsection{The effect of convective drying on organic acids concentrations}

The developed kinetic models are used to assess the effect of air drying of a tomato product on quality via the degradation of ascorbic acid and the formation of PCA, being important taste markers. A heat and mass transport model for a co- and counter-current air dryer was used to calculate the temperature and moisture content of the product during drying. In this case, a tomato-based product with an initial moisture content of $15.7 \mathrm{~kg} / \mathrm{kg}$ dry basis $(0.94 \mathrm{~kg} / \mathrm{kg}$ wet basis) is dried to a final moisture content of $0.05 \mathrm{~kg} / \mathrm{kg}$ dry basis. In both dryer configurations, the inlet air temperature is $150{ }^{\circ} \mathrm{C}$. The simulated product temperature and moisture content profiles are presented in Figure 2-5 (A). The temperature of the product is first heated up to the web bulb temperature and keeps constant during the initial constant rate drying period. When the moisture content is lower than the critical moisture content of $7.85 \mathrm{~kg} / \mathrm{kg}$ dry basis ${ }^{40}$, the process enters the falling rate drying period and the product temperature gradually increases to the air temperature. 
Subsequently, based on Figure 2-5 (A), the degradation and formation of the two organic acids were estimated. In Figure 2-5 (B, C) the reaction rate constants of ascorbic acid and PCA are shown as a function of temperature and moisture content. Additionally, in the same plot the estimated temperature and moisture content of the tomato product during co-current and countercurrent drying are shown. These figures provide information on the impact of these two different drying technologies on the reaction rates of ascorbic acid degradation and PCA formation. In Figure 2-5 (B) the ascorbic acid degradation is relatively fast in the initial constant rate drying period, while the formation of PCA is very slow as can be observed in Figure 2-5 (C). When the process enters the falling rate period, the degradation rate of ascorbic acid increases first while later in this period it decreases again. This is due to the opposite effect of the increasing temperature and the decreasing moisture content on the degradation rate. However, the formation rate of PCA increases strongly as decreasing moisture content and increasing temperature both promote a faster reaction.

In Figure 2-5 (D, E) the estimated concentrations of ascorbic acid and PCA are shown during the drying process. It is calculated that during co-current drying $25 \%$ of the ascorbic acid degrades, while during counter-current drying $21 \%$ degrades. Only at the end of the process there is a difference between both drying strategies, which is explained by the higher temperature at the end of the process during counter-current drying. Due to the higher temperature, the degradation in the counter-current dryer is faster. However, the residual ascorbic acid content is still higher as the total time for counter-current drying is shorter. For PCA the differences occur also primarily at the end of the process. The estimated PCA formation $(0.021 \mathrm{mmol} / \mathrm{g} \mathrm{FT})$ after co-current drying is much larger than after counter-current drying $(0.008 \mathrm{mmol} / \mathrm{g} F T)$. Therefore, on the basis of Figure 2-5 (D, E), one might suggest to apply counter-current drying to dry tomato-based products, which gives lower estimated concentrations of PCA and higher estimated concentrations of ascorbic acid. 
(A)

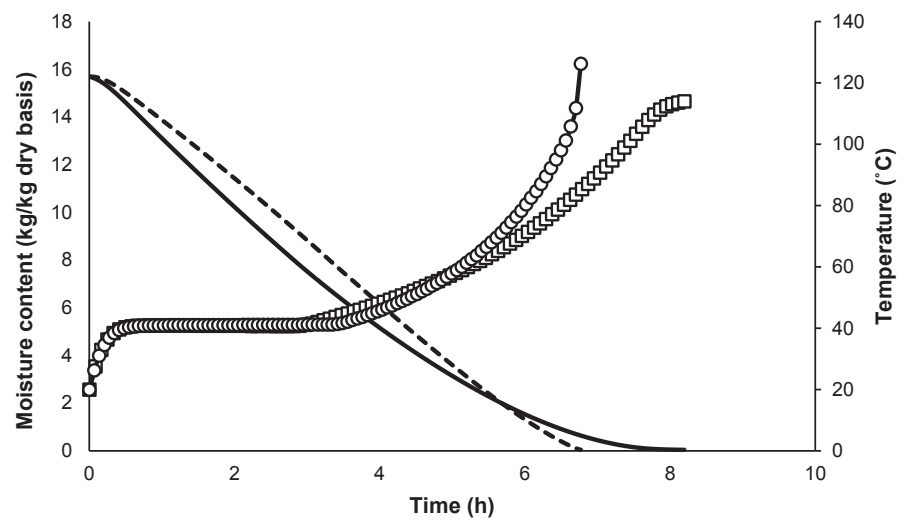

(B)

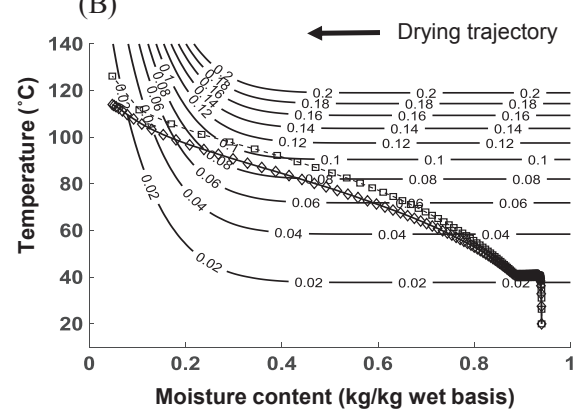

(D)

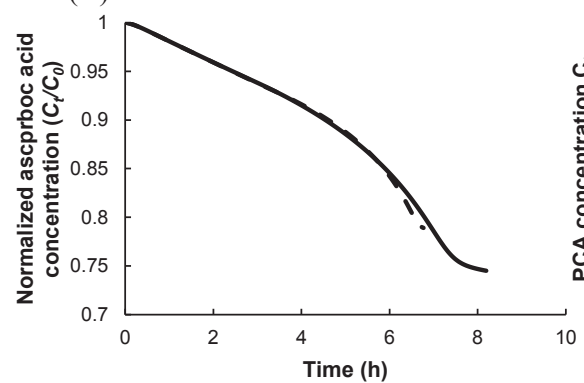

(C)

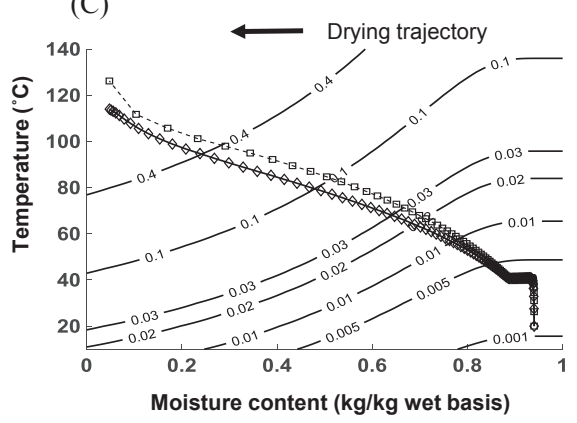

(E)

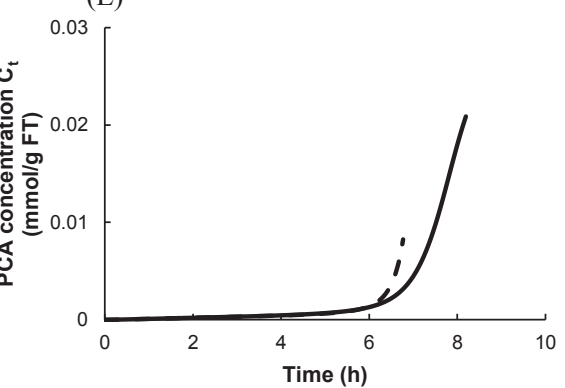

Figure 2-5 (A): Simulations of moisture content of the tomato-based product in cocurrent (solid line) and counter-current (dotted line) convective drying; and temperature profiles in co-current (solid line with symbol $\square$ ) and counter-current (solid line with symbol O) convective drying. (B) and (C): Contour plot of the reaction kinetic constants of (B) ascorbic acid and (C) pyroglutamic acid (PCA). The isolines represent the reaction kinetic constants; the solid lines are the average temperature-moisture content history of the tomato samples; the symbols in the line represent a time step of $0.02 \mathrm{~h}$ in co-current $(\diamond)$ and counter-current $(\square)$ convective drying. (D) and (E): (D) ascorbic acid degradation and (E) PCA formation with time during co-current (solid line) and counter-current (dotted line) convective drying. 
Concluding, during the drying process both moisture content and temperature vary in time, which has complex effects on the degradation and formation of the organic acids. The effects can be predicted using the developed kinetic models. The next step may be optimisation of the process towards less degradation of ascorbic acid and less formation of PCA, beyond mere cocurrent and counter-current process conditions. A possible optimisation method could be to split the process in two steps. In the second step, a lower air temperature may be used, to better retain the quality of the dried tomato product.

\subsection{Conclusions}

Thermal processing and drying affect the levels of organic acids in tomatobased products with a consequent impact on the perceived freshness. Both citric and malic acids are heat stable organic acids, which only increase in level by a concentration effect during drying. This is different for ascorbic and pyroglutamic acids (PCA), which are degraded and formed, respectively. Both organic acids can be considered as taste markers, indicating the taste retention of thermally processed tomato products. The reactions of ascorbic acid and PCA were described with first order kinetics using an extended Arrhenius model to describe the dependence of the kinetics on both moisture content and temperature. The full kinetic description of the degradation and formation kinetics of these two acids is a large improvement to previous studies that employ an empirical approach by correlated processing conditions and the levels of organic acids after processing. The availability of the kinetic model makes it possible to carry out further process optimisation on processing of tomato products on perceived freshness.

As an example the developed kinetic model was integrated in a process model of a convective air drying process. The simulations yielded an interesting insight on the effect of thermal drying on the final levels of both acids, where countercurrent appears to provide less ascorbic acid degradation and less PCA formation than co-current drying. Obviously, the kinetic models can also be 
integrated in other process models for e.g. sterilisation, evaporation or other drying processes.

\section{Acknowledgements}

This work was supported by the Institute of Sustainable Process Technology (ISPT). Partners in this project are Bodec, Danone, ECN and Unilever. We also thank Yuchen Wang for his support on performing experimental work. 


\section{Nomenclature}

$a_{v} \quad$ Contact area of the product and air per volume $\left[\mathrm{m}^{2} / \mathrm{m}^{3}\right]$

of the dryer chamber

C Concentration

$[\mathrm{mmol} / \mathrm{g} \mathrm{FT}]$

$c \quad$ Specific heat

Ea Activation energy

F $\quad$ Flow rate

$h_{w} \quad$ Latent heat of water

$J_{D} \quad$ Drying rate

K Mass transfer coefficient

$k \quad$ Reaction rate constant

p Parameter to describe the effect of moisture content on reaction rate constant

$[\mathrm{kJ} /(\mathrm{kg} \mathrm{K})]$

[J/mol]

$[\mathrm{kg} / \mathrm{s}]$

$[\mathrm{kJ} / \mathrm{kg}]$

$\left[\mathrm{kg} /\left(\mathrm{m}^{2} \mathrm{~s}\right)\right]$

$\left[\mathrm{kg} /\left(\mathrm{m}^{2} \mathrm{~s}\right)\right]$

$\left[\mathrm{h}^{-1}\right]$

$\begin{array}{ll}q & \text { Heat transfer rate } \\ \mathrm{R} & \text { Ideal gas constant }\end{array}$

$[-]$

$S \quad$ Cross-sectional area of the dryer chamber

T Temperature

$\left[\mathrm{kJ} /\left(\mathrm{m}^{2} \mathrm{~s}\right)\right]$

J/(mol k)]

$\left[\mathrm{m}^{2}\right]$

$[\mathrm{K}]$

Time

[h]

$W \quad$ Moisture content

$[\mathrm{kg} / \mathrm{kg} \mathrm{db}]$

X Mass fraction

$x \quad$ Position along the length of the dryer

[kg/ $\mathrm{kg}$ total $]$

[m]

$\begin{array}{ll}\alpha & \text { Heat transfer coefficient } \\ \chi & \text { Co- (1) or counter (-1) current operation }\end{array}$

$\left[\mathrm{kJ} /\left(\mathrm{K} \mathrm{m}^{2} \mathrm{~s}\right)\right]$

\section{Subscript}

$0 \quad$ Initial condition

c Critical value $\left(W_{c}=7.85 \mathrm{~kg} / \mathrm{kg} \mathrm{db}\right)$

e Equilibrium

g Gas

p Product

ref Reference

$\mathrm{s} \quad$ In pure solid form $\left(X_{w}=0\right)$

$\mathrm{t} \quad$ At certain time

v Vapour

$\mathrm{w} \quad$ In a solution with infinite dilution $\left(X_{w}=1\right)$ 


\section{References}

[1]. Qiu, J., Khalloufi, S., Martynenko, A., Van Dalen, G., Schutyser, M. and Almeida-Rivera, C. (2015). Porosity, bulk density, and volume reduction during drying: review of measurement methods and coefficient determinations. Drying Technology, 33(14), 1681-1699.

[2]. Krebbers, B., Matser, A. M., Hoogerwerf, S. W., Moezelaar, R., Tomassen, M. M. and van den Berg, R. W. (2003). Combined high-pressure and thermal treatments for processing of tomato puree: evaluation of microbial inactivation and quality parameters. Innovative Food Science \& Emerging Technologies, 4(4), 377-385.

[3]. Akanbi, C. T., Adeyemi, R. S. and Ojo, A. (2006). Drying characteristics and sorption isotherm of tomato slices. Journal of food engineering, 73(2), 157 163.

[4]. Shi, J. and Maguer, M. L. (2000). Lycopene in tomatoes: chemical and physical properties affected by food processing. Critical reviews in food science and nutrition, 40(1), 1-42.

[5]. Gahler, S., Otto, K. and Böhm, V. (2003). Alterations of vitamin C, total phenolics, and antioxidant capacity as affected by processing tomatoes to different products. Journal of Agricultural and Food Chemistry, 51(27), 79627968.

[6]. Toor, R. K. and Savage, G. P. (2005). Antioxidant activity in different fractions of tomatoes. Food Research International, 38(5), 487-494.

[7]. Valerio, M., Lovelli, S., Perniola, M., Di Tommaso, T. and Ziska, L. (2013). The role of water availability on weed-crop interactions in processing tomato for southern Italy. Acta Agriculturae Scandinavica, Section B-Soil \& Plant Science, 63(1), 62-68.

[8]. Anthon, G. E., LeStrange, M. and Barrett, D. M. (2011). Changes in pH, acids, sugars and other quality parameters during extended vine holding of ripe processing tomatoes. Journal of the Science of Food and Agriculture, 91(7), 1175-1181.

[9]. Petro-Turza, M. (1986). Flavor of tomato and tomato products. Food Reviews International, 2(3), 309-351. 
[10]. Thakur, B., Singh, R. and Nelson, P. (1996). Quality attributes of processed tomato products: a review. Food Reviews International, 12(3), 375401.

[11]. Marconi, O., Floridi, S. and Montanari, L. (2007). Organic acids profile in tomato juice by HPLC with UV detection. Journal of food quality, 30(2), 253-266.

[12]. Dewanto, V., Wu, X., Adom, K. K. and Liu, R. H. (2002). Thermal processing enhances the nutritional value of tomatoes by increasing total antioxidant activity. Journal of agricultural and food chemistry, 50(10), 30103014.

[13]. Jacob, K., Periago, M. J., Böhm, V. and Berruezo, G. R. (2008). Influence of lycopene and vitamin $\mathrm{C}$ from tomato juice on biomarkers of oxidative stress and inflammation. British Journal of Nutrition, 99(01), 137-146.

[14]. Chelius, D., Jing, K., Lueras, A., Rehder, D. S., Dillon, T. M., Vizel, A., . . . Bondarenko, P. V. (2006). Formation of pyroglutamic acid from Nterminal glutamic acid in immunoglobulin gamma antibodies. Analytical chemistry, 78(7), 2370-2376.

[15]. Schoenemann, D. and Lopez, A. (1973). Heat processing effects on physical and chemical characteristics of acidified canned tomatoes. Journal of Food Science, 38(2), 195-201.

[16]. Kumar, A. and Bachhawat, A. K. (2012). Pyroglutamic acid: throwing light on a lightly studied metabolite. Curr Sci, 102(2), 288.

[17]. Grill, E., Löffler, S., Winnacker, E.-L. and Zenk, M. H. (1989). Phytochelatins, the heavy-metal-binding peptides of plants, are synthesized from glutathione by a specific $\gamma$-glutamylcysteine dipeptidyl transpeptidase (phytochelatin synthase). Proceedings of the National Academy of Sciences, 86(18), 6838-6842.

[18]. Pérez-Arellano, I., Carmona-Álvarez, F., Martínez, A. I., Rodríguez-Díaz, J. and Cervera, J. (2010). Pyrroline-5-carboxylate synthase and proline biosynthesis: From osmotolerance to rare metabolic disease. Protein Science, 19(3), 372-382. 
[19]. Krishna, R. V. and Leisinger, T. (1979). Biosynthesis of proline in Pseudomonas aeruginosa. Partial purification and characterization of $\gamma$ glutamyl kinase. Biochemical Journal, 181(1), 215-222.

[20]. Mena, F. V., Baab, P. J., Zielke, C. L., Huang, Y. and Zielke, H. R. (2005). Formation of extracellular glutamate from glutamine: exclusion of pyroglutamate as an intermediate. Brain research, 1052(1), 88-96.

[21]. Beck, A., Bussat, M. C., Klinguer-Hamour, C., Goetsch, L., Aubry, J. P., Champion, T., Corvaia, N. (2001). Stability and CTL activity of N-terminal glutamic acid containing peptides. The Journal of Peptide Research, 57(6), 528538.

[22]. Arii, K., Kobayashi, H., Kai, T. and Kokuba, Y. (1999). Degradation kinetics of l-glutamine in aqueous solution. European Journal of Pharmaceutical Sciences, 9(1), 75-78.

[23]. Uddin, M., Hawlader, M. and Zhou, L. (2001). Kinetics of ascorbic acid degradation in dried kiwifruits during storage. Drying Technology, 19(2), 437446.

[24]. Tritsch, G. L. and Moore, G. E. (1962). Spontaneous decomposition of glutamine in cell culture media. Experimental Cell Research, 28(2), 360-364.

[25]. Erenturk, S., Gulaboglu, M. S. and Gultekin, S. (2005). The effects of cutting and drying medium on the vitamin $\mathrm{C}$ content of rosehip during drying. Journal of Food Engineering, 68(4), 513-518.

[26]. Luyben, K., Liou, J. and Bruin, S. (1982). Enzyme degradation during drying. Biotechnology and Bioengineering, 24(3), 533-552.

[27]. Perdana, J., Fox, M., Schutyser, M. and Boom, R. (2012). Enzyme inactivation kinetics: Coupled effects of temperature and moisture content. Food Chemistry, 133(1), 116-123.

[28]. Pakowski, Z. and Mujumdar, A. S. (2014). Basic process calculations and simulations in drying Handbook of Industrial Drying, Fourth Edition (pp. 5175). Boca Raton: CRC Press.

[29]. Selli, S., Kelebek, H., Ayseli, M. T. and Tokbas, H. (2014). Characterization of the most aroma-active compounds in cherry tomato 
by application of the aroma extract dilution analysis. Food Chemistry, 165, 540-546.

[30]. Barbooti, M. M. and Al-Sammerrai, D. A. (1986). Thermal decomposition of citric acid. Thermochimica acta, 98, 119-126.

[31]. Jeyaprakash, S., Frank, D. C. and Driscoll, R. H. (2016). Influence of heat pump drying on tomato flavor. Drying Technology, 34(14), 1709-1718.

[32]. Wiese, K. L. and Dalmasso, J. P. (1994). Relationships of color, viscosity, organic acid profiles and ascorbic acid content to addition of organic acids and salt in tomato juice. Journal of food quality, 17(4), 273-284.

[33]. Villari, P., Costabile, P., Fasanaro, G., Sio, F. D., Laratta, B., Pirone, G. and Castaldo, D. (1994). Quality loss of double concentrated tomato paste: evolution of the microbial flora and main analytical parameters during storage at different temperatures. Journal of food processing and preservation, 18(5), 369-387.

[34]. Igual, M., García-Martínez, E., Camacho, M. and Martínez-Navarrete, N. (2010). Effect of thermal treatment and storage on the stability of organic acids and the functional value of grapefruit juice. Food Chemistry, 118(2), 291-299.

[35]. Pratta, G., Zorzoli, R., Boggio, S., Picardi, L. and Valle, E. (2004). Glutamine and glutamate levels and related metabolizing enzymes in tomato fruits with different shelf-life. Scientia horticulturae, 100(1), 341-347.

[36]. Salvioli, A., Zouari, I., Chalot, M. and Bonfante, P. (2012). The arbuscular mycorrhizal status has an impact on the transcriptome profile and amino acid composition of tomato fruit. BMC plant biology, 12(1), 44-56.

[37]. Gregory III, J. F. (1985). Chemical changes of vitamins during food processing Chemical changes in food during processing (pp. 373-408). Boston, MA: Springer US.

[38]. Djendoubi Mrad, N., Boudhrioua, N., Kechaou, N., Courtois, F. and Bonazzi, C. (2012). Influence of air drying temperature on kinetics, physicochemical properties, total phenolic content and ascorbic acid of pears. Food and Bioproducts Processing, 90(3), 433-441. 
[39]. Dimarchi, R. D., Tam, J. P., Kent, S. B. and Merrifield, R. (1982). Weak acid-catalyzed pyrrolidone carboxylic acid formation from glutamine during solid phase peptide synthesis. International journal of peptide and protein research, 19(1), 88-93.

[40]. Reyes, A., Mahn, A., Huenulaf, P. and González, T. (2014). Tomato dehydration in a hybrid-solar dryer. Journal of Chemical Engineering \& Process Technology, 5(4), 196-204. 


\section{CHAPTER 3}

\section{Conductive thin film drying kinetics relevant to drum drying}

This chapter has been published as: Qiu, J., Kloosterboer, K., Guo, Y., Boom, R. M., \& Schutyser, M. A. I. (2019). Conductive thin film drying kinetics relevant to drum drying. Journal of Food Engineering, 242, 68-75. 


\section{Abstract}

Direct assessment of the kinetics of drum drying operations has been a difficult task as the mass and temperature profiles are hard to monitor. Still, developing a better understanding of conductive drying would help to identify new operating windows for this technology. The drying kinetics was investigated by drying maltodextrin and starch suspensions with a novel custom-built laboratory-scale apparatus, which allows on-line monitoring of mass and temperatures. During drying, three separate periods were identified: the heating, the boiling and the conductive drying (declining rate) periods. The duration of the initial heating period was proportional to the film thickness and was responsible for a relatively small amount of water evaporated due to natural convection. During the boiling period, the drying rate kept constant while bubble formation impeded the heat transfer. Larger bubbles were observed for starch suspensions due to its viscoelastic properties. Thus, large temperature gradients between the heating pan and the film were observed for starch suspensions. During the conductive drying period, the initial amount of dry solids per surface area determines the drying rate as it determines the thickness of the semi-moist layer subjected to conductive drying. Application of a thin film is preferred to avoid boiling, especially at increasing solid content. This situation also better approaches double drum drying processes, where boiling occurs in the pool and conductive drying occurs on the drum. 


\subsection{Introduction}

Drying is a widely applied technique in food industry to reduce moisture content and to extend product shelf-life. Drying facilitates packaging, transportation and storage of foods by reducing weight and volume of the product ${ }^{1}$. Although many types of drying techniques exist, one can distinguish two main categories, i.e. convective and conductive drying technologies that rely on a different mode of heat transfer. Convective dryers, also known as direct dryers, constitute over $85 \%$ of the industrially applied dryers ${ }^{2,3}$. During convective drying the heat for evaporation is supplied by hot air, which contacts with the wet product to remove the moisture ${ }^{4}$. In contrast, during conductive drying heat is supplied through a (metal) wall ${ }^{5}$. Conductive dryers are more energy efficient than convective dryers, having a more efficient heat supply and lower energy loss via the exhaust gases ${ }^{\mathbf{5}, \mathbf{6}}$. During conductive drying the product feed is usually applied as a thin wet film ${ }^{4}$. A potential disadvantage of conductive drying is that the product is dried at the boiling point, which is detrimental to heat sensitive products. This can only be alleviated by operating at reduced pressure to reduce the boiling temperature. Moreover, powders obtained from conductive drying have different properties such as bulk density and reconstitution behaviour compared to those obtained with direct drying processes, such as spray drying ${ }^{7}$.

Different conductive dryer designs have been developed throughout the years, such as drum dryers, refractance window dryers and agitated thin film dryers ${ }^{8-}$ 10. Drum drying is frequently applied to dry pasty or viscous (food) materials, for example for drying starch, sodium caseinate, baby foods, mashed potatoes, fruit purees, and soup formulations ${ }^{11-13}$. The influence of design and operating variables of conductive drying processes on product quality has been investigated especially for drum dryers, the most commonly applied conductive drying method.

Fritze ${ }^{14}$ compared the performance of different drum dryer designs during drying of gelatinized maize starch with varying combinations of feed concentration and drum speed. Kalogianni et al. ${ }^{12}$ used an industrial-scale 
double drum dryer to prepare pre-gelatinized maize starch and showed that in addition to the drying temperature, also the rheological and handling properties of the material are important in the drying process. Valous et al. ${ }^{15}$ examined the effects of the steam pressure, drum rotation speed and feed pool level, on the final moisture content and capacity during double drum drying of pregelatinized maize starch. Gavrielidou et al. ${ }^{16}$ measured the temperature profiles inside the feed pool of pre-gelatinized starch slurries and suggested that the heat transport in the pool is dominated by the convection of flow currents induced by the rising bubbles. After pool boiling, the product is rolled into a wet film on the rotating drum wall. Depending on the conditions, the film is still boiling or is further dried by conductive drying. During conductive drying, the temperature of the film increases above the boiling point. A dry layer forms and grows, starting from the hot wall surface, until it encompasses the whole film. In this period the heat conduction of the dry layer limits the drying rate ${ }^{17}$. Apart from drum drying, other conductive thin film drying technologies have emerged, such as agitated thin film and refractance window drying 9, 10,18.

The previous studies were conducted on pilot or industrial-scale equipment, and therefore could not accurately establish the transient drying kinetics. Only a few studies investigated the drying kinetics at laboratory scale. Fudym et al. ${ }^{\mathbf{8}}$ used an experimental device to monitor the product temperature and thus the heat flux during contact drying, but did not measure the mass decrease as a function of time. Karapantsios ${ }^{19}$ used a Simultaneous Thermal Analyser to combine thermo-gravimetric and differential scanning calorimetry (DSC) measurements to record mass and product temperature during drying of starch, but the pan temperature was not registered, which is important to determine the heat flux during drying. Thus, the heat transfer between the hot pan and the product could not be well characterized. Therefore, to better understand the conductive drying processes, an in depth analysis of the drying kinetics is still necessary.

Therefore, the objective of this study was to unravel the transient drying kinetics of conductive thin film drying using an experimental system that allows simultaneous on-line monitoring of both mass and relevant temperatures. 
Potato starch and maltodextrin were chosen as representative model systems for conductive drying.

\subsection{Materials and Methods}

\subsubsection{Sample preparation}

Maltodextrin suspensions with different solid concentrations $(10 \%, 15 \%$ and $30 \% \mathrm{w} / \mathrm{w}$ total) were prepared by dispersing maltodextrin DE12 powders (Roquette, Hoofddorp, the Netherlands) into cold deionized water. The samples were mixed at room temperature for $1 \mathrm{~h}$ by a magnetic stirrer (IKA KMO2 basic, Staufen, Germany) with a mixing speed of $400 \mathrm{rpm}$, to ensure the homogeneity and dissolution. The suspensions were freshly prepared and used on the same day.

Native potato starch was purchased from Merck KGaA (Darmstadt, Germany). Potato starch suspensions were prepared with different solid concentrations $(5 \%, 10 \%, 15 \%$ and $40 \% \mathrm{w} / \mathrm{w}$ total) by adding native potato starch granule powders to cold deionized water in a glass beaker. The suspensions with low solid concentrations (5\%-15\%) were heat treated to gelatinize the starch according a procedure used by Karapantsios ${ }^{19}$. The suspensions were stirred $(500 \mathrm{rpm})$ and heated to $80{ }^{\circ} \mathrm{C}$ for approximately 10 min (IKA C-MAG HS 7, Staufen, Germany). To avoid evaporation of water during the heat treatment, the beaker was covered with aluminium foil. The duration of this procedure (10 min) matches approximately with the residence time of the product inside the feeding pool of a double drum dryer ${ }^{16}$. After heating, the agitated gelatinized starch suspensions were allowed to cool down to room temperature prior to drying. The heat treatment was skipped for the highest solid concentration $(40 \% \mathrm{w} / \mathrm{w})$ due to gel formation, which hindered the application of the suspensions as a homogeneous film for subsequent drying.

\subsubsection{Design of the DryVaGram}

Figure 3-1 (A) shows a schematic drawing of the laboratory-scale conductive thin film dryer. The major parts are the steel heating pan, the induction coil and 
the Sartorius Cubis MSE analytical balance with $1 \mathrm{mg}$ resolution (Geottingen, Germany).

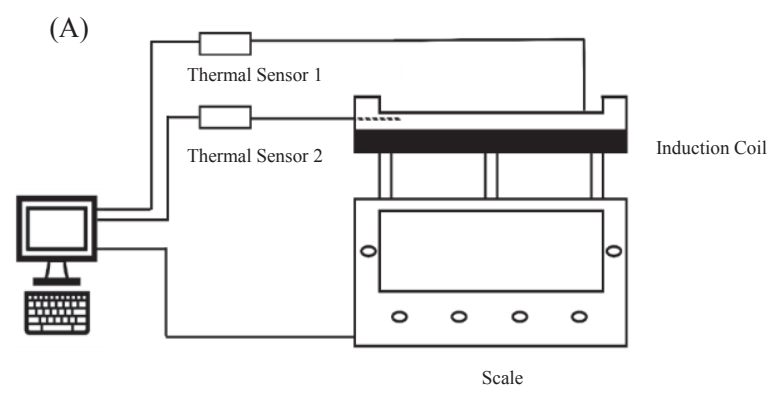

(B)

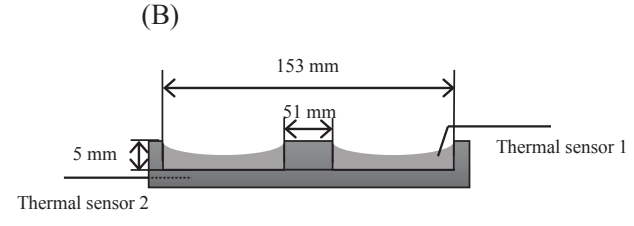

Side view

(C)

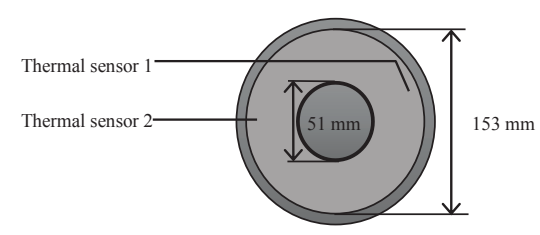

Top view

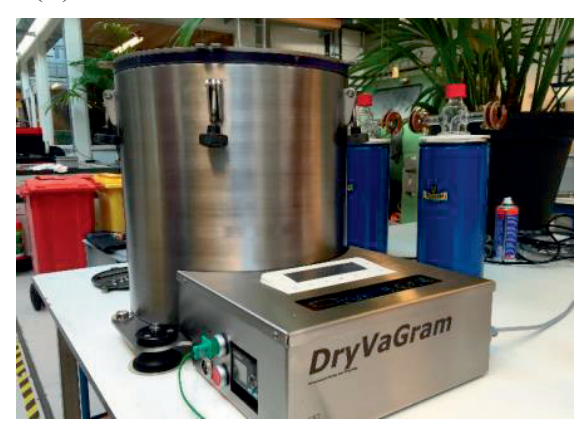

Figure 3-1 Schematic drawing of (A) the system and (B) side and top views of the steel pan and $(\mathrm{C})$ a picture of the experimental thin film dryer set-up.

The induction coil was designed to avoid any undesired interaction with the balance and/or the pan. During heating a small systematic deviation (e.g. $0.4 \mathrm{~g}$ at $200{ }^{\circ} \mathrm{C}$ ) in mass recording was observed, which scaled linearly with the measured pan temperature. The measurements were corrected for this small deviation. The equipment was also equipped with two Type $\mathrm{K}$ thermocouples (National Instruments ${ }^{\mathrm{TM}}$, Woerden, the Netherlands), which were used to record temperatures of the product and the pan. Mass and temperatures were 
recorded each second. Figure 3-1 (B) shows the side and top views of the steel pan. The pan had an inner and an outer ring with a height of $5 \mathrm{~mm}$ to avoid loss of sample. The pan area between the rings $\left(0.0163 \mathrm{~m}^{2}\right)$ was evenly heated with the induction coil and thus used to dry the sample.

\subsubsection{Experimental procedure}

To evaluate the operation of the apparatus, the evaporation of a water film was evaluated. A film of $1 \mathrm{~mm}$ thickness was prepared by spreading $16.3 \mathrm{~mL}$ water onto the surface between the rings. Induction heating of the pan at a constant power was used to evaporate the water. The experiment was stopped until all water evaporated. These experiments were repeated six times.

Films of maltodextrin and starch suspensions with different thickness were dried with the apparatus as well. For this, 8.2, 16.3 and $32.6 \mathrm{~mL}$ of suspensions were carefully spread across the pan surface, to form thin films of 0.5, 1.0 and $2.0 \mathrm{~mm}$, respectively. Again, films were dried at a constant power input. The drying process was automatically stopped when the pan temperature reached $190{ }^{\circ} \mathrm{C}$ to prevent overheating of the system. All measurements were conducted in duplicate.

The drying process was recorded on video, while the mass decay and temperatures were measured every 1 second. Subsequently, the obtained data were used to investigate the corresponding drying kinetics. The specific drying rate is expressed in $\mathrm{g} /\left(\mathrm{s} \cdot \mathrm{m}^{2}\right)$. For the experiments with pure water, the coefficient of variation (= standard deviation/mean) was calculated to evaluate the repeatability of the system.

\subsection{Results and discussions}

\subsubsection{Conductive thin film evaporation of water}

Six experiments were carried out with water to evaluate the operation of the system. Figure 3-2 shows the mass and temperature profiles against drying time during the evaporation of water. A thin film of water of $1 \mathrm{~mm}$ thickness took $83.2 \pm 3.7 \mathrm{~s}$ to evaporate completely. The coefficient of variation of the evaporation time (= standard deviation/mean) was less than 0.05 . From the 
mass and temperature curves three distinct periods could be distinguished (Figure 3-2). In period 1, the films gradually heat up from room temperature to the boiling temperature, while the mass of the film slightly decreases, due to the difference in relative humidity of the air and the water, respectively ${ }^{17}$. In the second period the film is boiling. Both the evaporation rate and the difference between the temperatures of the pan and film remain constant, which indicates that all transferred heat is used for evaporation. For periods 1 and 2 , the accuracies of mass and temperature measurements were high. The coefficients of variation of the film mass, film temperature and pan temperature were lower than $0.08,0.05$ and 0.06 , respectively.
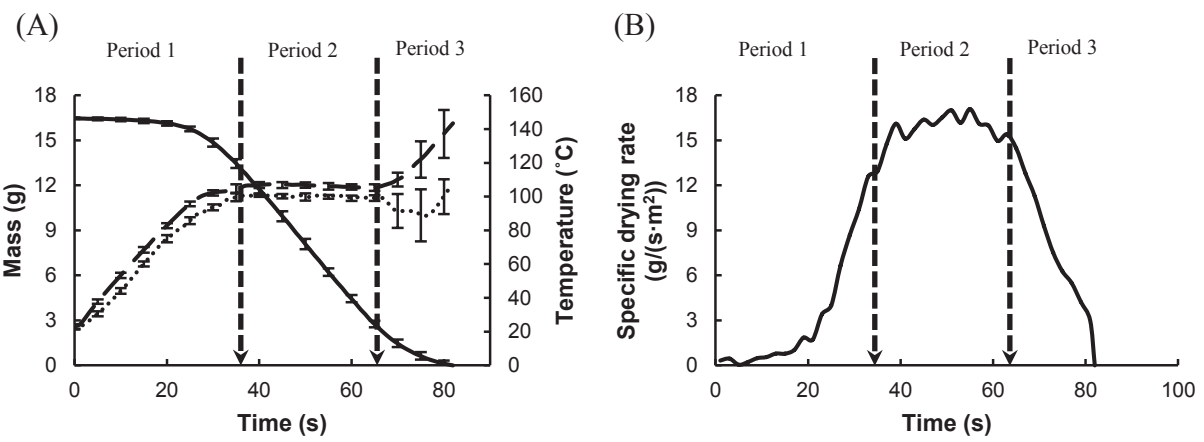

Figure 3-2 (A) The mass (solid line) and temperature (dotted line) profiles of water and the temperature profile (dashed line) of the heated pan during the conductive thin film drying measurement (Film thickness $=1 \mathrm{~mm}$ ). The curves represent the average of six independent measurements. The error bars show the standard deviation of the experimental data $(\mathrm{n}=6)$; (B) specific drying rate curves versus time of the water film.

Towards the end of period 2 and during period 3, the evaporation rate declines and the temperature difference between the pan and the film increases. This is observed as dry spots on the pan appear (according to video analysis) and thus not all supplied heat is used anymore for evaporation. In period 3 a temporary decrease of the film temperature can be observed, because the sensor was not submerged in the water anymore, and measured the temperature of the air instead. This may be the reason why the accuracy of the temperature measurements in period 3 was lower than those in periods 1 and 2 . 


\subsubsection{Drying kinetics of maltodextrin}

Figure 3-3 shows the temperatures during drying of maltodextrin DE12 slurries, using three different thickness of slurry layers. Also here, the drying process can be split into three different periods. The temperatures of pan and film linearly increase until the film temperature reaches the boiling temperature (period 1). The duration of period 1 increases with film thickness due to the increased thermal mass. In period 2 the film temperatures and evaporation rate are constant, whereas the pan temperatures gradually increase during this period (Figure 3-3 and Figure 3-4). This temperature increase can be explained by the reduced heat transfer coefficient from the pan to the film due to bubble formation and increased solid concentration. With increasing solute concentration and thus viscosity vapour bubbles are hindered to depart from the boiling film and collapse, which resists heat transfer. Towards the end of period 2 and in period 3, both the pan and film temperatures increased faster due to a decline in the evaporation rate and boiling temperature elevation (Figure 3-3 and Figure 3-4). This decreasing evaporation rate occurs when most of free water is removed. The remaining water is bound water, which results in a higher boiling temperature ${ }^{20}$. At this point the concentrated liquid film transforms into a moist semi-solid film, in which bubbles cannot nucleate and grow and thus boiling is inhibited ${ }^{21}$. Instead vapour is removed via diffusion, most probably progressively from the interface close to the heating wall towards the surface of the film ${ }^{19}$. At this stage we assume that a dry layer is first formed close to the wall, which grows thicker until the total film is dried ${ }^{17}$. The drying is therefore limited by the conductive heat transfer through the dry layer. For the film with a thickness of $0.5 \mathrm{~mm}$ a distinct boiling stage (period 2) was not observed, due to the limited amount of water available. Small deviations across the pan can be observed: closer to the edges of the rings, less vigorous boiling takes place than in the middle position between the rings, which might result from a local thicker film near the edge due to capillary action (Figure 3-9). Despite this edge effect, we expect that this has limited influence on the overall observed drying behaviour of the film. 


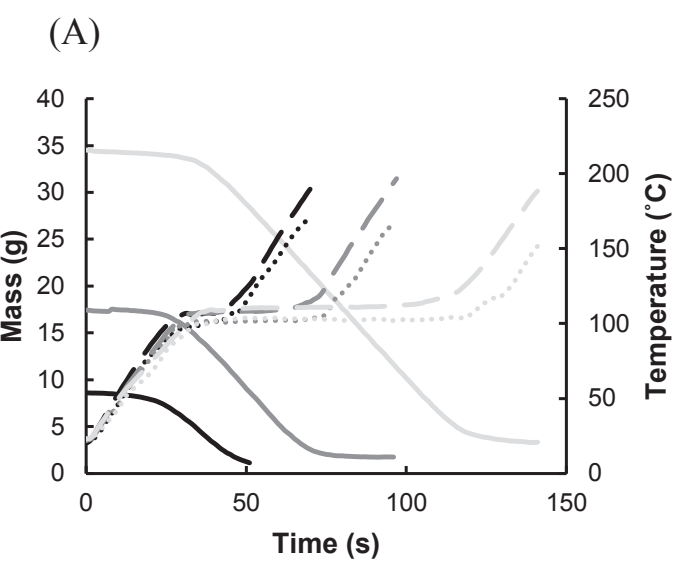

(B)

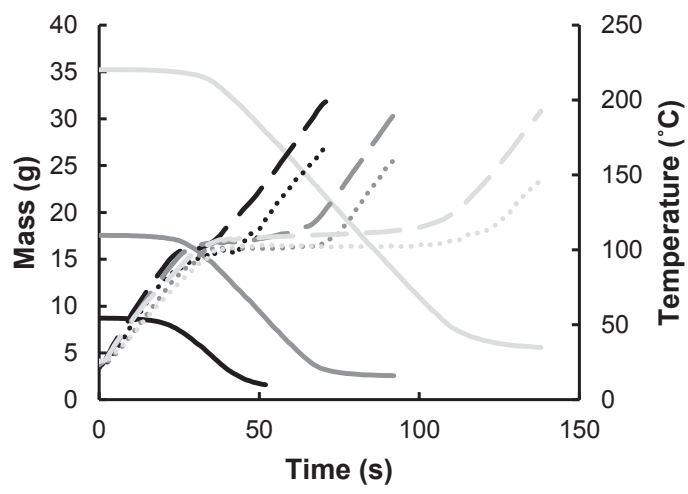

(C)

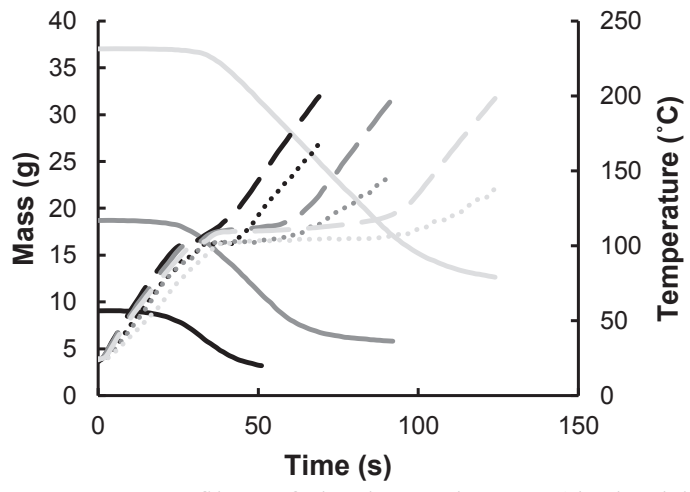

Figure 3-3 The temperature profiles of the heated pans (dashed lines); and the mass (solid lines) and temperature profiles (dotted lines) of the maltodextrin DE12 films of varying film thickness: $0.5 \mathrm{~mm}$ (black lines), $1 \mathrm{~mm}$ (dark grey lines), $2 \mathrm{~mm}$ (white grey lines); and varying initial concentrations: (A) $10 \% \mathrm{w} / \mathrm{w}$ total, (B) 15\% w/w total, (C) $30 \% \mathrm{w} / \mathrm{w}$ total. 
The mass (g) profiles of the maltodextrin DE12 films were also studied (Figure 3-3). During heating up, already some evaporation was observed, due to the differences in relative humidity between the film and the environment as explained before. The slopes of the drying curves became progressively steeper and reached a maximum value, and period 2 has started in which the drying rates and film temperatures are constant. The duration of period 2 increases with increasing film thickness, due to the larger amount of water that needs to be evaporated. Only for the smallest film thickness ( $0.5 \mathrm{~mm}$ thickness), the drying rates quickly declined after the heating up stage and the maximum drying rate was not achieved.

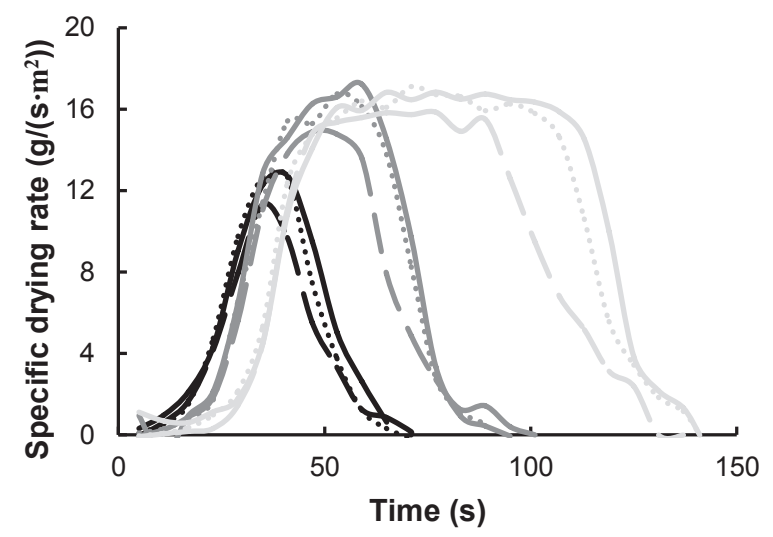

Figure 3-4 Specific drying rate versus time of the maltodextrin DE12 films of varying initial solid concentrations: $10 \% \mathrm{w} / \mathrm{w}$ total (solid lines), $15 \% \mathrm{w} / \mathrm{w}$ total (dotted lines), $30 \% \mathrm{w} / \mathrm{w}$ total (dashed lines); and film thickness: $0.5 \mathrm{~mm}$ (black lines), $1 \mathrm{~mm}$ (dark grey lines) and $2 \mathrm{~mm}$ (white grey lines).

The specific drying rate $\left(\mathrm{g} /\left(\mathrm{s} \cdot \mathrm{m}^{2}\right)\right)$ for the maltodextrin DE12 films were also investigated using one film thickness, but using different solid contents (Figure 3-4). It shows that films with similar thickness, but different initial dry matter content exhibit different maximum drying rates. With increasing initial dry matter content, a lower maximum drying rate was observed (especially for $30 \%$ $\mathrm{w} / \mathrm{w}$ ), while period 2 becomes shorter. The increasing solid mass results in a larger solid matrix, which leads to more resistance to vapour migration and thus slower heat transfer due to the creation of a porous matrix. Because the process 
is operated at a constant heat flux, the pan temperature increases as a result (Figure 3-3), while the evaporation will slow.

The amount of solids present also affects the drying during the last period. Figure 3-5 shows the comparison of the specific drying rates of the films with different initial conditions (e.g. thickness and initial solid content) but similar initial amount of dry matter. The drying rates start to decline after the solid content increases to $\sim 40 \% \mathrm{w} / \mathrm{w}$. It should be noticed that to increase the solid content from $15 \%$ to $40 \% \mathrm{w} / \mathrm{w}$, approximately $74 \%$ of water is dehydrated. After removal of such a large amount of water, the drying rate curves of the films converge in the last period, indicating that the amount of solids determines the drying behaviour in the last stage.

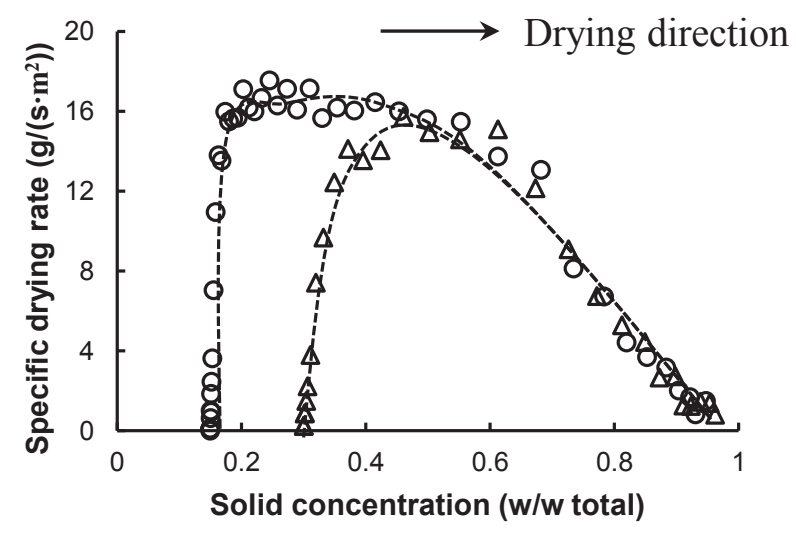

Figure 3-5 Specific drying rate versus solid concentration for the maltodextrin DE12 films with varying initial solid concentrations and film thickness: $30 \% \mathrm{w} / \mathrm{w}$ total and $1 \mathrm{~mm}(\Delta), 15 \% \mathrm{w} / \mathrm{w}$ total and $2 \mathrm{~mm}(\mathrm{O})$. The symbols represent a time step of $3 \mathrm{~s}$. The lines are added to guide the eye.

\subsubsection{Drying kinetics of pre-gelatinized starches}

Figure 3-6 shows the temperature of the pans and films during drying of starch slurries. Films of $2 \mathrm{~mm}$ thickness with solid content of $10 \%$ and $15 \% \mathrm{w} / \mathrm{w}$ could not be dried due to excessive bubble formation. Similar to the drying of the 1 and $2 \mathrm{~mm}$ maltodextrin films, the temperature curves can be split into 3 periods, whereas the film of $0.5 \mathrm{~mm}$ does not exhibit a clear period 2 . 
The pan temperatures increased faster and more significantly in period 2 for the films of $10 \%$ and $15 \% \mathrm{w} / \mathrm{w}$ total, compared to those during drying of maltodextrin. These higher pan temperatures may be attributed to the different molecular properties of starch compared to maltodextrin that result in different boiling behaviour. Starch is built from linear amylose and branched amylopectin components ${ }^{22}$. The linear amylose molecules are responsible for entanglement and network formation and thus give starch suspensions high viscosity and elasticity, leading to gelation. These properties are also responsible for the entrapment of vapour bubbles inside the boiling films and hinder fast bubble departure due to retarded film breakup ${ }^{23}$. Bubbles in the boiling starch suspensions need to expand much in volume before they collapse, leading to suboptimal heat transfer. In contrast, maltodextrin, being a hydrolysed product from starch, has much lower molecular weights. Maltodextrin solutions exhibit therefore lower viscosity and no molecular network formation, leading to bubbles that collapse quickly, allowing better heat transfer ${ }^{23}$. The higher porosity from the larger and more numerous bubbles during drying of starch films especially at the end of period 2 ( $\sim 70$ s) (Figure 3-9), provide higher thermal resistance, leading to larger temperatures in the pan. Similar behaviour was observed during double-drum drying of pre-gelatinized starch slurries and is generally known as vapour blanketing ${ }^{16}$. 


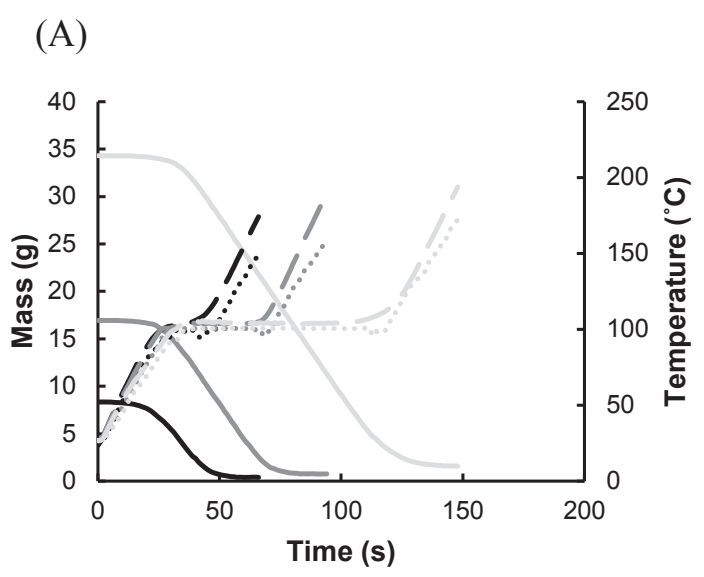

(B)

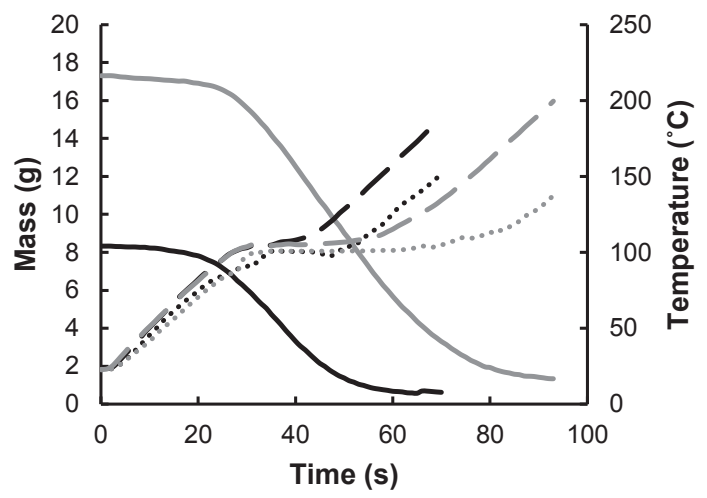

(C)

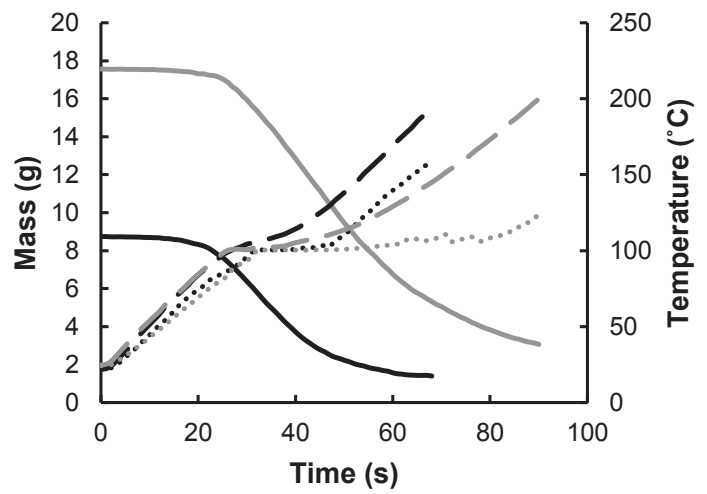

Figure 3-6 The temperature profiles of the heated pans (dashed lines); and the mass (solid lines) and temperature profiles (dotted lines) of the potato starch films of varying film thickness: $0.5 \mathrm{~mm}$ (black lines), $1 \mathrm{~mm}$ (dark grey lines), $2 \mathrm{~mm}$ (white grey lines); and varying initial concentrations: (A) $5 \% \mathrm{w} / \mathrm{w}$ total, (B) $10 \% \mathrm{w} / \mathrm{w}$ total, (C) $15 \% \mathrm{w} / \mathrm{w}$ total. 
The temperature profiles for the starch films of $5 \% \mathrm{w} / \mathrm{w}$ differed not much from those of the maltodextrin films, because the amount of solids was not large enough to provide sufficient viscosity and network formation ${ }^{23}$. Similar to the drying behaviour of maltodextrin, the drying rate for the starch films of 1 and $2 \mathrm{~mm}$ reached a maximum constant value for a certain period (period 2) after which it decreased again (Figure 3-7). Again for the film of $0.5 \mathrm{~mm}$, the drying rate declines rapidly after the initial increase without achieving a significant period 2.

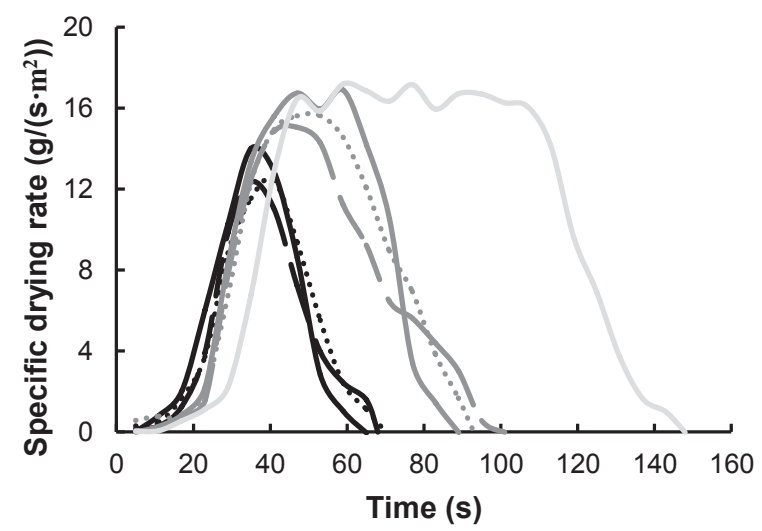

Figure 3-7 Specific drying rate curves versus time of the starch films of varying initial solid concentrations: $5 \% \mathrm{w} / \mathrm{w}$ total (solid lines), 10\% w/w total (dotted lines), 15\% $\mathrm{w} / \mathrm{w}$ total (dashed lines); and film thickness: $0.5 \mathrm{~mm}$ (black lines), $1 \mathrm{~mm}$ (dark grey lines) and $2 \mathrm{~mm}$ (white grey lines).

To identify the influence of the amount of solids present, we compared the specific drying rates of the starch films with different film thickness but similar initial amount of dry matter (Figure 3-8). The drying rate curves for the film being 1 and $2 \mathrm{~mm}$ thick converge rapidly after the initial steep increase, while the drying rate for the film with $0.5 \mathrm{~mm}$ curve converges at a later stage with the two other curves. This shows that the amount of solids determines the drying behaviour especially of the last period in which the last bits of water are removed from the semi-moist film. 


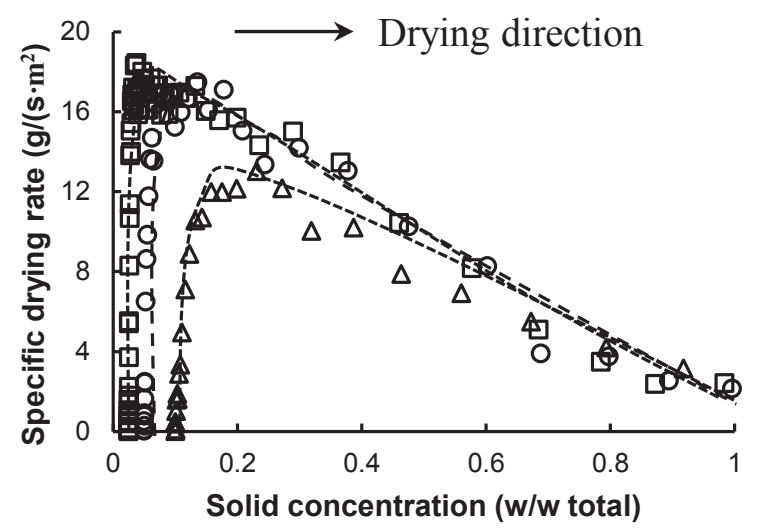

Figure 3-8 Specific drying rate versus solid concentration for the starch films with varying initial solid concentrations and film thickness: $10 \% \mathrm{w} / \mathrm{w}$ total and $0.5 \mathrm{~mm}(\Delta)$, $5 \% \mathrm{w} / \mathrm{w}$ total and $1 \mathrm{~mm}(\mathrm{O}), 2.5 \% \mathrm{w} / \mathrm{w}$ total and $2 \mathrm{~mm}(\square)$. The symbols represent a time step of $2 \mathrm{~s}$. The lines are added to guide the eye.

If we compare the influence of solids on drying between maltodextrin and starch, we can observe that the amount of initial dry matter affects the drying rate more for starch slurries than for maltodextrin slurries (Figure 3-4 and Figure 3-7). As an example, if we compare the drying curves of the films with $1 \mathrm{~mm}$ thickness, the maximum specific drying rate of the starch drying curves change more sharply than that of maltodextrin, indicating the more difficult heat transfer to comparable starch slurries. In conclusion, the differences in the properties of starch and maltodextrin greatly affect the boiling behaviour (in period 2) and drying behaviour (in period 3). 

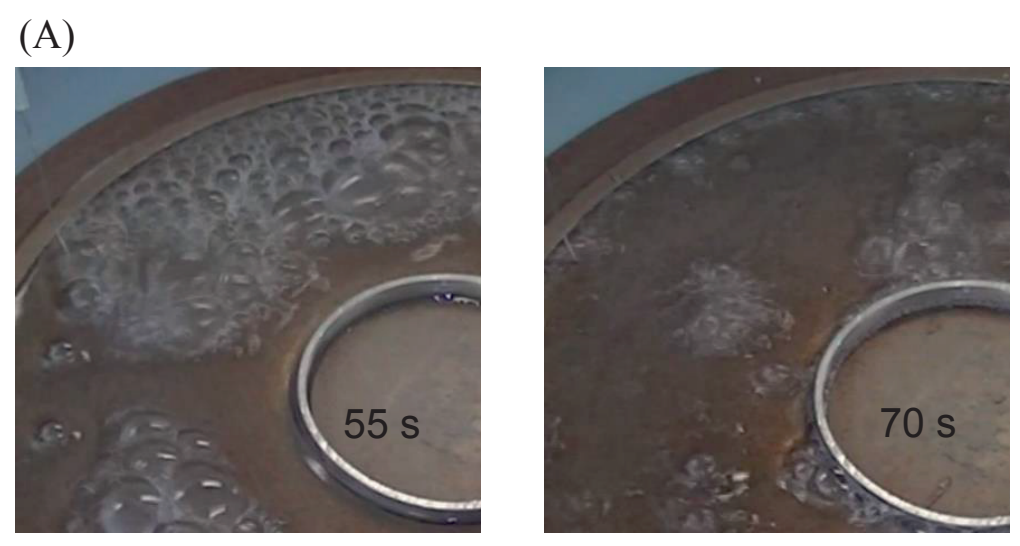

(B)
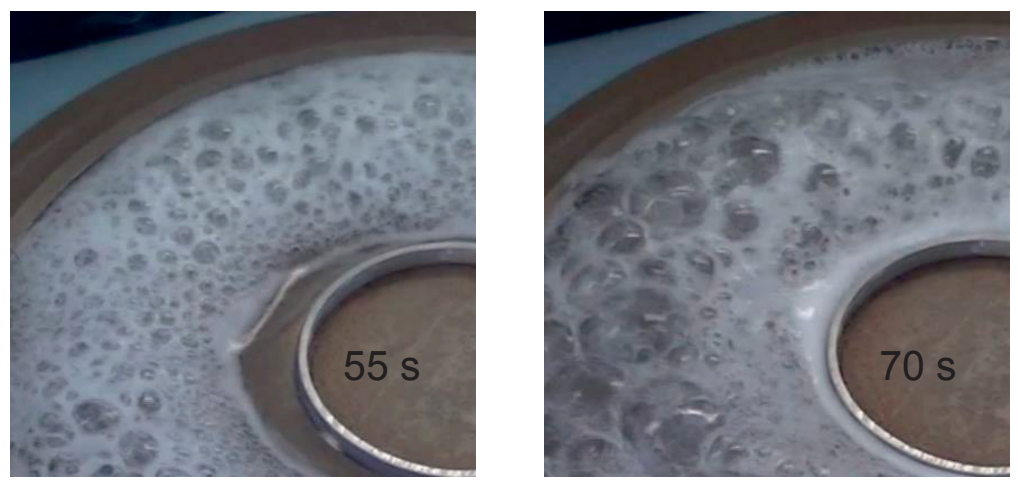

Figure 3-9 Images of drying (A) maltodextrin and (B) starch films of $1 \mathrm{~mm}$ and 15\% $\mathrm{w} / \mathrm{w}$ total.

\subsubsection{Conductive thin film drying of high starch concentrations}

One of the major advantages of conductive drying is that also more viscous products can be dried. Drying of starch suspensions up to $40 \% \mathrm{w} / \mathrm{w}$ total has been reported for drum dryers ${ }^{14}$. Drying of such concentrated starch films requires thinner film thickness to avoid the formation of large vapour bubbles that impede the drying and may result in local overheating. With a thin film, undesired bubble formation and even the formation of a vapour blanket beneath the film can be prevented. Moreover, the application of only a thin solid layer will result in lower resistance to heat transfer in period 3. In experiments with native starch solutions with a solid content of $40 \% \mathrm{w} / \mathrm{w}$, it was found that with decreasing film thickness, smaller bubbles formed and 
vapour blanketing became much less present (Figure 3-10). For films with a thickness of 0.5 and $1 \mathrm{~mm}$, a vapour blanket formed below the gelled starch film, which was so strong that the vapour bubbles expanded, but did not collapse. Ultimately, the bubbles combined and the starch layer detached from the pan surface. The formation of large vapour bubbles also lead to irregular drying across the pan. Homogeneous drying was only observed with the smallest film thickness of $0.25 \mathrm{~mm}$. This illustrates that the mass of the solids present, should be less than a critical value. In our system we estimate this for starch to be approximately $76.3 \mathrm{~g} / \mathrm{m}^{2}$. In terms of maltodextrin DE12, no critical value is estimated, because maltodextrin could not form strong molecular network, resulting in quick collapse of bubbles. Thus, vapour bubbles will not induce irregular drying.

The constant power conditions applied in our system do not fully mimic the conditions during drum drying, which is operated at a constant wall temperature. This is partly a limitation of the experimental system, which is heated via induction heating. During drum drying the heat flux becomes lower when the heat resistance increases, while in our system the heat flux is constant. During drum drying, the formation of larger bubbles is therefore more limited and somewhat higher amount of initial solids in the feed may be applied. However, the blanketing vapour film could still be observed, hindering energy transport from the hot drum walls to the starch films ${ }^{16}$. 
(A)

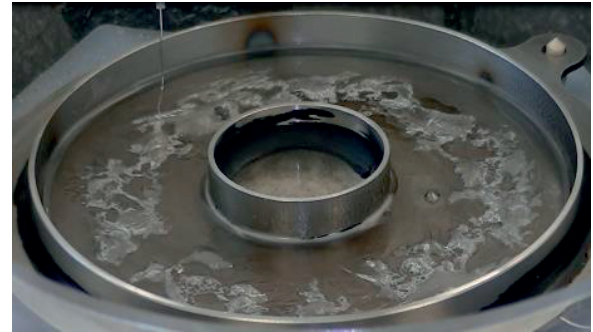

Beginning of drying

(B)

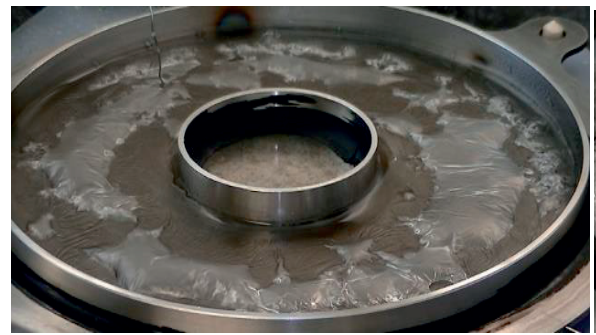

Beginning of drying

(C)

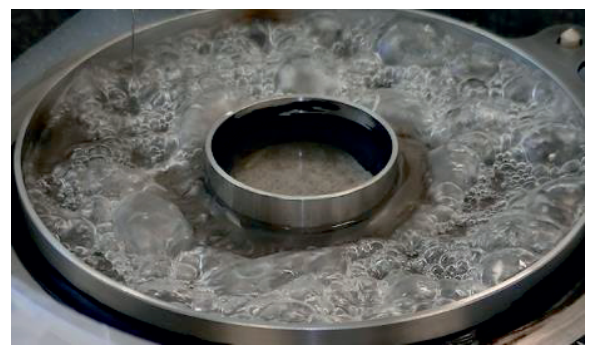

Beginning of drying

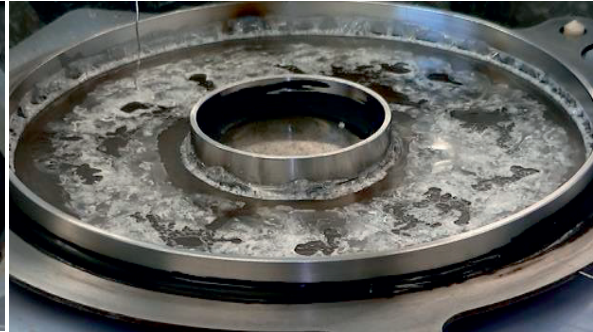

End of drying

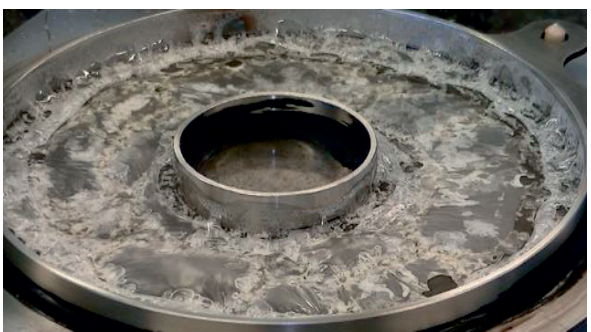

End of drying

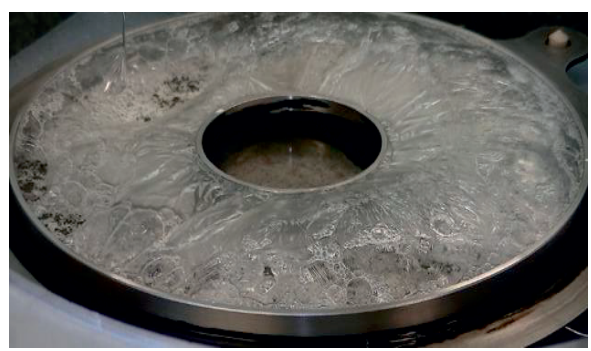

End of drying

Figure 3-10 Images of drying 40\% w/w native starch films with (A) $0.25 \mathrm{~mm}$, (B) 0.5 $\mathrm{mm}$ and (C) $1 \mathrm{~mm}$.

\subsection{Conclusions}

The transient drying kinetics during conductive thin film drying of maltodextrin DE12 and native potato starch suspensions were investigated using a noveldeveloped laboratory-scale device. Drying of films of more than $1 \mathrm{~mm}$ thickness could be subdivided in three distinct periods. In the first period, the product is heated up to the boiling temperature. In period 2 the films are boiling and water is evaporated at a constant rate, whereas in period 3 evaporation is 
limited by heat transfer and the drying becomes progressively slower. A distinct boiling stage (period 2) could not be observed when drying $0.5 \mathrm{~mm}$ films, due to the limited amount of free water present.

In addition to the free water, the amount of solids strongly affect the conductive drying behaviour. For films with the same thickness, the increased solid content leads to slower drying in period 2, since the increased porosity formed by stable bubbles, hinder the heat transfer. The amount of solids also determines the drying behaviour of the last period, by leaving a thicker film that represents more resistance against heat transfer.

Comparison of the drying curves of maltodextrin and starch shows that material properties influence the conductive drying kinetics. The starch suspensions form more stable bubbles and hence form a more porous matrix, slowing the drying down, due to its higher viscosity and elasticity. This accumulation of vapour (vapour blanketing) is detrimental to the heat transfer from the pan to the film and leads to less homogeneous drying, and local overheating of the solids. A thin film is therefore required.

The results of this study may contribute to verification of physical models that describe the conductive drying behaviour and thus can be used to establish guidelines for this technology to achieve higher energy efficiency and better product quality.

\section{Acknowledgements}

This work was supported by the Institute of Sustainable Process Technology (ISPT). Partners in this project are Bodec, Danone, ECN and Unilever. We also thank Leoné Biewenga for her support on performing experimental work. 


\section{References}

[1]. Qiu, J., Vuist, J.-E., Boom, R. M. and Schutyser, M. A. I. (2018). Formation and degradation kinetics of organic acids during heating and drying of concentrated tomato juice. LWT - Food Science and Technology, 87(C), 112121.

[2]. Zarein, M., Samadi, S. H. and Ghobadian, B. (2015). Investigation of microwave dryer effect on energy efficiency during drying of apple slices. Journal of the Saudi Society of Agricultural Sciences, 14(1), 41-47.

[3]. Moses, J., Norton, T., Alagusundaram, K. and Tiwari, B. (2014). Novel drying techniques for the food industry. Food Engineering Reviews, 6(3), 4355.

[4]. Mujumdar, A. S. (2006). Principles, classification, and selection of dryers. Handbook of Industrial Drying, Fourth Edition (pp. 4-31). Boca Raton: CRC Press.

[5]. Devahastin, S. and Mujumdar, A. S. (2006). Indirect dryers. Handbook of Industrial Drying, Fourth Edition (pp. 137-149). Boca Raton: CRC Press.

[6]. Sahni, E. K. and Chaudhuri, B. (2012). Contact drying: A review of experimental and mechanistic modeling approaches. International Journal of Pharmaceutics, 434(1), 334-348.

[7]. Caparino, O. A., Tang, J., Nindo, C. I., Sablani, S. S., Powers, J. R. and Fellman, J. K. (2012). Effect of drying methods on the physical properties and microstructures of mango (Philippine 'Carabao' var.) powder. Journal of Food Engineering, 111(1), 135-148.

[8]. Fudym, O., Carrère-Gée, C., Lecomte, D. and Ladevie, B. (2003). Drying kinetics and heat flux in thin-layer conductive drying. International Communications in Heat and Mass Transfer, 30(3), 333-347.

[9]. Nindo, C. and Tang, J. (2007). Refractance window dehydration technology: a novel contact drying method. Drying Technology, 25(1), 37-48.

[10]. Pawar, S. B., Patil, R., Mujumdar, A. and Thorat, B. (2011). Mathematical modeling of agitated thin-film dryer. Drying Technology, 29(6), 719-728.

[11]. Trystram, G. and Vasseur, J. (1992). The modeling and simulation of a drum-drying process. International Chemical Engineering, 32, 689-689. 
[12]. Kalogianni, E., Xynogalos, V., Karapantsios, T. and Kostoglou, M. (2002). Effect of feed concentration on the production of pregelatinized starch in a double drum dryer. LWT-Food Science and Technology, 35(8), 703714.

[13]. Rodriguez, G., Vasseur, J. and Courtois, F. (1996). Design and control of drum dryers for the food industry. Part 1 . Set-up of a moisture sensor and an inductive heater. Journal of Food Engineering, 28(3), 271-282.

[14]. Fritze, H. (1973). Dry gelatinized starch produced on different types of drum dryers. Industrial \& Engineering Chemistry Process Design and Development, 12(2), 142-148.

[15]. Valous, N., Gavrielidou, M., Karapantsios, T. and Kostoglou, M. (2002). Performance of a double drum dryer for producing pregelatinized maize starches. Journal of Food Engineering, 51(3), 171-183.

[16]. Gavrielidou, M. A., Valous, N. A., Karapantsios, T. D. and Raphaelides, S. N. (2002). Heat transport to a starch slurry gelatinizing between the drums of a double drum dryer. Journal of Food Engineering, 54(1), 45-58.

[17]. Leniger, H. A. and Beverloo, W. (2012). Physical operations. Food Process Engineering. Dordrecht: Springer Science \& Business Media.

[18]. Ochoa-Martínez, C., Quintero, P., Ayala, A. and Ortiz, M. (2012). Drying characteristics of mango slices using the Refractance Window ${ }^{\mathrm{TM}}$ technique. Journal of Food Engineering, 109(1), 69-75.

[19]. Karapantsios, T. D. (2006). Conductive drying kinetics of pregelatinized starch thin films. Journal of Food Engineering, 76(4), 477-489.

[20]. Daud, W. R. W. (2006). Drum dryers. Handbook of Industrial Drying, Fourth Edition. Boca Raton: CRC Press.

[21]. Kim, J. (2009). Review of nucleate pool boiling bubble heat transfer mechanisms. International Journal of Multiphase Flow, 35(12), 1067-1076.

[22]. Lee, S. J., Yang, Y. J., Chung, H. J. and Lim, S. T. (2017). Effect of dry heating on physicochemical properties of Pregelatinized rice starchp. Cereal Chemistry, 94(6), 928-933.

[23]. Shogren, R., Lawton, J., Doane, W. and Tiefenbacher, K. (1998). Structure and morphology of baked starch foams. Polymer, 39(25), 6649-6655. 


\section{CHAPTER 4}

\section{Model development for conductive thin film drying processes}




\section{Abstract}

A heat-transfer governed model is proposed to describe drying in a lab-scale conductive thin film dryer, which was designed to investigate the drying kinetics relevant to drum drying. The model calculations were compared to experimental data from drying experiments with maltodextrin DE12 and potato starch, considering the three distinct periods (heating, boiling and conductive drying) of the lab-scale process. The model uses the measured temperatures and evaporation rate during the boiling period, to estimate the decrease in moisture content over time during the entire drying process. The model was successful in describing the decrease in moisture content during drying of maltodextrin and starch slurries. The model was subsequently adapted to describe the drum drying of maltodextrin suspensions, which involves only the third (conductive) drying period. The initial heat transfer coefficient for drum drying of maltodextrin was obtained from the experiments (starting heat transfer coefficient of period 3). The simulations provide the moisture contents and optimal drying times for different drying conditions. 


\subsection{Introduction}

Drying is one of the most ancient processing methods applied for preserving perishable foods ${ }^{1}$. The two most commonly applied drying principles in food industry are convective and conductive drying. Of these two principles, conductive drying is more energy efficient as it does not suffer from large energy loss via the exhaust air ${ }^{2-4}$. Drum drying relies on conductive drying and is used extensively for industrial drying of pasty or viscous food materials, such as starch, vegetable and fruit purees ${ }^{5}$. During drum drying, the product slurry is applied as a thin film on the heated surface of a rotating drum, where it is rapidly dried at the boiling temperature and even exposed to higher temperatures within a short residence time ${ }^{6}$. Despite drying time typically shorter than one minute, the exposure to high temperatures can still lead to colour changes, aroma loss and degradation of heat sensitive components in the product. A better understanding on the drying kinetics during drum drying processes, may contribute to more optimal operation of these processes achieving high energy efficiency combined with good product quality.

Drum drying conditions are usually determined via trial and error or at most via statistical approaches using pilot-scale experiments that are costly and time consuming 7 . An experimental study was carried out on the effect of drum drying on jackfruit powders by Pua et al. ${ }^{8}$. The water activity, solubility and colour of double-drum dried jackfruit powders were assessed and optimal drying conditions were determined following a statistical approach. Jittanit et al. 9 studied the feasibility of double-drum drying of tamarind juice using maltodextrin or Arabic gum as process additives and determined the optimal combination of the additive ratio and drying temperature for the sensory quality of the tamarind powder. Tonin et al. ${ }^{\mathbf{1 0}}$ experimentally evaluated the use of different process additives in single-drum drying of mango pulp, considering various powder quality aspects, such as nutrient concentration, colour, hygroscopicity and solubility.

As a complement to experimental studies, modelling can help in process development and optimization of drum drying. To evaluate the impact of 
drying on the quality changes, a process model of the drying process can be applied together with kinetic models of specific product quality parameters ${ }^{\mathbf{1 1}}$. Subsequently, the models can be used to optimize the drying conditions ${ }^{7,11}$. However, modelling of drum drying is still challenging, due to the limited knowledge of the complex drying kinetics of drum drying. Direct assessment of the kinetics is difficult because the mass and temperature profiles are hard to be monitored on-line on drum dryers. Therefore, we earlier developed a laboratory-scale conductive thin film dryer to analyse the drying kinetics relevant to drum drying ${ }^{5}$. This dryer allows on-line monitoring of mass and temperatures, which supports the analysis of the transient conductive drying behaviour and facilitates model development.

This study focuses on the development of a model, to complement the experiments with this lab-scale conductive thin film dryer. The model calculations are compared to the experimental data reported in our previous paper ${ }^{5}$, which were used for the parametrization of the model description of the drum drying process using the heat transfer coefficient obtained from the lab-scale drying experiments.

\subsection{Model description}

\subsubsection{Modelling of the lab-scale conductive thin film dryer}

Three periods can be distinguished during conductive thin film drying: heating up (period 1), boiling (period 2) and conductive drying (period 3) ${ }^{5}$. The following assumptions were made to model water evaporation during operation of the lab-scale conductive thin film dryer:

1. The temperature and moisture content are homogeneous during the heating up and boiling periods.

2. In the boiling period, a thin layer of vapour is formed between the wall and the fluid, which acts as a resistance to heat conduction (Figure 4-1 (A)).

3. During conductive drying, a dry layer gradually develops starting close to the pan surface and increasing in thickness until the total film is 
dried. This dried porous layer has a low thermal conductivity, limiting the heat transfer from the pan to the evaporation front (Figure 4-1 (B)).

4. During conductive drying, evaporation takes place at the evaporation front. The wet film is assumed homogenous in both temperature and moisture content.

5. To simplify the calculations, shrinkage of the film during drying is neglected.

(A)

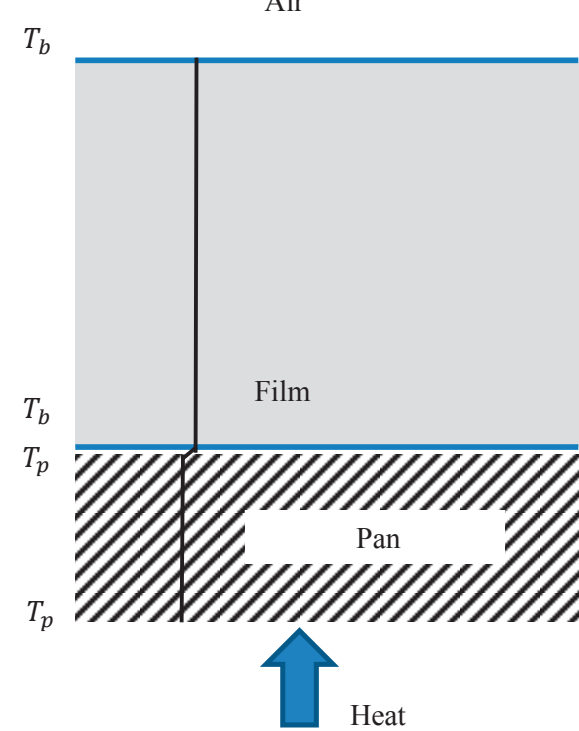

(B)

Air

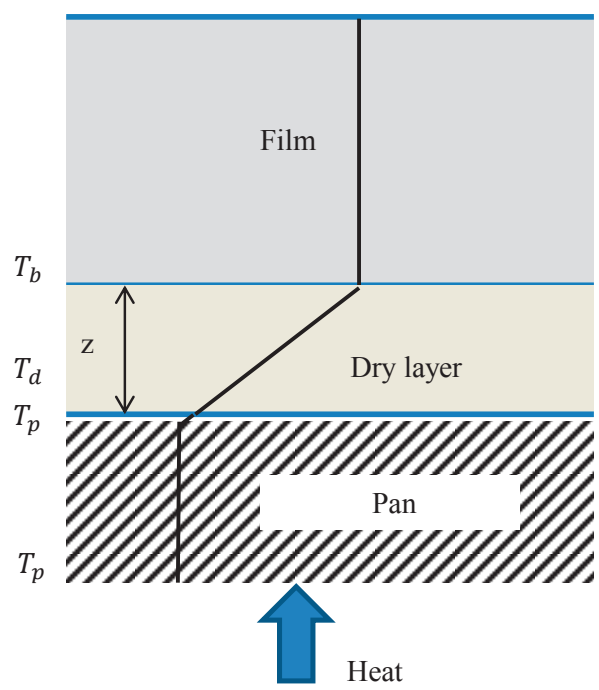

Figure 4-1 Schematic diagram of the film during conductive drying in (A) period 2 and (B) period 3.

During the heating period, the film temperature gradually increases to the boiling temperature, while the mass of the film $\left(m_{f}\right)$ decreases slightly due to evaporation driven by the difference of the relative humidity between the air and the film:

$$
\frac{d m_{f}}{d t}=\frac{A k_{w v} M_{w}}{R}\left(\frac{P_{s a t, f}}{T_{f}}-\frac{R H \cdot P_{\text {sat }, \text { air }}}{T_{\text {air }}}\right) \quad \text { Eq. 4-1 }
$$

where $A$ is the surface area of the pan, $k_{w v}$ is the convective mass transfer coefficient of water vapour in air, $M_{w}$ is the molecular weight of water, $\mathrm{R}$ is the 
ideal gas constant, $R H$ is the relative humidity of the air, $P_{\text {sat } f}$ and $P_{\text {sat }, \text { air }}$ are the saturated vapour pressures at film $\left(T_{f}\right)$ and air temperatures $\left(T_{a i r}\right)$, respectively. In the heating-up period, the evaporation rate is calculated on the basis of the measured film temperature $\left(T_{f}\right)$. Specifically, the convective mass transfer coefficient $\left(k_{w v}\right)$ is calculated from ${ }^{12}$ :

$$
S h=\frac{k_{w v}}{D_{w v} d_{\text {pan }}}=0.664 R e^{1 / 2} S c^{1 / 3} \quad \text { Eq. } 4-2
$$

where $D_{w v}$ is the diffusivity of water vapour in air and $d_{p a n}$ is the diameter of the pan.

During the subsequent drying periods (periods 2 and 3), the water evaporation rate can be expressed by:

$$
\frac{d m_{f}}{d t}=\frac{h_{o v}\left(T_{p}-T_{f}\right)}{h_{w}}
$$

where $h_{w}$ is the latent heat of water vapour, $h_{o v}$ is the overall heat transfer coefficient from the pan to the film, $T_{P}$ and $T_{f}$ are the temperatures of the pan and the film, respectively. Specifically, for the custom-built lab-scale apparatus, $T_{P}$ is not constant as the dryer operates with constant heat flux, instead of constant temperature. It is noted that during boiling the pan temperature is a few degrees above the boiling temperature $\left(T_{f}\right)$, due to the thin layer of water vapour between the pan and the fluid. The boiling temperature itself increases slowly in time due to the boiling point elevation.

A direct measurement of the heat transferred from the device to the film was not possible due to undefined heat losses to the environment. Therefore, we used the measured temperatures and the measured constant evaporation rate during boiling (period 2). This yields the overall heat transfer coefficient $\left(h_{o v}\right)$ during the boiling period via Eq. 4-3. We interpret that this heat transfer coefficient results from the small vapour layer between the pan and the product (Figure 4-1 (A)), which develops during the boiling period, as the increasing solute concentration and viscosity hinder the escape of vapour ${ }^{5}$. At the end of the boiling period, this heat transfer resistance is assumed to remain constant 
until the end of drying and thus determines the starting heat transfer coefficient of period 3 .

When the water evaporation rate declines, the temperature in the film near the pan wall starts to increase. This corresponds to the start of period 3. The overall heat transfer coefficient $\left(h_{o v}\right)$ is now calculated by:

$$
h_{o v}=\left(\frac{1}{h_{0}}+\frac{z}{\lambda_{f}}\right)^{-1} \quad \text { Eq. } 4-4
$$

in which $h_{0}$ is the overall heat transfer coefficient at the beginning of period 3 , $\lambda_{\mathrm{f}}$ is the thermal conductivity of the dried solid layer and $\mathrm{z}$ is the thickness of the dry layer. The growth of the dry layer can be described by:

$$
z=d\left(1-\frac{X_{w, t}}{X_{w, c}}\right) \quad \text { Eq. } 4-5
$$

where $d$ is the thickness of the film, $X_{w, t}$ is the moisture content at time $t$, and $X_{w, c}$ is the moisture content at the start of period 3. The water evaporation rate is calculated by substituting Eq. 4-4 and Eq. 4-5 into Eq. 4-3.

The above equations were solved simultaneously using MATLAB R2016b (Mathworks, Natick, USA). The physical parameters used in the model calculations were listed in Supplementary data 4-1. The calculated moisture content profiles were compared to the experimental data.

\subsubsection{Modelling of drum drying}

The proposed model was modified to describe the larger scale drum drying process. We do this by using the heat transfer coefficient of maltodextrin obtained from the lab-scale model calculations. In contrast to the lab-scale dryer, in larger scale drum drying the wall temperature ( $T_{p}$ in Eq. 4-3) remains constant throughout the process. The following assumptions were made:

1. During larger scale drum drying only the third period is considered, i.e. no heating up and no boiling. The drums are heated continuously, while most boiling occurs in the feeding pool between the drums. As soon as the material is cast as a film, it enters the third period. We also assume 
that the initial heat transfer coefficient for the larger scale drum drying, can be determined by the lab-scale dryer (starting heat transfer coefficient of period 3).

2. The undried film material is at boiling temperature $T_{f}$, which increases during drying due to boiling point elevation. The film temperature is calculated by combining the Clausius-Clapeyron equation and Raoult's law ${ }^{13}$ :

$$
T_{f}=T_{w}+\frac{-T_{w}}{1+\frac{H_{v w}}{R T_{w} \ln \left(1-X_{s}\right)}}
$$

where $T_{w}$ is the boiling temperature of water, $H_{w w}$ is the latent heat of water in $\mathrm{J} / \mathrm{mol}$, and $X_{s}$ is the molar fraction of the solute. It should be mentioned that Eq. 4-6 is less accurate at lower moisture content since the semi-dried film can no longer be regarded as an ideal system. A more complete thermodynamic model of the solution may mitigate this. We did not do this here to avoid too much complexity in the model.

\subsection{Results and discussions}

\subsubsection{Model development for the lab-scale conductive thin film dryer}

Data from the drying experiments with maltodextrin DE12 and potato starch films of 1 and $2 \mathrm{~mm}$ reported in our previous research ${ }^{5}$ were used as the basis for model development. The results from $0.5 \mathrm{~mm}$ films were not used because the measurements of the film temperatures of such thin films were not accurate. Figure 4-2 shows the calculated and measured values of the moisture contents of films with thicknesses of 1 and $2 \mathrm{~mm}$ for different initial solid contents. The model describes the moisture content profiles of all experiments well. It should be noticed that for the starch films with an initial solid content of $5 \%$, the model underestimated the moisture content at the end of period 2 and in period 3 (Figure 4-2 (B)). This may be attributed to the larger shrinkage of these more dilute films in experiments, which was neglected in the model. With a larger apparent film thickness, the model underestimates the heat transfer and thus the drying rate, leading to higher calculated moisture contents. 
(A)

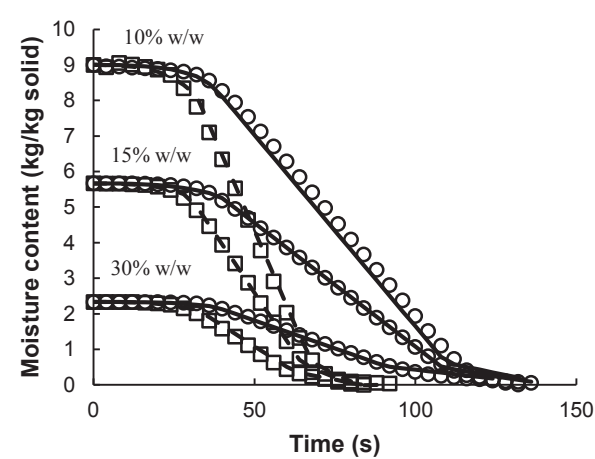

(B)

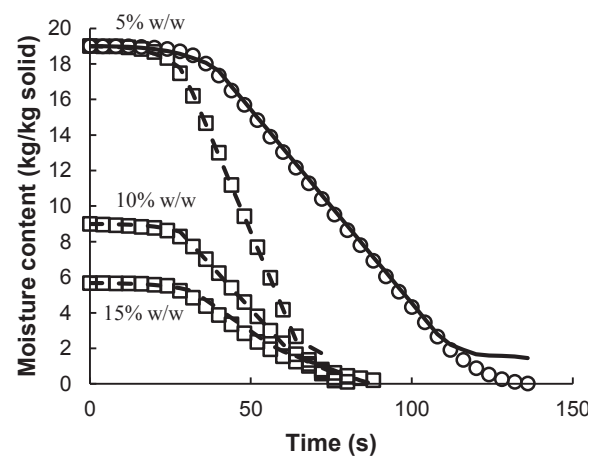

Figure 4-2 Calculated and measured moisture content profiles of the (A) maltodextrin DE12 and (B) photo starch films. The symbols represent the experimental data with a time step of $5 \mathrm{~s}: 1 \mathrm{~mm}(\square)$ and $2 \mathrm{~mm}(\mathrm{O})$. The lines represent the model calculations: $1 \mathrm{~mm}$ (dashed line) and $2 \mathrm{~mm}$ (solid line).

The calculated overall heat transfer resistance $\left(1 / h_{o v}\right)$ during period 3 is visualised as a function of the dry layer thickness (Figure 4-3). The starting heat transfer resistance of period $3\left(1 / h_{0}\right)$ was obtained from the end of period 2 , related to the bubble formation during boiling. The starch films had higher initial heat transfer resistance than maltodextrin, because drying of starch resulted in the formation of larger vapour bubbles in the boiling period that impeded the heat transfer ${ }^{5}$. The initial heat transfer resistance of the films with varying dry matter amounts on the pan surface were similar. During period 3, the heat transfer resistance significantly increased with increasing dry layer thickness (Figure 4-3). When the dry layer thickness increased to $1 \mathrm{~mm}$, the heat transfer coefficients of the maltodextrin and starch films were reduced by $\sim 92 \%$ and $\sim 88 \%$, respectively, which indicates that the dry layer determined the heat transfer and thus the drying behaviour. 


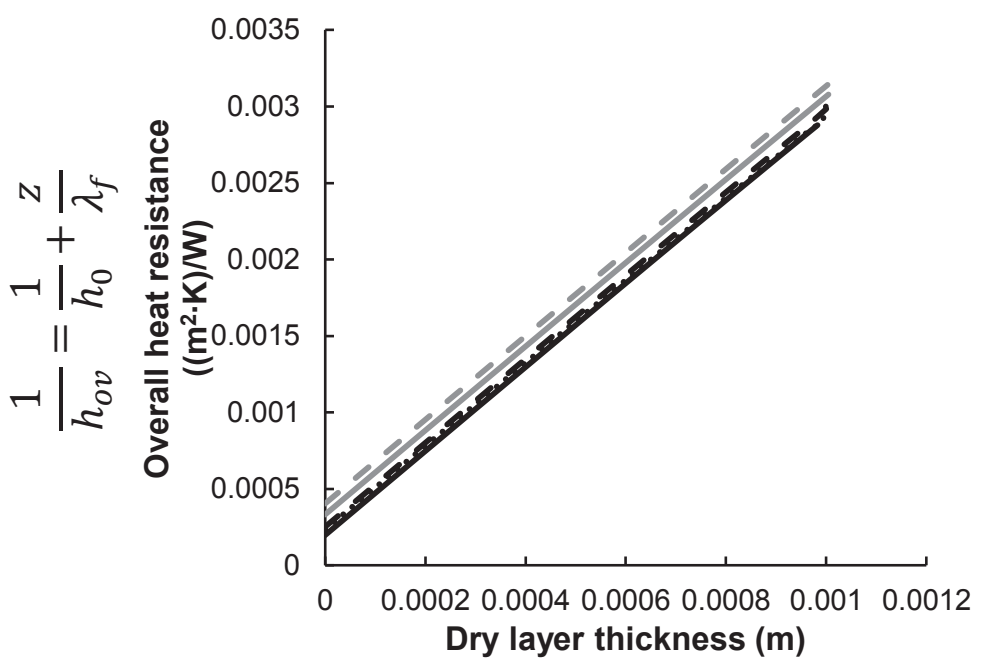

Figure 4-3 Calculated overall heat transfer resistance $\left(1 / h_{o v}\right)$ as a function of dry layer thickness of $1 \mathrm{~mm}$ films of maltodextrin DE12 (black lines) and potato starch (grey lines) with varying initial concentrations: $10 \% \mathrm{w} / \mathrm{w}$ total (solid lines), $15 \% \mathrm{w} / \mathrm{w}$ total (dashed lines) and 30\% w/w total (dotted lines).

To conclude, even though the model calculations are on the basis of measured data, a fairly good description of the moisture content profiles during lab-scale conductive drying is obtained. From the experiments on the lab-scale dryer, the starting heat transfer coefficient of period 3 can be determined, which is related to the material properties of the feed product, and can be subsequently used in the modelling of drum drying. Therefore, the proposed model calculations combined with the lab-scale drying experiments are useful from an engineering point of view and can be exploited to describe the drum drying process.

\subsubsection{Modelling of drum drying}

The proposed model for the lab-scale conductive dryer can be modified to describe the drum drying process using the heat transfer coefficient obtained from the lab-scale model calculations. In this case, films of maltodextrin with an initial solid content of $30 \% \mathrm{w} / \mathrm{w}$ total $(2.33 \mathrm{~kg} / \mathrm{kg}$ solid) are dried using a drum dryer at a drying temperature of $130{ }^{\circ} \mathrm{C}$ ( $T_{p}$ in Eq. 4-3). The rotation speed of the drum is $1 \mathrm{rpm}$ and the angular distance between the feeding point and the scraper is $270^{\circ}$. Thus, the drying time of the maltodextrin film is about 45 
s. As discussed before, only the conductive drying period is considered with an initial heat transfer coefficient of $4000 \mathrm{~W} /\left(\mathrm{m}^{2} \mathrm{~K}\right)$ obtained from the lab-scale dryer.

The simulated moisture content and product temperature profiles are presented in Figure 4-4. As expected, thicker films yield a slower relative moisture loss. When the moisture content reduces to $\sim 0.006 \mathrm{~kg} / \mathrm{kg}$ solid, the drying curves reach a plateau, indicating that the drying stops because the film temperature is heated up to the wall temperature (Figure 4-4 (B)). For the films of $0.2,0.3,0.4,0.5 \mathrm{~mm}$, their drying curves reach the plateau at about $8,15,24$ and $35 \mathrm{~s}$, respectively, indicating the optimal drying time for these films to avoid overheating. The drying times were comparable to those reported in literature 14 .

(A)

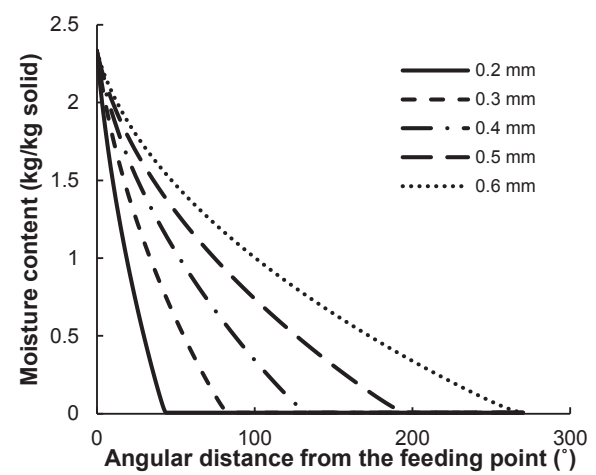

(B)

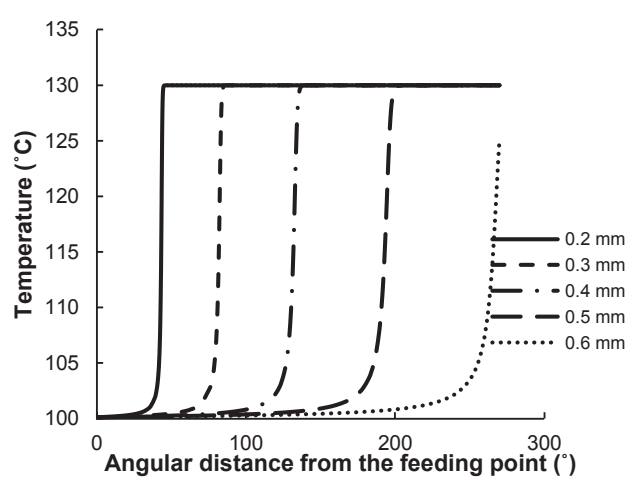

Figure 4-4 Simulated (A) moisture content and (B) product temperature profiles of maltodextrin films with varying film thickness as a function of angular distance from the feeding point (Steam temperature: $130{ }^{\circ} \mathrm{C}$; Rotation speed of the drum: $1 \mathrm{rpm}$; Angular distance between feeding point and scraper: $270^{\circ}$ ).

\subsection{Conclusions}

A water evaporation model was developed for a lab-scale conductive thin film dryer, and subsequently was translated to larger scale drum dryers. The model is based on the assumption that the drying process is controlled by heat transfer. The model takes into account three distinct periods during drying. 
- In period 1, the heating-up period, a small amount of water evaporates during heating, due to the difference in relative humidity between the air and the film.

- In period 2, the boiling period, the water evaporation generates an insulating layer of vapour between the wall and the drying fluid, but also extensive turbulence in the film, giving homogeneous temperatures and water contents in the film itself.

- In period 3, the conductive drying (declining rate) period, the insulating layer gradually enlarges and encompasses the dried porous material situated between the pan wall and the still drying film.

The model calculations were compared with the experimental data obtained from the drying experiments with 1 and $2 \mathrm{~mm}$ maltodextrin DE12 and potato starch films. A good description of the moisture content profiles was obtained.

The overall heat transfer coefficient obtained from the lab-scale system was used to describe large scale drum drying of maltodextrin suspension. Moisture content profiles during drum drying were calculated and optimal drying times for different drying conditions were suggested. The predicted drying times were comparable to the values reported in literature.

The model can be further combined with kinetic models to describe product quality parameters, which offers opportunities for process optimization considering quality changes.

\section{Acknowledgements}

This work was supported by the Institute of Sustainable Process Technology (ISPT). Partners in this project are Bodec, Danone, ECN and Unilever. 


\section{Nomenclature}

\begin{tabular}{|c|c|c|}
\hline$A$ & Area & {$\left[\mathrm{m}^{2}\right]$} \\
\hline$b$ & Molality of the solution & {$[-]$} \\
\hline$D_{w v}$ & Diffusivity of water vapour in air & {$\left[\mathrm{m}^{2} / \mathrm{s}\right]$} \\
\hline$d$ & Film thickness & {$[\mathrm{m}]$} \\
\hline$d_{\text {Pan }}$ & Diameter of the pan & [m] \\
\hline$h_{w}$ & Latent heat of water & {$[\mathrm{J} / \mathrm{kg}]$} \\
\hline$H_{v n}$ & Latent heat of water & [J/mol] \\
\hline$b$ & Heat transfer coefficient & {$\left[\mathrm{W} /\left(\mathrm{m}^{2} \mathrm{~K}\right)\right]$} \\
\hline$J_{D}$ & Drying rate & {$\left[\mathrm{kg} /\left(\mathrm{m}^{2} \mathrm{~s}\right)\right]$} \\
\hline$k_{w p}$ & $\begin{array}{l}\text { Convective mass transfer coefficient of water } \\
\text { vapour in air }\end{array}$ & {$\left[\mathrm{kg} /\left(\mathrm{m}^{2} \mathrm{~s}\right)\right]$} \\
\hline$M_{w}$ & Molecular weight of water & {$[\mathrm{mol} / \mathrm{g}]$} \\
\hline$m$ & Mass & [g] \\
\hline$P_{\text {sat }}$ & Saturated pressure $\exp \left(\mathrm{A}-\frac{B}{C+T_{f}}\right)$ & {$[\mathrm{Pa}]$} \\
\hline$R$ & Ideal gas constant & {$[\mathrm{J} /(\mathrm{mol} \mathrm{K})]$} \\
\hline Re & Reynolds number $\frac{V_{a i r} d_{\text {pan }}}{v_{\text {air }}}$ & {$[-]$} \\
\hline $\mathrm{RH}$ & Relative humidity & {$[-]$} \\
\hline Sc & Schmidt number $\frac{v_{a i r}}{D_{w v}}$ & {$[-]$} \\
\hline Sh & Sherwood number $\frac{k_{w v}}{D_{w v} d_{p a n}}$ & {$[-]$} \\
\hline$T$ & Temperature & {$[\mathrm{K}]$} \\
\hline$t$ & Time & {$[\mathrm{s}]$} \\
\hline$V_{\text {air }}$ & Air velocity & {$[\mathrm{m} / \mathrm{s}]$} \\
\hline$X_{w}$ & Moisture content & {$[\mathrm{kg} / \mathrm{kg} \mathrm{db}]$} \\
\hline$X_{s}$ & Molar fraction of the solute & {$[\mathrm{mol} / \mathrm{mol}$ total $]$} \\
\hline$z$ & Dry layer thickness & {$[\mathrm{m}]$} \\
\hline$\lambda_{\mathrm{p}}$ & Thermal conductivity of the dry layer & {$[\mathrm{W} /(\mathrm{m} \mathrm{K})]$} \\
\hline$\nu$ & Kinematic viscosity & {$\left[\mathrm{m}^{2} / \mathrm{s}\right]$} \\
\hline
\end{tabular}

\section{Subscript}

c

$\mathrm{f}$

Critical value

$\mathrm{p}$

Film

p Pan

$\mathrm{t} \quad$ At certain time

$\mathrm{w}$

Water 


\section{References}

[1]. Qiu, J., Khalloufi, S., Martynenko, A., Van Dalen, G., Schutyser, M. and Almeida-Rivera, C. (2015). Porosity, bulk density, and volume reduction during drying: review of measurement methods and coefficient determinations. Drying Technology, 33(14), 1681-1699.

[2]. Devahastin, S. and Mujumdar, A. S. (2006). Indirect dryers. Handbook of Industrial Drying, Fourth Edition (pp. 137-149). Boca Raton: CRC Press.

[3]. Nindo, C. and Tang, J. (2007). Refractance window dehydration technology: a novel contact drying method. Drying Technology, 25(1), 37-48.

[4]. Qiu, J., Boom, R. and Schutyser, M. (2018). Agitated thin-film drying of foods. Drying Technology, 1-10.

[5]. Qiu, J., Kloosterboer, K., Guo, Y., Boom, R. M. and Schutyser, M. A. I. (2019). Conductive thin film drying kinetics relevant to drum drying. Journal of Food Engineering, 242, 68-75.

[6]. Daud, W. R. W. (2006). Drum dryers. Handbook of Industrial Drying, Fourth Edition. Boca Raton: CRC Press.

[7]. Perdana, J., Fox, M. B., Schutyser, M. A. I. and Boom, R. M. (2013). Mimicking spray drying by drying of single droplets deposited on a flat surface. Food and Bioprocess Technology, 6(4), 964-977.

[8]. Pua, C. K., Hamid, N. S. A., Tan, C. P., Mirhosseini, H., Rahman, R. B. A. and Rusul, G. (2010). Optimization of drum drying processing parameters for production of jackfruit (Artocarpus heterophyllus) powder using response surface methodology. LWT - Food Science and Technology, 43(2), 343-349.

[9]. Jittanit, W., Chantara-In, M., Deying, T. and Ratanavong, W. (2011). Production of tamarind powder by drum dryer using maltodextrin and Arabic gum as adjuncts. Songklanakarin J Sci Technol, 33(1), 33-41.

[10]. Tonin, I. P., Ferrari, C. C., da Silva, M. G., de Oliveira, K. L., Berto, M. I., da Silva, V. M. and Germer, S. P. M. (2018). Performance of different process additives on the properties of mango powder obtained by drum drying. Drying Technology, 36(3), 355-365. 
[11]. Qiu, J., Vuist, J.-E., Boom, R. M. and Schutyser, M. A. I. (2018). Formation and degradation kinetics of organic acids during heating and drying of concentrated tomato juice. LWT - Food Science and Technology, $87(\mathrm{C}), 112-121$.

[12]. Islam, M. R., Thaker, K. S. and Mujumdar, A. (2007). A diffusion model for a drum dryer subjected to conduction, convection, and radiant heat input. Drying Technology, 25(6), 1033-1043.

[13]. Crapiste, G. H. and Lozano, J. (1988). Effect of concentration and pressure on the boiling point rise of apple juice and related sugar solutions. Journal of Food Science, 53(3), 865-868.

[14]. Desobry, S. A., Netto, F. M. and Labuza, T. P. (1997). Comparison of spray-drying, drum-drying and freeze-drying for $\beta$-carotene encapsulation and preservation. Journal of Food Science, 62(6), 1158-1162.

[15]. Maroulis, Z., Shah, K. and Saravacos, G. (1991). Thermal conductivity of gelatinized starches. Journal of food science, 56(3), 773-776.

[16]. Saavedra-Leos, Z., Leyva-Porras, C., Araujo-Díaz, S. B., Toxqui-Terán, A. and Borrás-Enríquez, A. J. (2015). Technological application of maltodextrins according to the degree of polymerization. Molecules, 20(12), 21067-21081.

[17]. Engineering-ToolBox. (2003). Air - Dynamic and Kinematic Viscosity. https:/ /www.engineeringtoolbox.com/air-absolute-kinematic-viscosityd_601.html.

[18]. Engineering-ToolBox. (2018). Air - Diffusion Coefficients of Gases in Excess of Air. https://www.engineeringtoolbox.com/air-diffusioncoefficient-gas-mixture-temperature-d_2010.html. 
Supplementary data 4-1: Physical parameters used in the model calculation and modelling of drum drying.

\begin{tabular}{|c|c|c|}
\hline Parameters & Value & Units \\
\hline \multicolumn{3}{|l|}{ Material properties } \\
\hline $\begin{array}{l}\text { Thermal conductivity of dry } \\
\text { layer }\left(\lambda_{\mathrm{f}}\right) * \mathbf{1 5}\end{array}$ & $\lambda_{f}=4.1 \cdot 10^{-3} \mathrm{~T}_{\mathrm{f}}-0.21$ & $\mathrm{~W} /(\mathrm{m} \mathrm{K})$ \\
\hline Molar mass of maltodextrin ${ }^{\mathbf{1 6}}$ & 1625 & $\mathrm{~g} / \mathrm{mol}$ \\
\hline Relative humidity of air $(R H)$ & 0.25 & - \\
\hline kinematic viscosity of air $(v){ }^{17}$ & $v=6 \cdot 10^{-11} \mathrm{~T}_{\mathrm{f}}^{2}+6 \cdot 10^{-8} \mathrm{~T}_{\mathrm{f}}-9 \cdot 10^{-6}$ & $\mathrm{~m}^{2} / \mathrm{s}$ \\
\hline $\begin{array}{l}\text { Diffusivity of water vapour in } \\
\text { air }\left(D_{w v}\right){ }^{18}\end{array}$ & $\mathrm{D}_{\mathrm{wv}}=10^{-10} \mathrm{~T}_{\mathrm{f}}^{2}+10^{-7} \mathrm{~T}_{\mathrm{f}}-2 \cdot 10^{-5}$ & $\mathrm{~m}^{2} / \mathrm{s}$ \\
\hline Latent heat of water $\left(h_{w}\right)$ & 2257000 & $\mathrm{~J} / \mathrm{kg}$ \\
\hline Air velocity & 2 & $\mathrm{~m} / \mathrm{s}$ \\
\hline Air temperature & 20 & ${ }^{\circ} \mathrm{C}$ \\
\hline
\end{tabular}

Antoine constants (Temperature in ${ }^{\circ} \mathrm{C}$ )
A
16.38
B
3878.82
C
229.86

Other parameters used in modelling of drum drying

\begin{tabular}{|c|c|c|}
\hline Diameter of the drum & 0.3 & $\mathrm{~m}$ \\
\hline Length of the drum & 0.3 & $\mathrm{~m}$ \\
\hline Rotation speed of the drum & 1 & $\mathrm{rpm}$ \\
\hline Drying temperature & 130 & ${ }^{\circ} \mathrm{C}$ \\
\hline $\begin{array}{l}\text { Initial heat transfer coefficient } \\
\text { for conductive drying of } \\
\text { maltodextrin }\left(b_{0}\right)\end{array}$ & 4000 & $\mathrm{~W} /\left(\mathrm{m}^{2} \mathrm{~K}\right)$ \\
\hline Latent heat of water $\left(H_{v w}\right)$ & 45000 & $\mathrm{~J} / \mathrm{mol}$ \\
\hline
\end{tabular}




\section{CHAPTER 5}

\section{Agitated thin-film drying of foods}

This chapter has been published as: Qiu, J., Boom, R., \& Schutyser, M. (2018). Agitated thin-film drying of foods. Drying Technology, 1-10. 


\section{Abstract}

Agitated thin film drying (ATFD) has been proposed for efficient and mild drying of viscous liquid foods, pastes or pureed foods. We reported a study on the influence of product and process parameters on ATFD. During ATFD of spinach leaf slurries, the wall temperature mainly affected the specific evaporation rate, while the absolute evaporation rate was proportional to the feed rate. The fact that blade rotation speed had limited effect on the drying rate suggested that the process is limited by heat transfer through the wall. ATFD is especially suitable for slurries that show relatively limited sticky behaviour during drying and liquid-solid phase transition with corresponding brittle viscoelastic behaviour. This was demonstrated by drying juices from tomato and bell pepper, giving poor results, and by drying solutions from whey protein isolate (WPI) and sucrose, which could be successfully dried. 


\subsection{Introduction}

Drying is a commonly used technology to preserve food products. Various types of dryers have been developed that are tailored to specific feed properties and product requirements ${ }^{1}$. The most commonly applied drying technologies to liquid feeds can be categorised into two types, i.e. convective and conductive drying. Spray drying is one of the most commonly applied convective drying methods, where energy for evaporation is supplied by contacting a dispersion of the product with hot air ${ }^{2}$. Drum drying, refractance window drying and agitated thin film drying (ATFD) are examples of conductive drying methods, where energy for evaporation is supplied by steam condensation and/or hot water, which is then transferred through a wall to a thin product film that is present at the other side of the wall. ATFD is done by spreading the product on the inside of a hollow cylinder, and supplying heat from the outside. The product film is continuously agitated with a knife that rotates inside the cylinder. In general, conductive drying is especially suitable for high viscous (food) products. Drum drying is for example extensively applied for drying of starch, mashed potatoes, fruit purees, dry soup mixtures, casein, etc. ${ }^{3}$. Refractance window drying is reported especially suitable for drying of pureed fruits and vegetables, i.e. strawberry pulp, mango pulp, carrot puree and pumpkin puree ${ }^{4-6}$. Whereas drum drying and refractance window drying are more readily applied and effective for drying of viscous liquid foods, pastes or purees, agitated thin film drying is not yet widely applied ${ }^{1,5,7,8}$.

The advantage of spray drying is that it is a mild and fast dehydration process due to the fast evaporation. Reported disadvantages of spray drying are the low energy efficiency, the high capital costs and the relatively low bulk density of the dried products ${ }^{9}$. The lower energy efficiency of spray drying is related to the large energy loss via the warm and moist exhaust gas. In that respect, drum drying is more efficient as it consumes on average $40 \%$ less energy due to almost others lower energy loss via the exhaust gas ${ }^{2,9}$. A major drawback of atmospheric drum drying is however that the product is exposed to the boiling temperature $\left(100{ }^{\circ} \mathrm{C}\right)$, which can lead to undesired damage to heat sensitive foods ${ }^{1,7}$. The operation of drum drying processes under reduced pressure 
could be an attractive alternative, but the capital costs of vacuum drum dryers are relatively large. During refractance window drying the product is dried as a thin film on a belt, which moves over a bath filled with hot water $\left(\sim 90^{\circ} \mathrm{C}\right)$ and the film is dried under atmospheric conditions ${ }^{6}$. A drawback is for example that very thin films need to be casted to facilitate the drying, which limits capacity and troubles scale-up. Agitated thin film drying is therefore identified as a promising alternative conductive drying method.

ATFD is a continuous drying process carried out in a scraped heat exchanger, which can be easily operated under reduced pressure and is thus suitable for heat sensitive products. The ATFD consists of two major elements, i.e. the drying chamber with a heating jacket and the rotor with fixed blades. Two different blade configurations can be distinguished, namely the small-gap and the scraped surface blades. For the small-gap blade configuration, a gap is present between the blade-tips and the wall. The rotating blades agitate the liquid feed, which spreads as a falling thin film within the gap and a falling bow wave is created at the tip of the blades, as shown in Figure 5-1 (A) ${ }^{\mathbf{1 0}} \mathbf{1 1}^{\mathbf{1}}$. For the scraped surface blade configuration, the blade-tips directly contact the wall with a negligible gap. This blade constitution forms a larger falling bow wave with minimal film formation, as shown in Figure 5-1 (B) ${ }^{12}$. The latter blade configuration is more efficient in preventing the formation of an undesired dry, insulating layer on the wall and thus promote efficient heat transfer, especially for materials with higher fouling tendency ${ }^{13,14}$. 

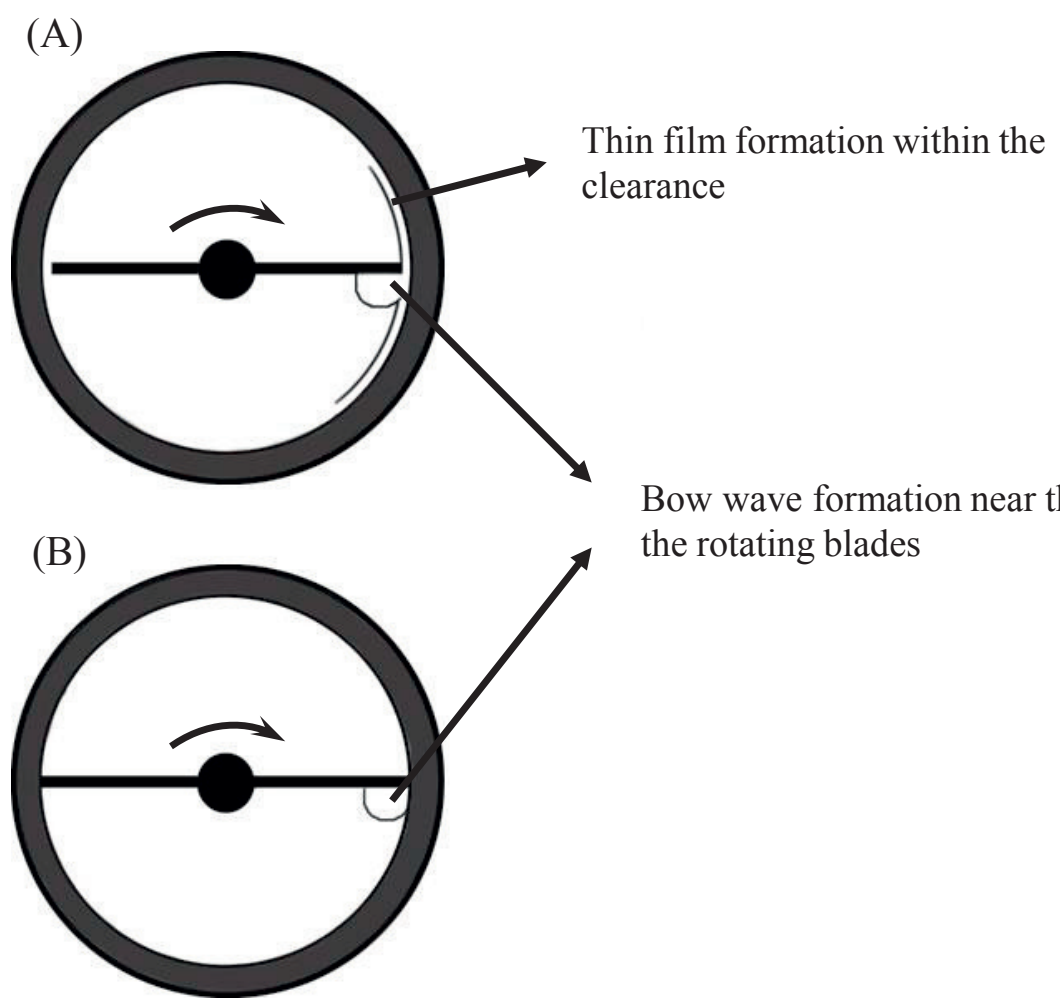

Bow wave formation near the tip of the rotating blades

Figure 5-1 Schematic representation of product distribution in the ATFD with different blade constitutions: (A) small-gap blades and (B) scraped surface blades.

Figure 5-2 provides a schematic drawing of the drying process within the ATFD with scraped surface blades. The product progressively passes through different consistencies, i.e. liquid, paste, and solid. When the feed enters the ATFD, the liquid feed forms two bow waves on the front edge of the blades. The blades rotate fast and contact the liquid feed with the heating wall. The high rotation speed generates a well-mixed liquid flow within the two bow waves. The liquid flows down spirally due to gravity and concentrates as water is removed by evaporation. Due to this concentration, the viscosity increases and thus the flow rate goes down. The concentrated product becomes increasingly viscous and transforms from a paste into a brittle material. Depending on the brittleness of the resulting product, which is dependent on its moisture content and material properties, the product will fracture into smaller powder particles due to the rotating action of the blades. 


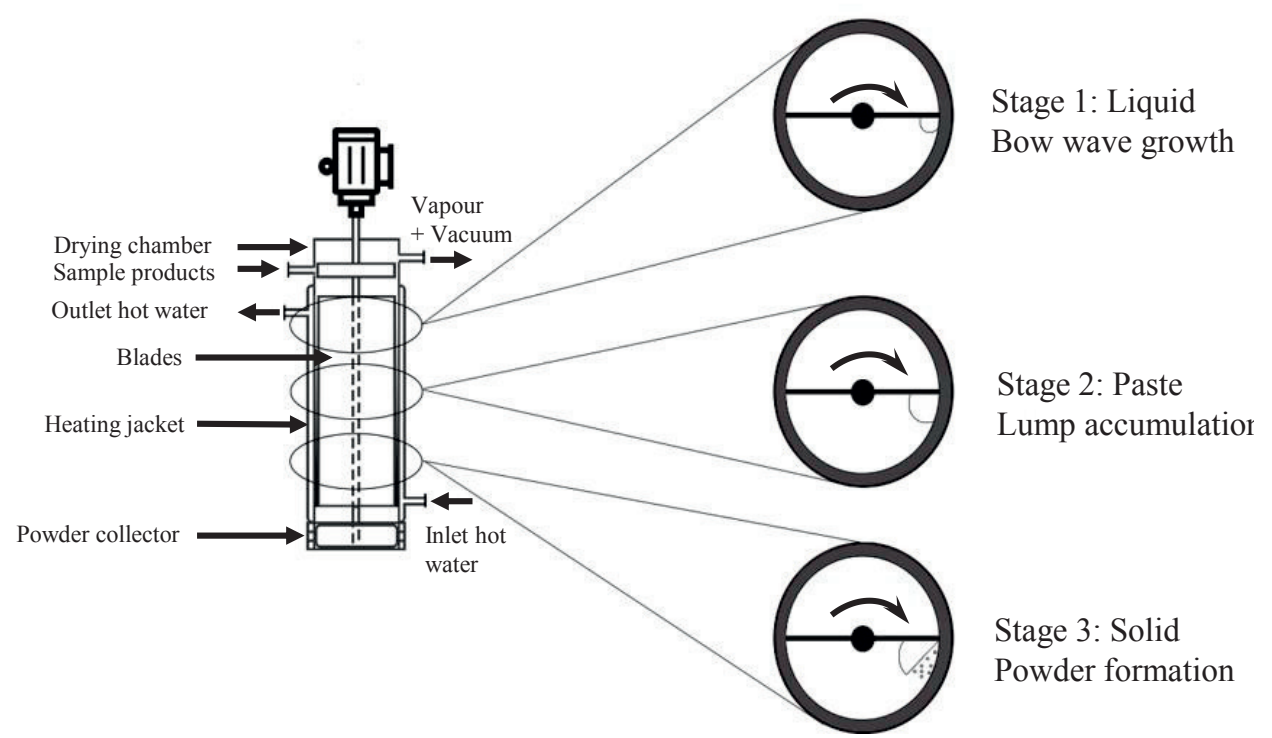

Figure 5-2 Schematic representation of the drying process in an agitated thin film dryer.

Several studies have investigated flow distribution and heat and mass transfer during agitated thin film evaporation (ATFE) processes, which are the first stages of ATFD. Komari, Takata and Murakami ${ }^{\mathbf{1 0}}$ investigated the flow and mixing behaviour of a fluid with a high viscosity in an agitated thin film evaporator with a single small-gap blade. They found that more than $70 \%$ of the supplied feed end up in the bow waves and that the mass transfer between the bow waves and the thin film was negligible. Komari, Takata and Murakami 15 improved the apparatus by using multiple vertically aligned blades, and reported that the vertically aligned blades could strongly promote mass transfer between the bow waves and the thin film and thus increase the efficiency of the equipment. De Goede and De Jong ${ }^{16}$ studied the heat transfer properties of a scraped surface heat exchanger and developed a model by combining a regular model for turbulent pipe flow with the penetration theory. McKenna ${ }^{17}$ presented a model for the design of a wiped film evaporator, by considering both fluid and mass transport phenomena.

Only very few studies investigated ATFD as such. Pawar et al. ${ }^{1,11}$ studied the heat and mass transfer during ATFD and proposed a stage-wise penetration 
theory model, by assuming ideal mixing between the bow wave and the thin film. Their model implies that the resistance to heat transfer would be in the film. The model was validated with ATFE instead of ATFD experiments, which is only one part of the overall ATFD process: during ATFD, the feed will transform from a viscous liquid into a paste and subsequently into a solid, and the mass and heat transfer during operation will be different ${ }^{18}$. Hitherto, to the best of our knowledge no experimental studies have systematically investigated this product transformation during ATFD drying and its consequence on the drying behaviour. Given the changes in product consistency, we expect that the product properties will have large influence on the drying behaviour in an ATFD.

The aim of this study was therefore to create a better understanding of drying behaviour of foods during ATFD drying and how it is affected by process parameters and product properties. Juice from spinach leaves was selected as a model system to investigate the influence of drying parameters, i.e. heating temperatures, feeding rates and rotation speeds. The obtained results were compared to the existing ATFD model proposed by Pawar et al. ${ }^{1}$. Different food formulations, such as whey protein isolate (WPI) solution, sucrose solution, bell pepper juice and tomato juice, were dried using ATFD. Drying behaviour of spinach juice was taken as a reference and compared to drying behaviour of the other materials in the ATFD.

\subsection{Materials and Methods}

\subsubsection{Materials}

Spinach suspensions for ATFD experiments were prepared starting from fresh spinach leaves, which were purchased from the local supermarket. The fresh spinach leaves were juiced by an Angelia AG-7500 Juicer (Angel Co. Ltd, Republic of Korea). After juicing, the squeezed juice and fibre residues were collected separately. The obtained insoluble fibre residues were dried in a hot air oven (Binder, Tuttlingen, Germany) at $60{ }^{\circ} \mathrm{C}$ for $20 \mathrm{~h}$. The dried fibres were milled by the Rotor Mill Pulverisette-14 (FRITSH International, USA) at 6000 rpm with a $0.2 \mathrm{~mm}$ sieve. The drying and milling of fibres was necessary 
because the fibre particles had to be small enough to avoid blockage of the feeding pump. Subsequently, the milled fibres were added back into the squeezed juice to obtain a spinach suspension with approximately again $2 \%$ w/w fibers. In addition, around 5 drops of Antifoam B aqueous silicone emulsion (Sigma-Aldrich ${ }^{\circledR}$, Zwijndrecht, the Netherlands) were added into $1 \mathrm{~L}$ juice to prevent excessive foaming.

\subsubsection{Lab-scale Agitated Thin Film Drying}

Figure 5-3 shows a schematic diagram of the experimental lab scale apparatus. The ATFD chamber was made from transparent glass to facilitate observation of the heat exchange area. The ATFD chamber was equipped with a Liebig condenser and a dropping funnel (L.G.S. B.V, Ubbena, the Netherlands) to condense and quantify the vapour release. The entire system was operated under reduced pressure (50 mbar) using a vacuum pump (SC 950, KNF Neuberger GmbH, Freiburg, Germany). The dimensions of the lab-scale ATFD are shown in Table 5-1.

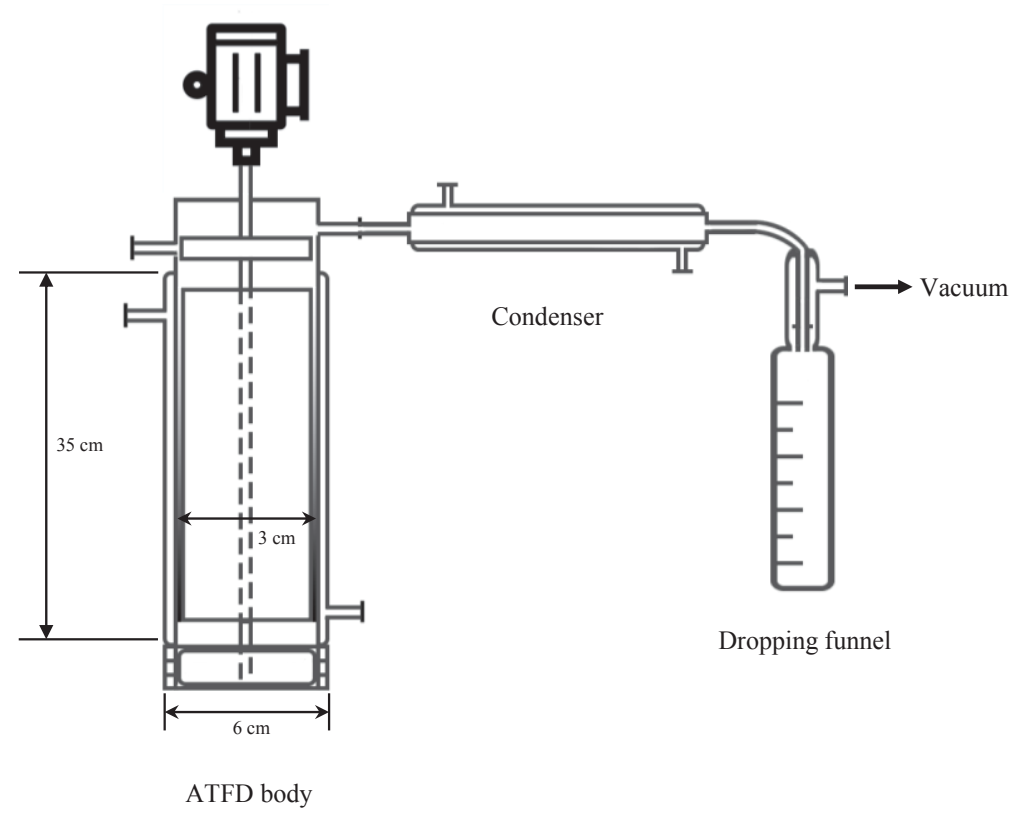

Figure 5-3 Schematic representation of the experimental apparatus. 
Experiments were performed to determine the (specific) evaporation rates of the spinach suspensions at different drying conditions. The spinach suspension was preheated to $33^{\circ} \mathrm{C}$ and then supplied to the system with a flow rate ranging from 0.3 to $0.5 \mathrm{~kg} / \mathrm{h}$, by a peristaltic pump (205S, Watson Marlow, Falmouth, England) with rotation speeds from 30 to $50 \mathrm{rpm}$. The drying temperatures of the heating chamber ranged from 70 to $90{ }^{\circ} \mathrm{C}$. The condenser was operated with cooling water of $2{ }^{\circ} \mathrm{C}$. The amount of condensed water was measured and used to obtain the evaporation rate. The specific evaporation rate was calculated by dividing the evaporation rate by the used heat exchange area.

Table 5-1 Dimensions of the lab-scale agitated thin film dryer.

\begin{tabular}{lcc}
\hline Parameters & Value & Unit \\
\hline Inner diameter of the drying chamber & 0.030 & $\mathrm{~m}$ \\
Outer diameter of the heating jacket & 0.060 & $\mathrm{~m}$ \\
Diameter of the scraped surface blades & 0.030 & $\mathrm{~m}$ \\
Effective length of the drying chamber & 0.350 & $\mathrm{~m}$ \\
Thickness of the wall & 0.002 & $\mathrm{~m}$ \\
Maximum heat exchange area & 0.033 & $\mathrm{~m}^{2}$ \\
Numbers of blades & 2 & - \\
\hline
\end{tabular}

\subsubsection{Analysis of the moisture content and water activity}

Powders were collected at the bottom of the lab-scale ATFD for analysis of the moisture content and water activity. To determine the moisture content, around $1.5 \mathrm{~g}$ of the powder was dried in a hot air oven (Binder, Tuttlingen, Germany) at $105{ }^{\circ} \mathrm{C}$ for $16 \mathrm{~h}$. The water activity was measured by an AquaLab 4TE dew point water activity metre (METER Food, Munich, Germany). Measurements were carried out in duplicate.

\subsubsection{Ratio of soluble and insoluble compounds}

The ratio of soluble and insoluble compounds was determined by adding $\sim 1 \mathrm{~g}$ of the powder into $30 \mathrm{~mL}$ of water, mixed for $60 \mathrm{~min}$ by the Multi Reax test tube shaker (Heidolph, Germay). Subsequently, the suspensions were centrifuged by the Sorvall Legend XFR Centrifuge (Thermo SCIENCE, USA) at $10,000 \mathrm{~g}$ and $20{ }^{\circ} \mathrm{C}$ for $30 \mathrm{~min}$. After centrifugation, the supernatant was 
removed and the pellet was dried in an oven at $105{ }^{\circ} \mathrm{C}$ for $16 \mathrm{~h}$. The fraction of soluble powder $\left(\eta_{p}\right)$ was calculated by:

$$
\eta_{p}=\frac{m_{1}\left(1-X_{w}\right)-\left(m_{2}-m_{3}\right)}{m_{1}\left(1-X_{w}\right)} \quad \text { Eq. } 5-1
$$

Where $X_{w}$ is the moisture content of the ATFD dried powders; $m_{1}, m_{2}$ and $m_{3}$ are the mass of the ATFD dried powders, the dried sediments and the centrifuge tube, respectively. The measurements were carried out in duplicate.

\subsubsection{Morphology of the ATFD dried powders}

Scanning electron microscopy images of ATFD dried powders were made using a Phenom G2 Pure SEM (Phenom-World BV, Eindhoven, the Netherlands). The dried powders were fixed on an aluminium pin-type mount (JEOL BV. Nieuw-Vennep, the Netherlands) with carbon tabs. Pre-treatment of the samples was not necessary.

\subsubsection{Statistical analysis and mathematical modelling}

A one-way analysis of variance (ANOVA) and a Tukey multiple regression analysis were applied to evaluate the obtained results at a significance level of 0.05. The ATFD process model from Pawar et al. ${ }^{1}$ was implemented and compared to experimental results. The statistical analysis and modelling work were carried out using MATLAB R2016b (Mathworks, Natick, USA).

\subsection{Results and discussions}

\subsubsection{ATFD experiments with spinach leaf suspensions}

The lab-scale ATFD rig was used to dry the spinach suspensions at different conditions, which are reported in Table 5-2. The effect of the drying temperature on the evaporation rate and the specific evaporation rate was determined. Figure 5-4 (A) shows that with the increase of drying temperature, the overall evaporation rate does not change significantly $(p>0.05)$, but the specific evaporation rate increases significantly $(p<0.05)$, based on one-way ANOVA analysis. At a higher drying temperature, the surface area required for drying decreases, as shown in Figure 5-4 (B). Since the feed is dried completely, the total evaporation rate is fixed. When the drying temperature is increased, 
the specific evaporation rate will increase due to the larger driving force, which will result in a smaller total surface used for evaporation. Indeed, we see at higher drying temperatures that a larger part of the wall is not used.

(A)

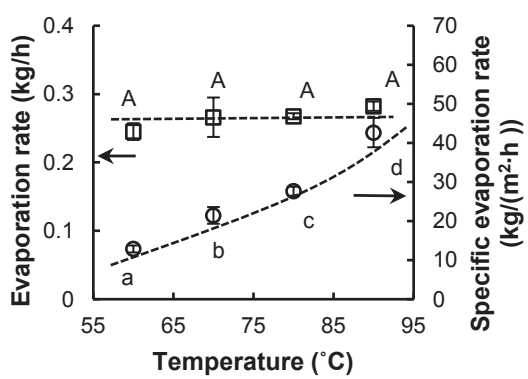

(B)

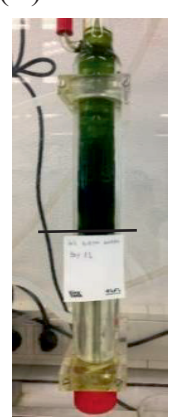

$60{ }^{\circ} \mathrm{C}$

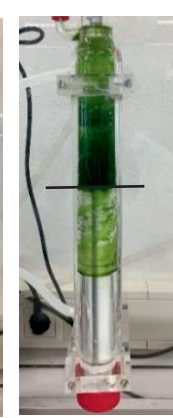

$70{ }^{\circ} \mathrm{C}$

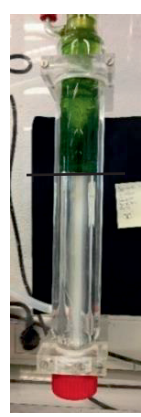

$80{ }^{\circ} \mathrm{C}$

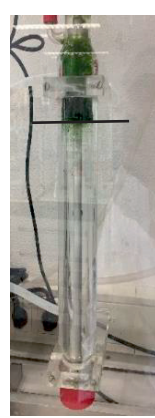

$90{ }^{\circ} \mathrm{C}$

Figure 5-4 (A) The evaporation rate and the specific evaporation rate in the ATFD for different temperatures (Rotation speed $=600 \mathrm{rpm}$, Feed rate $=0.3 \mathrm{~kg} / \mathrm{h}$ ). The error bars represent the standard deviation of the experimental data $(n=3)$. The same letters represent no significant difference at the $95 \%$ confidence interval. The dotted lines are added to guide the eye. (B) Images showing the occupied surface area in the ATFD chamber at different drying temperatures.

Figure 5-5 shows the influence of the rotation speed and the feed rate on the evaporation rate and the specific evaporation rate. As shown in Figure 5-5 (A), both the evaporation rate and the specific evaporation rate did not change at different rotation speeds $(\mathrm{p}>0.05)$. The constant specific evaporation rate implies that mixing of the feed is not rate limiting for the drying process. Therefore, the heat transfer has to be limited by the heat transfer through the glass wall. This observation is opposite to the predictions by the model proposed by Pawar et al. ${ }^{1}$, who proposed that the heat transfer coefficient of the ATFD may be derived from the heat penetration theory, and therefore should increase with the rotation speed. According to this model, the specific evaporation rate should increase as well. In fact, these authors also experimentally observed that the water evaporation rate was independent of the speed of the blades, when they concentrated a $20 \% \mathrm{w} / \mathrm{w}$ ammonium sulphate solution in an ATFE. Our conclusion is therefore that the blades do not directly influence the mass and heat transfer of the drying process, even though they are still essential for removing the solidified material from the wall. 
As shown in Figure 5-5 (B), we found that the effect of the feed rate is opposite to that of the temperature. The increased feed rate does not influence the specific evaporation rate $(\mathrm{p}>0.05)$, but does influence the total evaporation rate $(\mathrm{p}<0.05)$, since a larger feed rate leads to a larger surface covered by the drying feed, and therefore a larger total evaporation rate. The total evaporation rate depends on the feed rate, as long as the system is not at its maximum capacity.

(A)

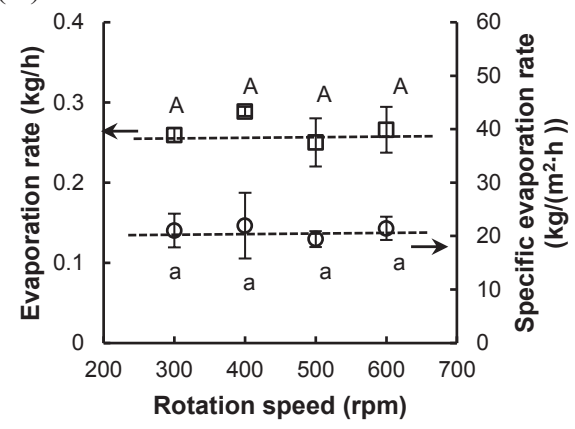

(B)

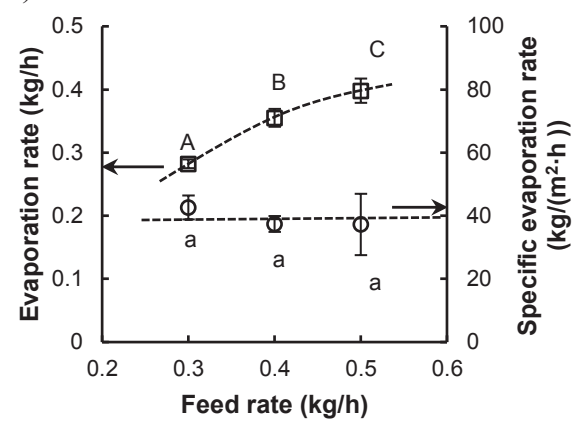

Figure 5-5 The evaporation rate and the specific evaporation rate in the ATFD for different (A) rotation speeds (Temperature $=70{ }^{\circ} \mathrm{C}$, Feed rate $=0.3 \mathrm{~kg} / \mathrm{h}$ ) and $(\mathrm{B})$ feed rates (Temperature $=90{ }^{\circ} \mathrm{C}$, Rotation speed $=600 \mathrm{rpm}$ ). The error bars represent the standard deviation of the experimental data $(n=3)$. The same letters represent no significant difference at the $95 \%$ confidence interval. The dotted lines are added to guide the eye. 
Table 5-2 shows the moisture content and water activity $\left(a_{w}\right)$ of the dried spinach powder and the fraction of soluble powder at different drying conditions. The moisture content of the powder ranges from 0.049 to 0.114 $\mathrm{kg} / \mathrm{kg}$ total and the water activity ranges from 0.26 to 0.60 . Although foods with $\mathrm{a}_{\mathrm{w}}<0.6$ may be considered as microbiologically stable, they may still be susceptible to undesired chemical reactions and stickiness, and further drying in such as a fluidized bed would be recommended for vegetable powders to further decrease the water activity to $a_{w}<0.2{ }^{19}$. In most cases, the fraction of soluble powder was higher than 0.31 . This was higher than that of spinach fibres after squeezing (0.21), indicating that the powders collected from ATFD were not only fibres. Therefore, ATFD did not selectively scrape insoluble particles from sticky lumps. It should be mentioned that during experiment No. 2 , no powder was collected at the bottom of the setup. Instead, all the material stuck to the blades as lumps so that the moisture content, water activity and fraction of soluble powder in this experiment could not be measured. Probably this was due to the low rotation speed, which did not provide enough mechanical stress to fracture the material. Therefore, even though the rotation speed does not affect the heat transfer (Figure 5-5 (A)), it is crucial for powder formation. 


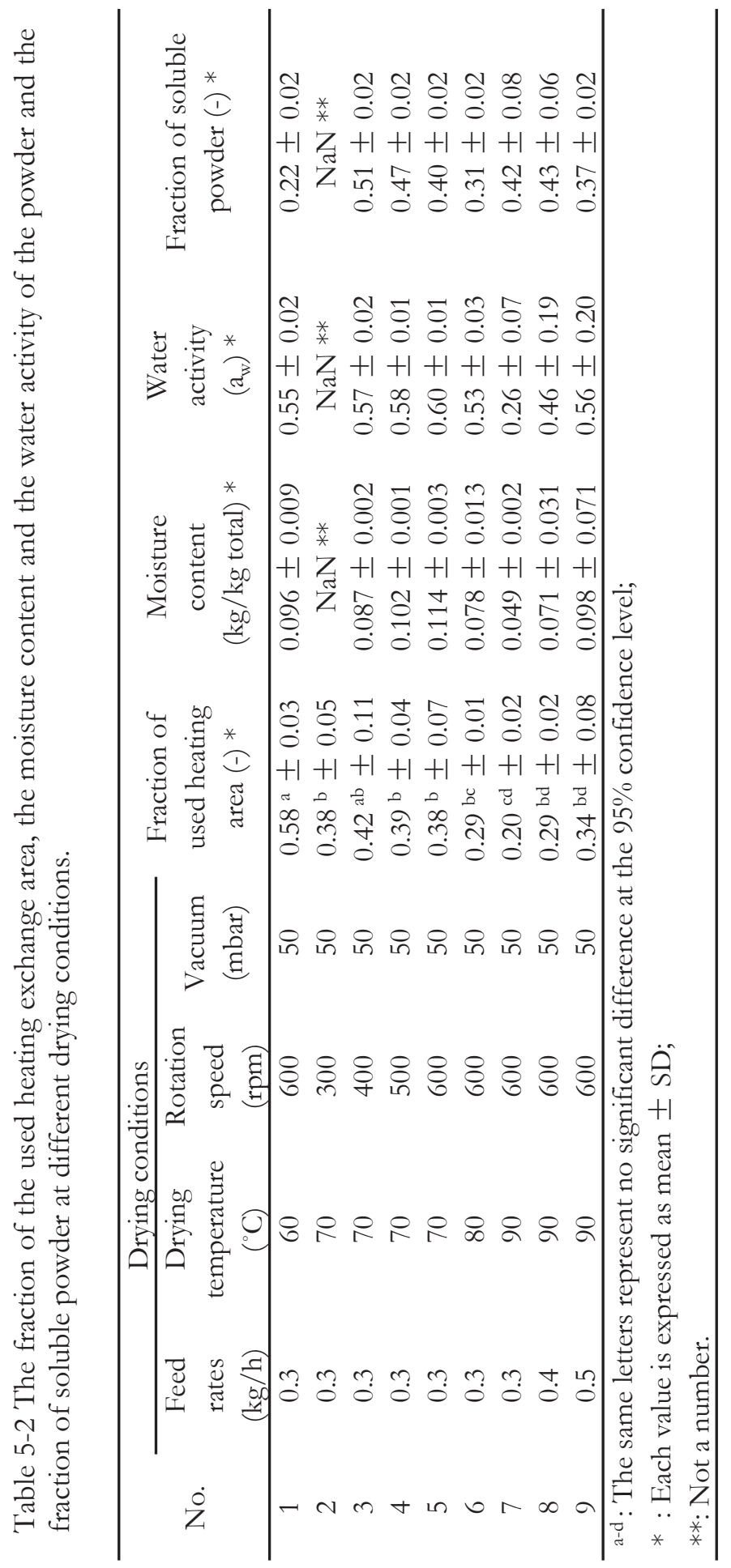




\subsubsection{Comparison between experimental data and model predictions}

As mentioned in the introduction a model was proposed by Pawar et al. ${ }^{1}$ for the ATFD process. Figure 5-6 compares the experimental and predicted fraction of the used heat exchange area. The predicted values are much lower than the experimental results. The underestimation by the model can be related to several inappropriate model assumptions.

(1) Our finding of the independence of the specific evaporation rate of the blade rotation speed (Figure 5-5 (A)) points towards heat transfer limited by the wall (and possibly the heating fluid outside), but not by the feed slurry itself. One should note that Pawar et al. ${ }^{1}$ found the same independence in their experiments, which in fact contradicts their own model.

(2) Their model assumes that the blades continuously remove the boundary layer and mix the feed suspension ideally. This assumption is not valid for highly concentrated products (Stage 2 in Figure 5-2), with high viscosity and thus a low rotational Reynolds number $\left(\operatorname{Re}_{\mathrm{R}}<100\right)^{1}$. For a solid-like product (Stage 3 in Figure 5-2), mixing will stop completely. This leads to overestimation of the heat transfer coefficient in the concentrated and final paste/solid phases.

(3) It is assumed that the rotating blade completely removes material from the heat exchange surface and thus heat transfer resistance due to fouling is neglected. In practice always some deposited material is observed on the wall probably leading to increased and significant heat transfer resistance over time, adding to the dominance of the heat transfer limitation of the wall (point 1).

(4) The model assumes that evaporation occurs only at the surface of the thin film, while the hottest location in the feed slurry is at the surface. Most probably, the evaporation already takes place close to the wall. Indeed, we see the generation of bubbles indicating boiling inside the slurry. If this is the case, then the mass transfer from wall to bow wave does not contribute directly to the evaporation process; even though it is still important to remove the dry matter from the wall. 


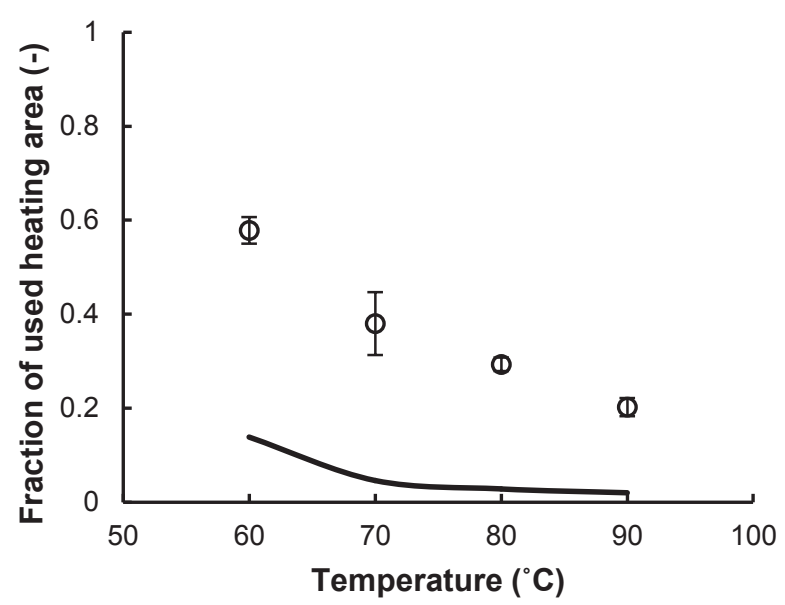

Figure 5-6 Fraction of used heating area for different drying temperature in the ATFD compared to predicted values (Rotation speed $=600 \mathrm{rpm}$; Feed rate $=0.3 \mathrm{~kg} / \mathrm{h}$ ). The symbols represent the experimental data. The solid line represents the predictions from the model developed by Pawar $e t$. $a l^{1}$. The error bars show the standard deviation of the experimental data $(n=3)$.

All of the above discussed assumptions contribute to the observed differences between predicted and experimental values and we therefore conclude that the penetration theory based model may be suitable for ATFE, but not for ATFD processes.

\subsubsection{Application of ATFD to other food products}

In addition to spinach juice, other food materials, i.e. whey protein isolate (WPI) solution, sucrose solution, bell pepper juice and tomato juice, were dried in the lab-scale ATFD, to investigate the role of the properties of the feed materials in the ATFD process. Both WPI and sucrose solution were dried successfully in the setup, while bell pepper and tomato juices could not. These juices were only concentrated into a paste-like rubbery lump, which became very sticky and could not be scraped off by the blades anymore. The sticky rubbery lump accumulated in the setup impaired the operation of the dryer. The high concentrations of glucose and fructose, approximately 10 times higher than in spinach leaves, probably explains the observed drying behaviour ${ }^{20}$. These low molecular weight sugars do not crystallise easily and have a low glass transition temperature. Thus, these components contribute very much to 
sticky behaviour during drying, leading to the formation of a paste-like rubbery lump instead of a hard brittle solid ${ }^{21-23}$. This was further confirmed by drying spinach juice with $2 \% \mathrm{w} / \mathrm{w}$ glucose and $2 \% \mathrm{w} / \mathrm{w}$ fructose added. This sugarrich spinach suspension could not be successfully dried, just as the bell pepper and tomato juices.

In contrast to glucose and fructose, sucrose solutions could be dried successfully, probably because of the fast crystallisation of sucrose. Figure 5-7 (A) indeed gives evidence of crystallised sucrose in the SEM micrograph of ATFD dried sucrose particles. The sucrose consists of agglomerates of amorphous sugar and small regular hexagon crystals, which are indicated in the micrograph. It is indicative of that the fast crystallisation may facilitate the solidification and fragmentation of the lump during drying. Also WPI could be dried with the lab-scale ATFD, as is shown in Figure 5-7 (B); The WPI powder particles are irregularly shaped with smooth break surfaces and some cracks, reflecting a brittle material fragmented by blade rotations. WPI consists of globular whey proteins that behave as 'hard spheres' ${ }^{24,25}$. During drying, when the volume fraction of the proteins increases to a critical level, the hard spheres jam, which results in a dramatic change from a liquid-like to a solid-like state with a corresponding large viscosity change ${ }^{26}$. The jammed WPI system is assumed to exhibit viscoelastic behaviour similar to that of non-deformable hard sphere colloids ${ }^{24,25}$. The dried WPI resists to further deformation ${ }^{24}$, being a hard brittle material, but can be broken by mechanical action via the blade rotation. Finally, Figure 5-7 (C) shows that the ATFD dried spinach powder consists of irregular agglomerated particles with fibres. 
(A) Sucrose
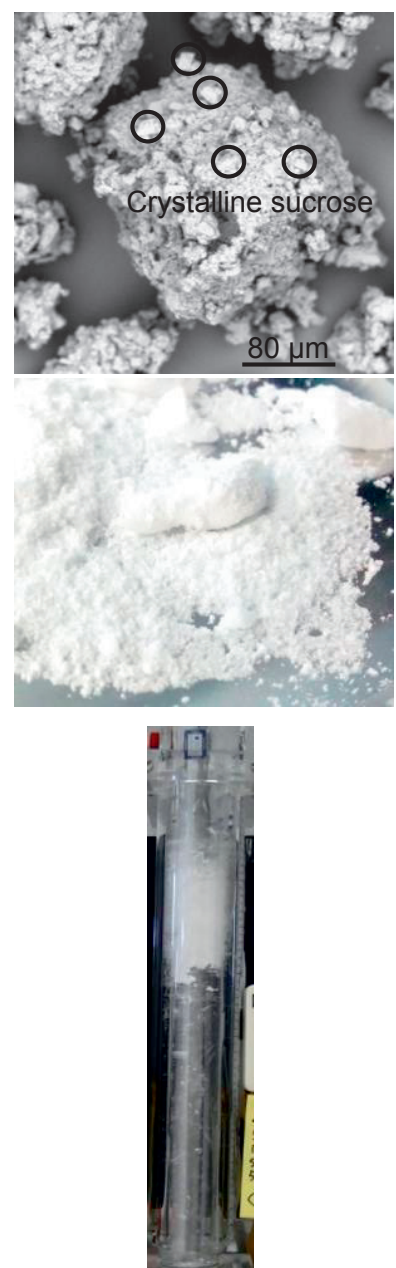

(B) WPI
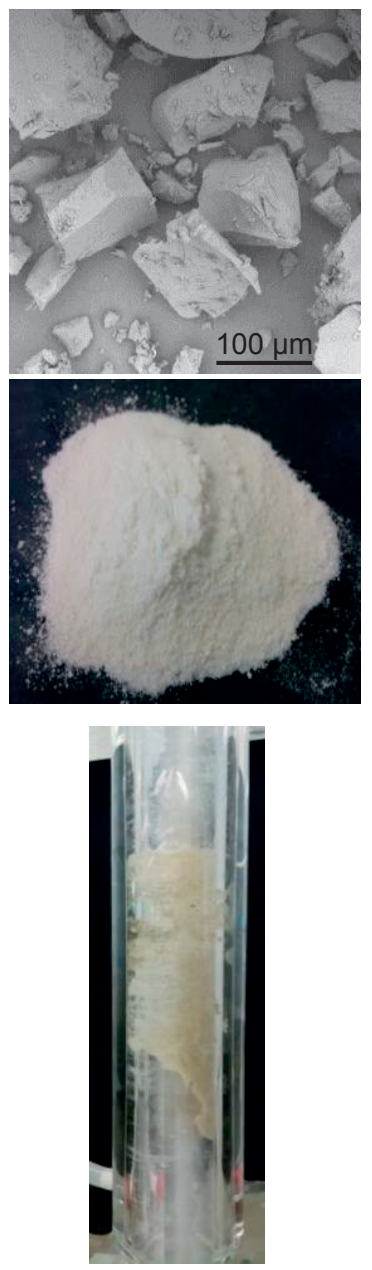

(C) Spinach
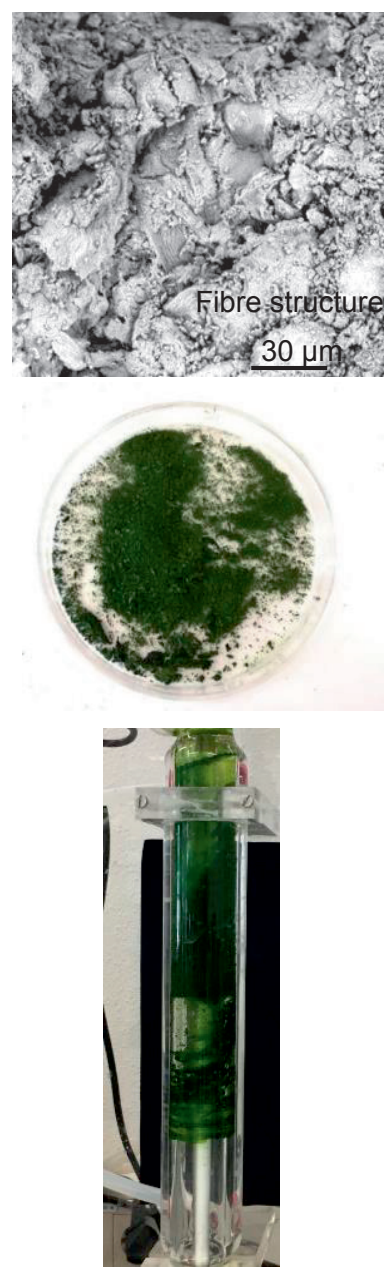

Figure 5-7 Regular and Scanning Electron Microscope images of ATFD dried (A) sucrose (B) whey protein isolate (WPI) and (C) spinach and the ATFD chamber with the respective products. 
A solid lump could be removed from the equipment after drying of WPI, as shown in Figure 5-8. The lump was tough (by manual tactile inspection), with a triangular cross section and probably did not contact the wall directly, but slid over a thin film on the surface. The powder formation may have resulted from attrition from the lump due to the mechanical action. This powder formation processes was also visualised in the schematic drawing of the ATFD process in Figure 5-2. Because the WPI lumps are mechanically tough, the degree of attrition was not sufficient in the lab-scale ATFD and after a certain time impaired the operation of the dryer. In large scale operations, the tip speed of the blades can be much higher and combined with a stronger impeller motor, the disintegration of such a tough bow wave is faster and more thorough. Very fast blade rotation and a strong impeller motor could however also lead to local heating and damage to the product components.

We conclude that the product properties, and especially the combination of phase transition and viscoelastic properties, determine whether ATFD is a suitable dying process. 


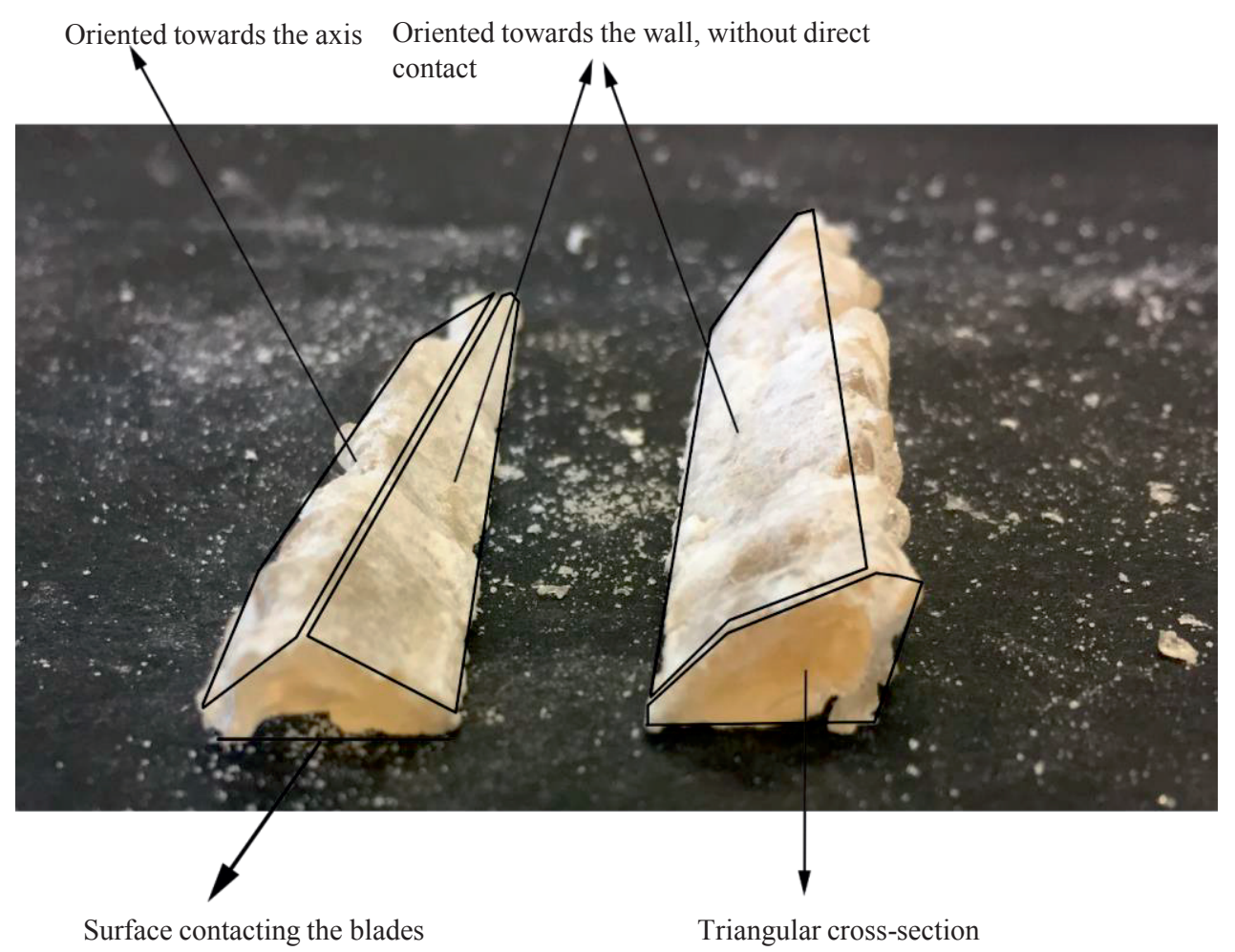

Figure 5-8 Pictures of solidified bow-waves formed by accumulation of material during drying of a WPI solution in the ATFD.

\subsection{Conclusions}

Suspensions prepared from spinach leaves were dried in a lab-scale agitated thin film dryer (ATFD). The spinach powders that were obtained had good flowability. The drying behaviour was characterised and especially wall temperature was identified as important for the specific evaporation rate, giving a parameter to set the dryer capacity. The blade rotation speed does not affect the drying rate, but mechanically disintegrates the material into small powder particles during drying. The independence of the specific drying rate of the blade rotation speed shows that in our system the drying process is limited by heat transfer through the wall, which falsifies the existing model for ATFD, based on the penetration theory. 
Successful drying is strongly dependent on the product properties. A liquidsolid phase transition at high concentrations and corresponding brittle viscoelastic behaviour make a material potentially suitable for ATFD. This was demonstrated by drying of slurries of whey protein isolate (WPI), sucrose, and bell pepper and tomato juices. Larger scale ATFD enables higher blade velocities and stronger shearing, which may make the process somewhat less sensitive to the product properties. Disadvantage of high blade speed velocities may however be undesired elevation of the local temperature due to friction.

\section{Acknowledgements}

This work was supported by the Institute of Sustainable Process Technology (ISPT). Partners in this project are Bodec, Danone, ECN and Unilever. We also thank Chaoyang Wang, Remco Boer and Rens van Roekel for their support on performing experimental work. 


\section{References}

[1]. Pawar, S. B., Patil, R., Mujumdar, A. and Thorat, B. (2011). Mathematical modeling of agitated thin-film dryer. Drying Technology, 29(6), 719-728.

[2]. Devahastin, S. and Mujumdar, A. S. (2006). Indirect dryers. Handbook of Industrial Drying, Fourth Edition (pp. 137-149). Boca Raton: CRC Press.

[3]. Rodriguez, G., Vasseur, J. and Courtois, F. (1996). Design and control of drum dryers for the food industry. Part 1. Set-up of a moisture sensor and an inductive heater. Journal of Food Engineering, 28(3), 271-282.

[4]. Zotarelli, M. F., Carciofi, B. A. M. and Laurindo, J. B. (2015). Effect of process variables on the drying rate of mango pulp by Refractance Window. Food Research International, 69, 410-417.

[5]. Abonyi, B., Feng, H., Tang, J., Edwards, C., Chew, B., Mattinson, D. and Fellman, J. (2002). Quality retention in strawberry and carrot purees dried with Refractance Window ${ }^{\mathrm{TM}}$ system. Journal of Food Science, 67(3), 10511056.

[6]. Nindo, C., Feng, H., Shen, G., Tang, J. and Kang, D. (2003). Energy utilization and microbial reduction in a new film drying system. Journal of Food Processing and Preservation, 27(2), 117-136.

[7]. Daud, W. R. W. (2006). Drum dryers. Handbook of Industrial Drying, Fourth Edition. Boca Raton: CRC Press.

[8]. Ochoa-Martínez, C., Quintero, P., Ayala, A. and Ortiz, M. (2012). Drying characteristics of mango slices using the Refractance Window ${ }^{\mathrm{TM}}$ technique. Journal of Food Engineering, 109(1), 69-75.

[9]. Nindo, C. and Tang, J. (2007). Refractance window dehydration technology: a novel contact drying method. Drying Technology, 25(1), 37-48.

[10]. Komori, S., Takata, K. and Murakami, Y. (1988). Flow structure and mixing mechanism in an agitated thin-film evaporator. Journal of Chemical Engineering of Japan, 21(6), 639-644.

[11]. Pawar, S. B., Mujumdar, A. and Thorat, B. (2011). Flow pattern and heat transfer in agitated thin film dryer. Chemical Engineering and Processing: Process Intensification, 50(7), 687-693.

[12]. Keller, E. (1965). U.S. Patent No. 3199575. U. S. P. a. T. Office. 
[13]. Wilkerson, K. L. (1985). U.S. Patent No. 4538428. U. S. P. a. T. Office.

[14]. Stamatiou, E., Meewisse, J. and Kawaji, M. (2005). Ice slurry generation involving moving parts. International Journal of Refrigeration, 28(1), 60-72.

[15]. Komori, S., Takata, K. and Murakami, Y. (1989). Flow and mixing characteristics in an agitated thin-film evaporator with vertically aligned blades. Journal of Chemical Engineering of Japan, 22(4), 346-351.

[16]. De Goede, R. and De Jong, E. (1993). Heat transfer properties of a scraped-surface heat exchanger in the turbulent flow regime. Chemical Engineering Science, 48(8), 1393-1404.

[17]. McKenna, T. F. (1995). Design model of a wiped film evaporator: applications to the devolatilisation of polymer melts. Chemical Engineering Science, 50(3), 453-467.

[18]. Zeboudj, S., Belhaneche-Bensemra, N., Belabbes, R. and Bourseau, P. (2006). Modelling of flow in a wiped film evaporator. Chemical Engineering Science, 61(4), 1293-1299.

[19]. Quek, S. Y., Chok, N. K. and Swedlund, P. (2007). The physicochemical properties of spray-dried watermelon powders. Chemical Engineering and Processing: Process Intensification, 46(5), 386-392.

[20]. Service, U. S. D. o. A. A. R. (2014). National nutrient database for standard reference.

[21]. Jaya, S. and Das, H. (2009). Glass transition and sticky point temperatures and stability/mobility diagram of fruit powders. Food and Bioprocess Technology, 2(1), 89-95.

[22]. Muzaffar, K., Nayik, G. A. and Kumar, P. (2015). Stickiness problem associated with spray drying of sugar and acid rich foods: a mini review. Journal of Nutrition \& Food Sciences(S12), 1.

[23]. O'Callaghan, D. and Hogan, S. (2013). The physical nature of stickiness in the spray drying of dairy products:a review. Dairy Science \& Technology, 93(4-5), 331-346.

[24]. Sadek, C., Pauchard, L., Schuck, P., Fallourd, Y., Pradeau, N., Le FlochFouéré, C. and Jeantet, R. (2015). Mechanical properties of milk protein skin layers after drying: Understanding the mechanisms of particle 
formation from whey protein isolate and native phosphocaseinate. Food Hydrocolloids, 48(Supplement C), 8-16.

[25]. Nicolai, T. and Durand, D. (2007). Protein aggregation and gel formation studied with scattering methods and computer simulations. Current Opinion in Colloid \& Interface Science, 12(1), 23-28.

[26]. Hogan, S. A., O'Loughlin, I. B. and Kelly, P. M. (2016). Soft matter characterisation of whey protein powder systems. International Dairy Journal, 52(Supplement C), 1-9. 


\section{CHAPTER 6}

\section{A systematic analysis on tomato powder quality prepared by four conductive drying technologies}

This chapter has been submitted as: Qiu, J., Acharya, P., Jacobs. D.M., Boom, R. M., \& Schutyser, M. A. I. (2019). A systematic analysis on tomato powder quality prepared by four conductive drying technologies. 


\section{Abstract}

Conductive drying is an energy-efficient drying method, suited for drying of highly viscous products, like tomato puree. Four pilot-scale conductive dryers, namely a vacuum drum dryer (VDD), a drum dryer (DD), an agitated thin film dryer (ATFD) and a refractance window dryer (RWD) were applied to dry tomato puree. Drying induced colour differences between the reconstituted tomato puree and the original tomato puree, especially for RWD and ATFD. In addition, drying strongly affected the volatile and non-volatile profiles of the powders. Four separated groups corresponding to the different drying methods were identified by principal component analysis (PCA), indicating that the drying methods caused significant variance in compound profiles. Subsequently, pairwise comparison of different dried powders was performed by partial least square discriminant analysis (PLS-DA). This resulted in a selection of discriminative volatile and non-volatile markers, which could be related to flavour quality variance of tomato powder caused by the different drying methods. RWD and VDD produced powders with high volatile markers that can be related to preservation of aroma. While DD dried products contained more non-volatile markers that can be related to flavour perception. ATFD processed powders had a lower level of discriminant compounds. The results and approach used in the study provide interesting insight on the impact of different drying technologies on tomato powder quality, and may benefit efficient drying of high quality tomato powder and even other vegetable powders. 


\subsection{Introduction}

Tomato (Lycopersicum esculentum) is a healthy source of nutrients such as fibres, proteins, vitamins, lycopene and other antioxidants ${ }^{1,2}$. With a water content of around $94 \%$, fresh tomatoes are easily perishable resulting in wastes and losses, thus drying is commonly applied for preservation.

Conductive drying is a good option to dry tomato puree into powders, as it is energy efficient and especially suitable for highly viscous (food) products ${ }^{3,4}$. Throughout the years different types of conductive dryers have been developed, such as drum dryers (DD), agitated thin film dryers (ATFD) and refractance window dryers (RWD) ${ }^{5-7}$.

Drum drying is successfully applied with viscous pasty or pureed foods, such as pre-gelatinized starches, mashed potatoes, caseinate and fruit purees ${ }^{\mathbf{8}-10}$. The puree is applied to the outer surface of the rotating drum, where it is rapidly dried by heat supplied through the steel wall by steam condensing inside the drum ${ }^{11}$. The dried product film is then scraped off from the drum surface, which allows reuse of the hot drum surface. Drum drying is one of the more energy-efficient drying techniques as it consumes on average $40 \%$ less energy than spray drying ${ }^{6}$, but the product is exposed to high temperatures, which can result in severe quality loss. The thermal damage can be alleviated by applying reduced pressure to lower the boiling temperature, although the capital costs of vacuum drum dryers (VDD) remain a concern ${ }^{12}$.

Agitated thin film drying (ATFD) is a continuous drying process carried out under reduced pressure. The ATFD mainly consists of a cylindrical drying chamber with a heating jacket and an internal rotor with fixed blades. The blades agitate and spread the liquid feed as a thin film across the heated surface. The liquid flows down by gravity and progressively passes through different phases, from liquid, to a paste and finally into a solid. The dried solid product is fractured by the rotor blades into smaller particles. The entire process can be easily operated under reduced pressure and is therefore suitable for heat and oxygen sensitive products ${ }^{7}$. Nevertheless, successful drying with an ATFD is strongly dependent on the material properties, such as its stickiness and 
viscoelasticity. A higher tip velocity of the blades provides stronger shearing, which can make the process more robust to the product properties, but it may also lead to local overheating due to friction and thermal damage to the product 12.

Refractance window drying (RWD) is a relatively new gentle drying technique, which has been applied on drying pureed or sliced fruits and vegetables under atmospheric conditions ${ }^{13-15}$. During RWD, a thin film of the food product is dried on a transparent polyethylene conveyor belt moving over circulating hot water. At the end of the drying process, the dried film moves over a cooling water bath, where the products cool down below its glass transition temperature to avoid stickiness and facilitate scraping-off ${ }^{16}$. RWD is aimed at heat sensitive products with a low drying temperature ${ }^{17}$. However, RWD has limitations with respect to capacity, throughput and scale-up, as very thin films need to be casted to accommodate reasonable drying rates.

Several studies evaluated the effects of different drying technologies on the perceived freshness and nutritional properties of various food products, such as asparagus, carrots, strawberry, mango, etc. ${ }^{14,18,19}$. However, no studies have yet been conducted to compare the effect of different conductive drying methods on tomato powders quality, especially in terms of the retention of taste and aroma specifically. The changes in perceived fresh-tomato flavour during the drying process can be related to loss and/or formation of specific volatile and non-volatile compounds, which have been described in previous studies ${ }^{20-}$ ${ }^{24}$. These changes may lead to the perception of lower quality by consumers ${ }^{25}$. Assessment of the volatile and non-volatile profiles in processed fruits and vegetable products, combined with multivariate data analysis, has been applied to investigate the process impact on flavour quality ${ }^{26-28}$. Nevertheless, to the best of our knowledge, no research has been performed to evaluate the effect of drying methods on the flavour quality of tomato powder by this approach.

The objective of this study is thus to create a better understanding of the relationship between organoleptic quality of tomato powders (colour and flavour) and conductive drying methods. The tomato powders were prepared 
with four conductive drying technologies (DD and VDD, ATFD and RWD) using different conditions (temperature and initial solid content). The flavour quality was evaluated by quantitatively determining the concentrations of key volatile and non-volatile compounds, which contribute to tomato flavour.

\subsection{Materials and Methods}

\subsubsection{Preparation of tomato puree}

The hot-break tomato puree used in this study was purchased from AGRAZ, S.A.U. (Badajoz, Spain). The tomato puree was sterilized and aseptically packed in multilayer polyethylene bags. The bags with puree were stored under freezing conditions in a galvanized steel drum, while transported to ILVO (Melle, Belgium), Bodec (Helmond, the Netherlands), ANDRITZ Gouda (Waddinxveen, the Netherlands), and Unilever R\&D (Vlaardingen, the Netherlands). The puree was kept frozen until it was ready for drying. The tomato puree was maintained at 20-22 ${ }^{\circ}$ Brix and $\mathrm{pH}$ 4.0-4.4 with a moisture content of $\sim 0.75 \mathrm{~kg} / \mathrm{kg}$ wet basis before drying.

\subsubsection{Drying experiments}

The frozen tomato puree was thawed just before it was used for drying. To vary the moisture content, a specific amount of puree was thoroughly mixed with added tap water. Thereafter, different batches of diluted tomato puree were obtained with moisture contents of $0.80,0.81$ and $0.82 \mathrm{~kg} / \mathrm{kg}$ wet basis. The range of the moisture content is small because the initial moisture content of the puree was restricted by the consistencies that could be used with the RWD. For the ATFD dryer, more diluted puree ( 0.86 and $0.93 \mathrm{~kg} / \mathrm{kg}$ wet basis) was needed. The prepared puree was dried to below $0.04 \mathrm{~kg} / \mathrm{kg}$ wet basis by regular and vacuum drum drying, agitated thin film drying or refractance window drying. The drying conditions of each experiment were shown in Supplementary data 6-1.

\subsubsection{Drum drying}

Two types of pilot scale double drum dryers, i.e. a regular drum dryer (DD) and a vacuum drum dryer (VDD), were utilised for drying tomato puree in this study. The DD (Tummers Machinebouw B.V., Hoogerheide, the Netherlands) 
had two hollow steel drums with $0.30 \mathrm{~m}$ external diameter and $0.30 \mathrm{~m}$ length. The drums were internally heated by steam with a pressure varying from 1.0 to 3.0 bars, which provided a hot wall temperature ranging from 99.6 to $133.5^{\circ} \mathrm{C}$. The rotation speed of the drums was set at $\sim 1.6 \mathrm{rpm}$. The VDD (ANDRITZ Gouda, Waddinxveen, the Netherlands) consisted of two steel drums with 0.20 $\mathrm{m}$ external diameter and $0.48 \mathrm{~m}$ length, was enclosed in a vacuum chamber and operated under reduced pressure (60 mbar). The drums rotated at a fixed speed of $~ 2.6 \mathrm{rpm}$ and a heating temperature ranging from 81.3 to $133.5^{\circ} \mathrm{C}$, by using steam of different pressures $(0.5$ to $3.0 \mathrm{bar})$. The vacuum chamber itself was maintained at $80{ }^{\circ} \mathrm{C}$ to prevent the condensation of vapour.

For both drum drying experiments, the clearance between the two drums was fixed at $0.2 \mathrm{~mm}$. The drum temperature was first stabilised before feeding the puree to the dryer. The prepared puree with different moisture contents $(0.80$ to $0.82 \mathrm{~kg} / \mathrm{kg}$ wet basis) was poured manually and evenly over the hot feeding pool and passed through the gap of the drums forming a thin layer attaching on the drum surface. After traveling approximately three fourths of the drum circumference, the dried sample was scraped from the drum surface by doctor blades. The dried product collected from the same drying conditions was mixed together for further analysis.

\subsubsection{Agitated thin film drying (ATFD)}

A pilot scale ATFD dryer was used to dry tomato puree (Bodec, Helmond, the Netherlands). The ATFD dryer consisted of a cylindrical drying chamber with a heating jacket and a rotor with three fixed blades. The drying chamber had an internal diameter of $0.20 \mathrm{~m}$ and an effective length of $0.40 \mathrm{~m}$, and the diameter of the blades was $0.198 \mathrm{~m}$. The clearance between the blade tip and the hot surface was $1.0 \mathrm{~mm}$. Before drying, the drying chamber was pre-heated by steam via the wall to the required temperature $\left(60,75\right.$ or $\left.80{ }^{\circ} \mathrm{C}\right)$. The prepared puree (0.86 and $0.93 \mathrm{~kg} / \mathrm{kg}$ wet basis) was then pumped into the system with a flow rate of $6 \mathrm{~kg} / \mathrm{h}$. The rotation speed of the blades was varied from 500 to $700 \mathrm{rpm}$, depending on the possibility of scraping the dried product from the drying surface. The dried product was collected at the bottom 
of the dryer for further analysis. The whole system was operated under a reduced pressure of 50 mbar.

\subsubsection{Refractance window drying (RWD)}

Refractance window drying was performed with a custom made system (ILVO, Melle, Belgium). The total effective length of the dryer was $3 \mathrm{~m}$ in the direction of the belt motion, including a heating part of $2 \mathrm{~m}$ and a cooling part of $1 \mathrm{~m}$. The conveyor belt was made of polyethylene terephthalate (Mylar). During drying, the prepared puree ( 0.80 to $0.82 \mathrm{~kg} / \mathrm{kg}$ wet basis) was continuously applied to the plastic conveyor belt with a film thickness of $\sim 1.5 \mathrm{~mm}$. The film of puree was gradually dried while conveyed across the surface of recirculating hot water $\left(85\right.$ and $\left.95^{\circ} \mathrm{C}\right)$, and then was cooled down by recirculating cold water $\left(30{ }^{\circ} \mathrm{C}\right)$. The water removal from the film was facilitated by an air suction hood $\left(\sim 20{ }^{\circ} \mathrm{C}\right)$ over the puree at an average air velocity of $1.5 \mathrm{~m} / \mathrm{s}$. The belt was set in motion with a speed of $0.1 \mathrm{~m} / \mathrm{min}$. At the end of the belt, the dried product was scraped off the belt and collected for further analysis.

\subsubsection{Colour measurements of reconstituted tomato puree}

For colour measurements $\sim 5 \mathrm{~g}$ of dried tomato powder was reconstituted by adding hot distilled water to attain the water content similar to that of the original tomato puree. The reconstituted puree was mixed with a spatula until a homogeneous puree was obtained. Subsequently, it was stored at room temperature for $24 \mathrm{~h}$ for full hydration. The prepared sample was transferred in a $5 \mathrm{~cm}$ diameter transparent PE petri dish. Their colour parameters $\left(\mathrm{L}^{*}, \mathrm{a}^{*}\right.$, and $b^{*}$ ) were measured with a colorimeter (Colorquest XE, Hunterlab, Murnau, Germany), with the original tomato puree as a reference. The total colour difference between original and reconstituted puree $\left(\Delta E^{*}\right)$ was calculated by:

$$
\Delta E^{*}=\sqrt{\left(\mathrm{L}_{\text {sample }}^{*}-\mathrm{L}_{\text {ref }}^{*}\right)^{2}+\left(\mathrm{a}_{\text {sample }}^{*}-\mathrm{a}_{\text {ref }}^{*}\right)^{2}+\left(\mathrm{b}_{\text {sample }}^{*}-\mathrm{b}_{\text {ref }}^{*}\right)^{2}} \quad \text { Eq. 6-1 }
$$

All measurements were conducted in duplicate.

\subsubsection{HS-SPME-GC-MS analysis of volatiles}

$\sim 1 \mathrm{~g}$ reconstituted puree was homogenised in a $20 \mathrm{~mL}$ headspace vial sealed with a screw cap and a PTFE/silicon septum (Supelco, Sigma-Aldrich, 
Zwijndrecht, the Netherlands). The vial was heated at $60{ }^{\circ} \mathrm{C}$ for $30 \mathrm{~min}$. Subsequently, the headspace vial was exposed to a PDMS fibre (Agilent Technologies, Santa Clara, USA) to adsorb the volatile compounds. This fibre had been preconditioned at $250{ }^{\circ} \mathrm{C}$ for $30 \mathrm{~min}$ before use. After extraction, the fibre was transferred to the injection port of a GC-MS, where the adsorbed volatiles were thermally desorbed for $1 \mathrm{~min}$ at $250{ }^{\circ} \mathrm{C}$. The GC-MS analysis was conducted on an Agilent 7890A-5975C system (Agilent Technologies, Santa Clara, USA), equipped with an MPS autosampler (Gerstel, Mülheim, Germany). The volatiles were injected in splitless mode, and separated on a DB-Wax column with $20 \mathrm{~m} \times 0.18 \mathrm{~mm}$ and $0.3 \mu \mathrm{m}$ film thickness (Agilent Technologies, Santa Clara, USA). Helium was the carrier gas with a constant rate of 1 $\mathrm{mL} / \mathrm{min}$. The column oven started with a temperature of $35{ }^{\circ} \mathrm{C}$ for $4 \mathrm{~min}$. It was then heated to $230{ }^{\circ} \mathrm{C}$ with a rate of $4.6{ }^{\circ} \mathrm{C} / \mathrm{min}$ and maintained at this temperature for $4 \mathrm{~min}$. Mass spectra were obtained by electron ionisation at $1758 \mathrm{eV}$, with a scanning range of $20-250 \mathrm{~m} / \mathrm{z}$. MS ion source and quadrupole temperatures were 230 and $150{ }^{\circ} \mathrm{C}$, respectively. All the measurements were conducted in triplicate.

The obtained chromatograms were processed using ChemStation and MassHunter software (Agilent Technologies, Santa Clara, USA). The peak areas were used for multivariate data analysis.

\subsubsection{NMR spectrometry analysis of non-volatiles}

\subsubsection{Materials}

Deuterated water $\left(\mathrm{D}_{2} \mathrm{O}, 99.96 \%\right.$ atom) was purchased from Euriso-top (Saclay, France). Ethylenediaminetetraacetic- $\mathrm{d}_{12}$-acid (EDTA- $\mathrm{d}_{12}, 98 \%$ atom) was purchased from Cambridge Isotope Laboratories, Inc (Tewksbury, USA). 3(Trimethylsilyl)propionic-2,2,3,3- $\mathrm{d}_{4}$ acid, sodium salt (TSP-D 4 , 98\% atom) was purchased from Sigma-Aldrich ${ }^{\circledR}$ (Zwijndrecht, the Netherlands). (Difluorotrimethylsilanyl-methyl)phosphonic acid (DFTMP) was purchased from Bridge Organics Co (Vicksburg, USA). 


\subsubsection{Sample preparation}

Tomato powder $(50 \mathrm{mg})$ was dissolved in $3 \mathrm{~mL} \mathrm{D} \mathrm{D}_{2} \mathrm{O}$. Next, $600 \mu \mathrm{L}$ of this sample solution were diluted with $100 \mu \mathrm{L}$ of internal standard solution $(0.2$ $\mathrm{mg} / \mathrm{mL}$ of TSP- $\mathrm{d}_{4}$ and $0.1 \mathrm{mg} / \mathrm{mL}$ DFTMP in $\left.\mathrm{D}_{2} \mathrm{O}\right), 100 \mu \mathrm{L}$ of $5 \mathrm{mg} / \mathrm{mL}$ EDTA- $\mathrm{d}_{12}$ solution in $\mathrm{D}_{2} \mathrm{O}$ and $300 \mu \mathrm{L}$ of $0.2 \mathrm{M}$ phosphate buffer in $\mathrm{D}_{2} \mathrm{O}(\mathrm{pD}$ 7.4, containing $0.05 \% \mathrm{w} / \mathrm{w} \mathrm{NaN}_{3}$ in $\mathrm{D}_{2} \mathrm{O}$ ). The NMR sample solution was mixed for 3 minutes using an Eppendorf Thermomixer ${ }^{\circledR} \mathrm{C}$ (Hamburg, Germany) at room temperature. Then the solution was centrifuged at 17,000 $\mathrm{g}$ and room temperature for $5 \mathrm{~min}$. Subsequently, $650 \mu \mathrm{L}$ of the supernatant was transferred to a $5 \mathrm{~mm}$ NMR tube for analysis.

\subsubsection{NMR spectrometry analysis}

1D ${ }^{1} \mathrm{H}$ NMR spectra were recorded at $25{ }^{\circ} \mathrm{C}$ on a Bruker Avance III 600 NMR spectrometer (Bruker BioSpin GmbH, Rheinstetten, Germany) equipped with a $5 \mathrm{~mm}$ cryoprobe. The probe was tuned to detect ${ }^{1} \mathrm{H}$ resonances at 600.25 MHz. 64 scans were collected in data points of $57 \mathrm{k}$ with a relaxation delay of $10 \mathrm{~s}$, an acquisition time of $4 \mathrm{~s}$ and a mixing time of $100 \mathrm{~ms}$. Low power water suppression $(16 \mathrm{~Hz})$ was applied for $0.99 \mathrm{~s}$. The resultant data were processed in TopSpin software Version 3.5 pl 1 (Bruker BioSpin GmbH, Rheinstetten, Germany). The data of the free induction decay (FID) were Fourier transformed after multiplying by an exponential window function with a linebroadening factor of $0.15 \mathrm{~Hz}$. Manual phase and baseline correction was applied to all $1 \mathrm{D}{ }^{1} \mathrm{H}$ NMR spectra. The spectra were referenced against the methyl signal of TSP ( $\delta 0.0 \mathrm{ppm})$. The measurements were carried out in duplicate.

The NMR spectra were imported in Chenomx software (Chenomx NMR Suite Professional v7.63, Edmonton, Alberta, Canada) to calculate the concentrations of the pre-selected target non-volatile compounds. The concentrations of the compounds were expressed as milligram per gram sample $(\mathrm{mg} / \mathrm{g})$. A relative error of $10 \%$ was taken into account. 


\subsubsection{Multivariate data analysis}

Experimental data of volatiles and non-volatiles were used for multivariate data analysis using SIMCA 14 (Sartorius Stedim, Malmö, Sweden). As a preprocessing step, all data were mean-centred and then weighed by their standard deviation to give them equal variance. Hereafter, principal component analysis (PCA) was performed to evaluate the variance of each sample and detect outliers without considering the information of the classes (i.e. drying methods). Subsequently, in order to detect the inter-class variance (differences between the samples dried with different conductive drying technologies), partial least square discriminant analysis (PLS-DA) was carried out. For PLS$\mathrm{DA}$, different volatiles and non-volatiles were considered as $\mathrm{X}$-variables and the four drying techniques as categorical $\mathrm{Y}$-variables. Considering the complexity of PLS-DA, only pairwise comparison was performed (in total 6 comparisons). The lowest number of latent variables $(\mathrm{LVs})$ resulting in the separation was selected for each comparison. To assess model performance, a permutation test was conducted and $r^{2}$ (goodness of fit) and $Q^{2}$ (goodness of prediction) values were calculated.

Variable importance in projection (VIP) scores were calculated to identify discriminant compounds, which contributed the most to the explanation of $\mathrm{Y}$ variable variance estimated by PLS-DA. In the present work, X-variables with a VIP score higher than 1 were considered as discriminant markers.

\subsection{Results and discussions}

\subsubsection{Performance of the four drying technologies for producing tomato powders}

The four dryers required different preconditioning. The original tomato puree $(0.75 \mathrm{~kg} / \mathrm{kg}$ wet basis) could be directly fed to the DD and VDD, while the RWD and ATFD required some dilution.

For DD and VDD, significant amounts of water were evaporated during boiling in the feeding pool. After the tomato passed through the gap between the two drums, it formed a moist, semi-solid film without visible boiling, as bubbles could not nucleate and grow ${ }^{29}$. It is assumed that water vapour 
migrates through pores in the film from the evaporation front inside the film towards to the surface of the film until the film has completely dried ${ }^{30}$. The drying processes lasted $\sim 17$ and $\sim 28$ s for VDD and DD, respectively.

For RWD, dilution of the feed was required due to the applicator design, the minimum belt speed and the maximum drying temperature of the applied RWD: the original puree was too viscous to be formed into a homogeneous thin film, while a puree that was too diluted could not be totally dried. At a drying temperature of $85{ }^{\circ} \mathrm{C}$ only the puree with a water content of $0.80 \mathrm{~kg} / \mathrm{kg}$ could be successfully dried. Due to the low drying temperature $\left(<95{ }^{\circ} \mathrm{C}\right)$, no boiling took place, and water evaporated due to the difference in relative humidity between the air and the film. Thus, the residence time of RWD $(\sim 30$ min) was much longer than that of drum drying.

For ATFD, also dilution of the original puree had to be carried out ( 0.86 and $0.93 \mathrm{~kg} / \mathrm{kg}$ wet basis). The puree with a moisture content of $0.86 \mathrm{~kg} / \mathrm{kg}$ could only be dried at low temperatures $\left(60^{\circ} \mathrm{C}\right)$. At higher temperatures, the concentrated puree transformed into a sticky mass forming large lumps, which could not be easily dried and scraped from the wall. Unfortunately, it is impossible to visually inspect the drying behaviour in the stainless steel ATFD equipment. The relatively difficult drying of tomato puree in ATFD could be related to its high concentration of glucose and fructose, which contributed to sticky behaviour during drying ${ }^{12}$. The rotation speed of the blades had to be well controlled as well: faster rotation facilitates powder formation, but can also lead to local overheating and damage to the product. Therefore the feed rate, feed moisture, drying temperature and blade rotation speed should be well tuned for proper operation of ATFD. To conclude, RWD and ATFD are more challenging in their operation and require more optimization for successful drying of tomato puree.

The different drying methods resulted in different product morphology (Figure 6-1). DD and RWD yielded smooth, thin flakes. VDD produced a sausage-like product due to the high chamber temperature $\left(80{ }^{\circ} \mathrm{C}\right)$ : after scraping-off, the film remained in the rubbery state and thus curled into a sausage shape along 
with the rotation of the drums ${ }^{31}$. During ATFD, the product was fractured into small particles by the rotating action of the blades.

(A) Vacuum drum drying

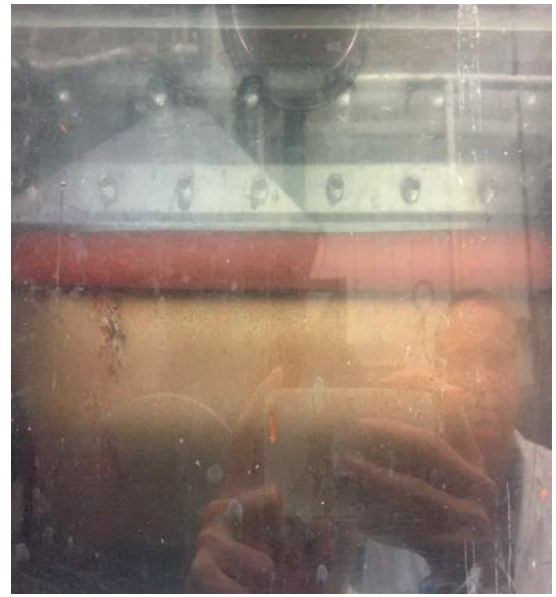

(C) Refractance window drying

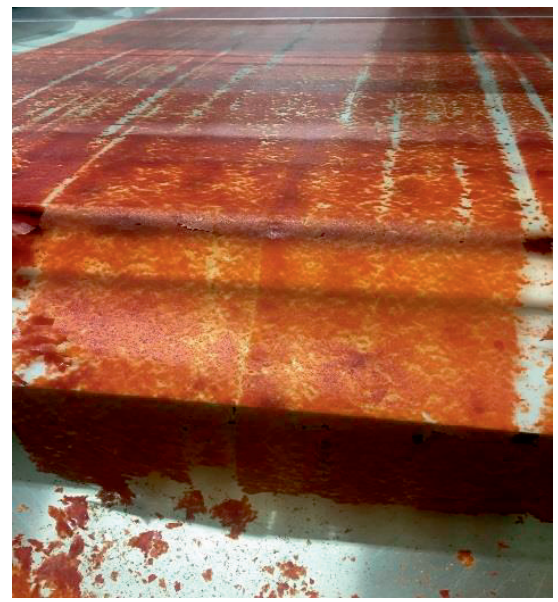

(B) Drum drying

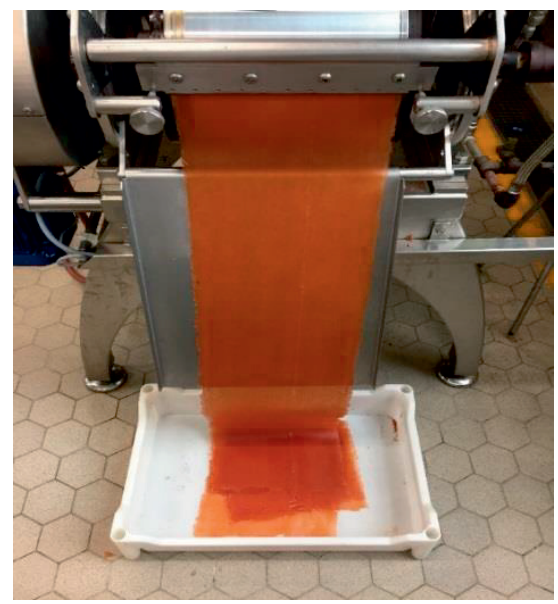

(D) Agitated thin film drying

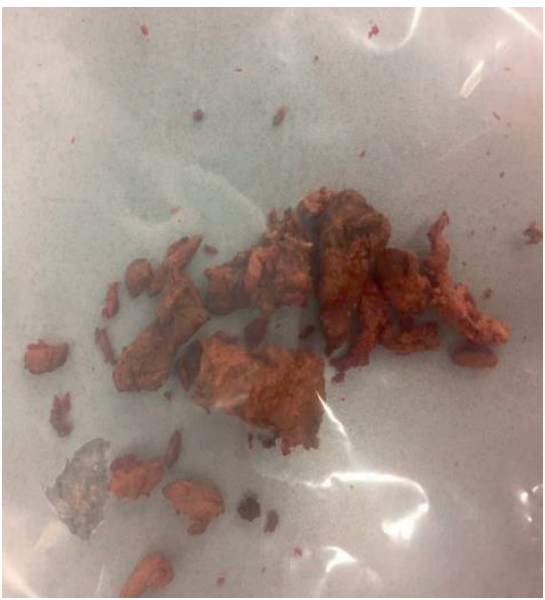

Figure 6-1 Visual images of the tomato powders produced from (A) vacuum drum drying; (B) drum drying; (C) refractance window drying and (D) agitated thin film drying.

\subsubsection{Impact of drying technologies on colour}

Figure 6-2 shows the luminosity values of the reconstituted tomato purees. All reconstituted samples had lower $\mathrm{L}^{*}$ values than the reference (original tomato puree) indicating a darker colour. This may be attributed to non-enzymatic 
browning (Maillard reaction) during drying ${ }^{18}$. Comparing each drying method, the $\mathrm{L}^{*}$ values of VDD (except the samples dried at $133.5^{\circ} \mathrm{C}$ ) and $\mathrm{DD}$ dried samples were closer to the reference than those from RWD and ATFD. The reconstituted ATFD dried puree was darker, due to local overheating by the blade rotation, in spite of the low drying temperature. Overheating might lead to caramelization of sugars contributing to darkening during drying. The colour degradation was more pronounced at a higher rotation speed. The unexpected darker samples produced by RWD could be attributed to the long drying time, and the extended exposure to oxygen. As the product stayed in a moist state with high water activity for long time, more browning or Maillard reactions might occur, although the drying temperature was much lower than during VDD and DD. The impact of temperature was more pronounced for VDD than the other methods. The possible reason could be that during VDD the product temperature quickly increases to the wall temperature, leading to more pronounced overheating and darkening. The effect of the moisture content on the feed was limited due to the small range of the moisture content considered.

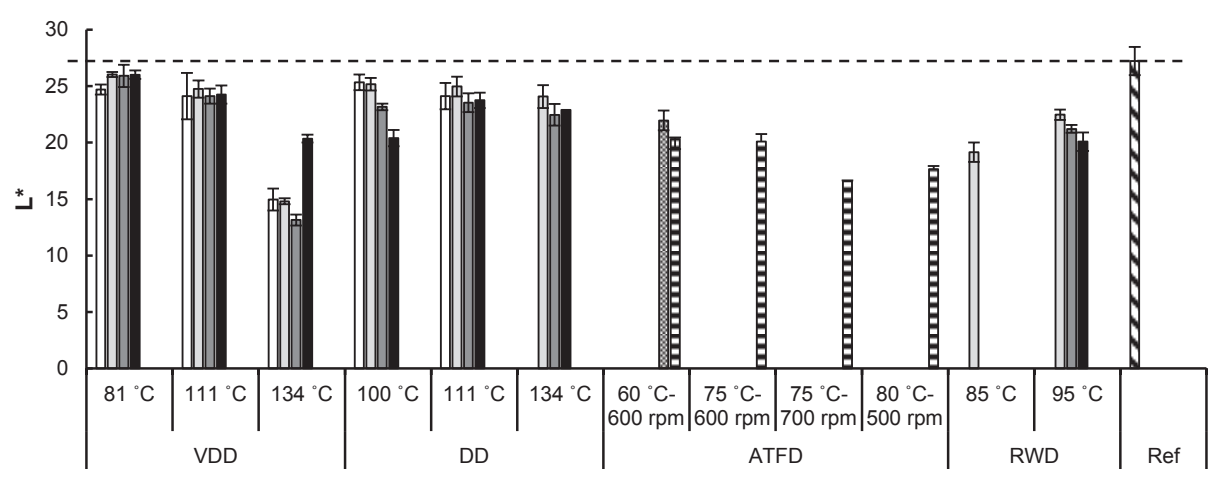

Figure 6-2 Luminosity of reconstituted tomato powders dried from puree of varying initial feed moisture contents at different drying conditions: $0.75 \mathrm{w} / \mathrm{w}$ (white bars); $0.80 \mathrm{w} / \mathrm{w}$ (light grey bars); $0.81 \mathrm{w} / \mathrm{w}$ (dark grey bars); $0.82 \mathrm{w} / \mathrm{w}$ (black bars); $0.86 \mathrm{w} / \mathrm{w}$ (bars with dots) and $0.93 \mathrm{w} / \mathrm{w}$ (bars with lines). The error bars represent the standard deviation of the experimental data $(n=2)$.

The colour of tomato puree is red, which is mainly due to the presence of lycopene ${ }^{32}$. It is commonly regarded as a measure of quality and can be represented by $a^{*}$ values (Figure 6-3). Similar to $L^{*}$, all reconstituted purees had 
lower $a^{*}$ values than the reference, mainly because of the degradation of lycopene during the process ${ }^{32}$. The decrease of $a^{*}$ was more pronounced with ATFD and RWD, probably also due to high blade rotation and long drying time, respectively. The impact of the temperature was more pronounced for VDD and DD. The higher temperature led to a decrease of $a^{*}$ in VDD, whereas an increase of $\mathrm{a}^{*}$ in DD. On one hand, a higher temperature may induce more lycopene degradation. On the other hand, an increased temperature leads to faster drying of the tomato matrix, which may prevent penetration of oxygen and limit the oxidation of the lycopene ${ }^{33}$. For VDD, the effect of temperature is dominant since the vacuum creates a low-oxygen environment. For the DD, the influence of oxidation is probably more pronounced. Again, the impact of moisture content was limited.

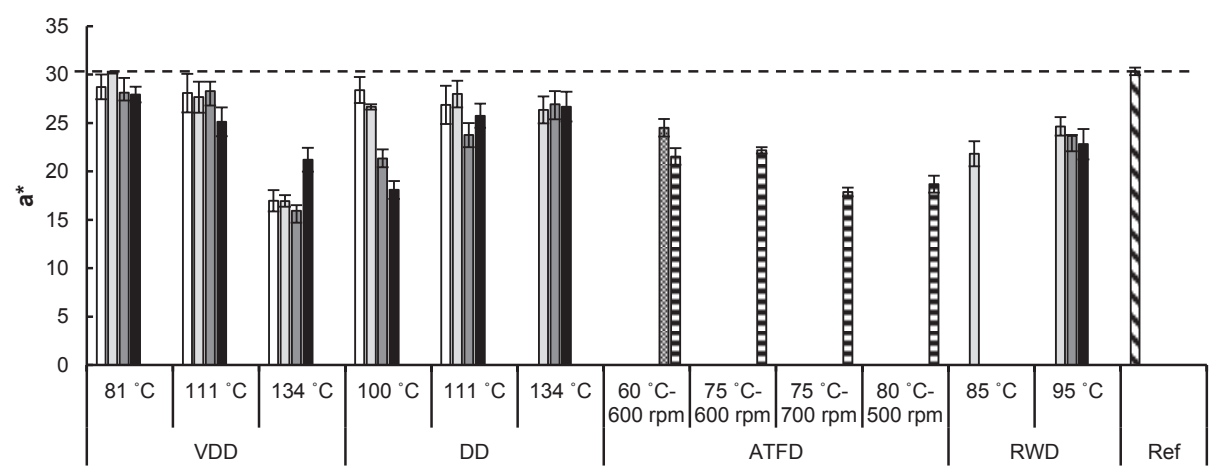

Figure 6-3 Redness of reconstituted tomato powders dried from puree of varying initial feed moisture contents at different drying conditions: $0.75 \mathrm{w} / \mathrm{w}$ (white bars); $0.80 \mathrm{w} / \mathrm{w}$ (light grey bars); $0.81 \mathrm{w} / \mathrm{w}$ (dark grey bars); $0.82 \mathrm{w} / \mathrm{w}$ (black bars); $0.86 \mathrm{w} / \mathrm{w}$ (bars with dots) and $0.93 \mathrm{w} / \mathrm{w}$ (bars with lines). The error bars represent the standard deviation of the experimental data $(\mathrm{n}=2)$.

Figure 6-4 shows the total colour difference between the reconstituted puree. The VDD $\left(81.3{ }^{\circ} \mathrm{C}\right)$ and DD $\left(99.6{ }^{\circ} \mathrm{C}, 0.75 \mathrm{~kg} / \mathrm{kg}\right)$ dried samples had minimal colour changes, indicating that their colour quality was closest to that of the reference. Increasing temperature induced larger colour changes for VDD, while smaller changes were observed for DD. Especially for drying at $133.5^{\circ} \mathrm{C}$, VDD led to more significant colour changes than DD. This could be explained by a faster increase in the product temperature during VDD as the samples 
were dried much faster, which resulted in a longer exposure to a high temperature and thus more thermal damage. Therefore, under applied high wall temperatures, the drums of VDD could be rotated faster to shorten the residence time and to prevent overheating. Another option to reduce thermal damage is to use low-pressure steam to operate at lower drum wall temperature. Among the applied conditions, the effect of temperature and moisture content was not obvious for RWD and ATFD.

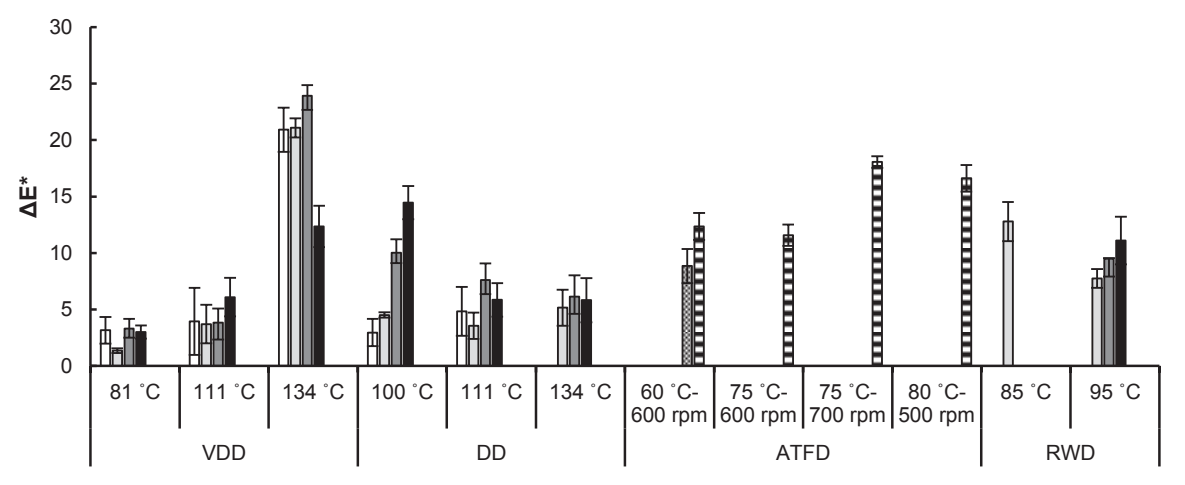

Figure 6-4 Total colour difference of reconstituted tomato powders dried from puree of varying initial feed moisture contents at different drying conditions: $0.75 \mathrm{w} / \mathrm{w}$ (white bars); $0.80 \mathrm{w} / \mathrm{w}$ (light grey bars); $0.81 \mathrm{w} / \mathrm{w}$ (dark grey bars); $0.82 \mathrm{w} / \mathrm{w}$ (black bars); $0.86 \mathrm{w} / \mathrm{w}$ (bars with dots) and $0.93 \mathrm{w} / \mathrm{w}$ (bars with lines). The error bars represent the standard deviation of the experimental data $(n=2)$.

\subsubsection{Impact of drying technologies on volatile and non-volatile profiles}

To assess the effect of the conductive drying methods on tomato flavour quality, we determined the concentrations of volatile and non-volatile compounds in the tomato powders. We selected 14 volatiles and 16 nonvolatile compounds that are key compounds for flavour of tomato products (shown in Supplementary data 6-2) 20, 21, 34. Some key volatile compounds, previously reported, e.g. hexanal, cis-3-hexenal, hexanol and cis-3-hexenol ${ }^{21}$, were not detected either in the tomato powders or the original tomato puree, possibly due to the hot-break process used for the production of the starting puree. These volatiles, known as $\mathrm{C}_{6}$ aldehydes, are derived from the oxidation of fatty acids via the lipoxygenase pathway. Inactivation of the enzymes at higher temperatures during hot-break (ranging from $85-100{ }^{\circ} \mathrm{C}$ ) resulted in 
the reduced generation of these volatiles ${ }^{35}$. In addition, the hot-break processing may have further reduced their level especially that of cis-3-hexenal, because of their instability to heat and metal surfaces ${ }^{36-38}$.

\subsubsection{Principal component analysis (PCA)}

Principal component analysis was first applied to the data of volatiles and nonvolatiles. The first two principal components (PCs) could explain 33.6\% and $21.0 \%$ of the total variability, respectively. The score plot (Figure 6-5) showed the differences in the volatile and non-volatile profiles of the different tomato powders. Four separated groups could be identified, corresponding to the different drying methods, which indicates that the variance of the compound profiles caused by the drying methods was more significant than that caused by the drying conditions within a single drying technology, i.e. temperature and initial moisture content.

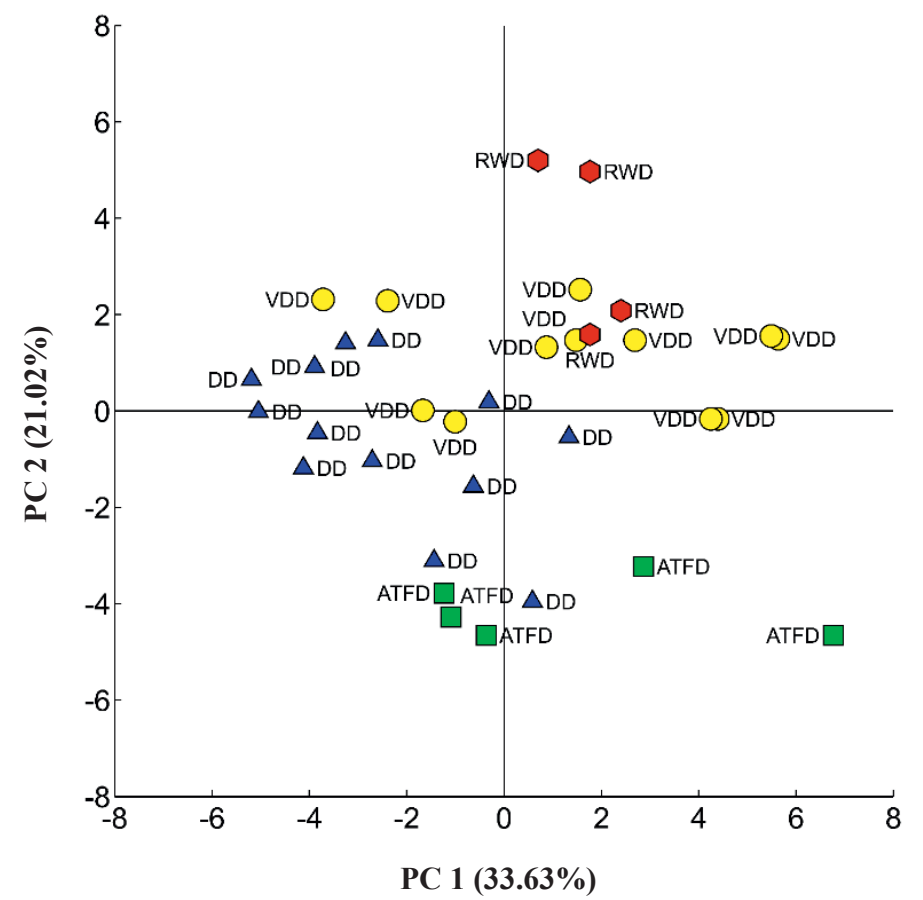

Figure 6-5 A score plot of the PCA performed on the volatile and non-volatile data of the tomato powders obtained from: vacuum drum drying (yellow circle), regular drum drying (blue triangle), agitated thin film drying (green square) and refractance window drying (red diamond). The variance explained by each component is indicated on the respective axis. 


\subsubsection{Partial least square discriminant analysis (PLS-DA)}

In order to further understand the variance, partial least square discriminant analyses (PLS-DA) were carried out to pairwise compare each drying method. All PLS-DA models had $\mathrm{Q}^{2}$ values $>0.5$ and were statistically significant, indicating that the groups could be discriminated beyond chance ${ }^{39}$. All the PLS-DA models were validated without overfitting according to permutation tests (Supplementary data 6-3).

A PLS-DA bi-plot using the first two latent variables (LVs) was constructed to visualize the different impact of VDD and DD on tomato powder quality (Figure 6-6). The VDD and DD dried samples are well separated and their variance can be explained mainly by the first LV, indicating processing impact. The significance of the individual compounds for the discrimination of differently processed samples increased with their distance from the centre. In Figure 6-6, compounds with higher concentrations in the VDD dried samples are projected close to the VDD side (mainly in the left-hand side of the plots). In contrast, compounds located closer to the DD side, have lower concentration in the VDD dried powders. PLS-DA bi-plots of the other comparisons are not shown. 


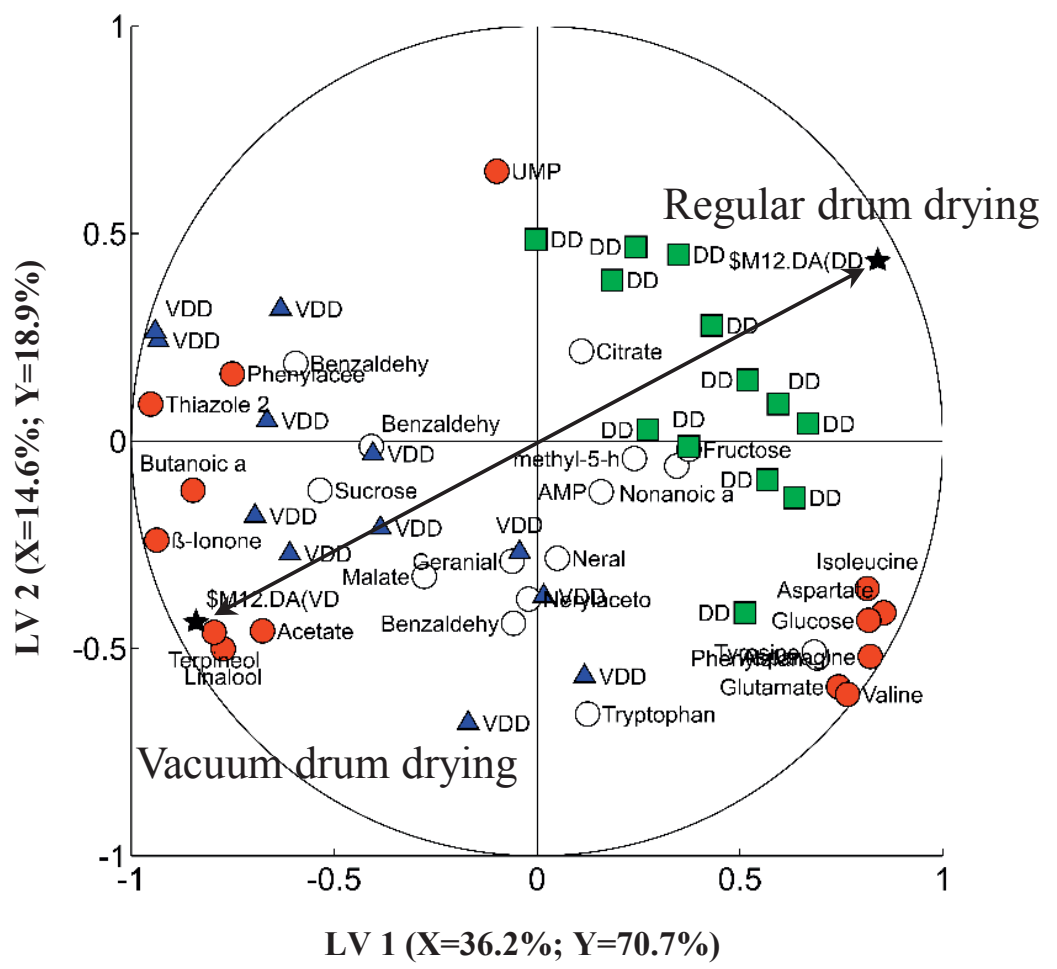

Figure 6-6 A PLS-DA bi-plot visualizing impact differences between vacuum drum drying (blue triangle) and regular drum drying (green square). The circles represent the volatile and non-volatile compounds detected, of which the selected discriminant compounds (VIP > 1) are highlighted in red. The vector and black stars represent the correlation loading for the categorical $\mathrm{Y}$-variables. The $\mathrm{X}$ - and $\mathrm{Y}$ - variance explained by each latent variable $(\mathrm{LV})$ is indicated on the respective axis.

To quantitatively rank the importance of volatiles to the discrimination between VDD and DD, variable-importance-in-projection (VIP) scores were calculated. In the present work, only compounds with VIP $>1$ were selected and considered as discriminant markers, and were highlighted in red (Figure 66). Table 6-1 shows the regression coefficients of the discriminant markers in the indicated class (VDD). Positive regression coefficients indicate higher concentrations in VDD, and vice versa. Six volatiles and eight non-volatiles markers were selected. Nine markers had positive coefficients, indicating their higher concentration in VDD dried powders. All the discriminative volatiles were detected in a higher abundance in VDD. 
The identification of the discriminative compounds provide valuable information about differences amongst drying technologies. For example, the higher concentration of 2-isobutylthiazole in VDD can be understood from the limited presence of oxygen in the vacuum chamber, as 2-isobutylthiazole is sensitive to oxidation ${ }^{40}$. Phenylacetaldehyde was also detected in larger amounts in VDD. This component can be associated with a cooked flavour, originating from Strecker degradation of amino acids (a minor pathway of the Maillard reaction) ${ }^{41}$. More Strecker and/or Maillard reactions could occur during VDD as the product temperature quickly increased to the wall temperature due to the fast drying and thus the product was exposed to high temperatures for longer time during the process. Conversely, many of the compounds with negative coefficients were amino acids in the VDD samples, which might also be explained by Strecker and/or Maillard reactions considering that amino acids are substrates for these reactions. In addition to the chemical changes, fast drying and solidification of the tomato matrix during VDD may also entrap volatiles in the matrix, facilitating the retention of volatiles despite the lower pressure that would in principle favour the release of volatiles ${ }^{40}$. 
Table 6-1 Discriminant volatile and non-volatile compounds, selected in tomato powders, based on VIP values. The compounds are listed in decreasing order of regression coefficients, where positive value indicates a higher concentration of a compound of the indicated class compared to the other; and negative value indicates lower concentration compared to the other class.

\begin{tabular}{|c|c|c|c|c|c|}
\hline \multicolumn{2}{|c|}{ VDD versus DD } & \multicolumn{2}{|c|}{ VDD versus ATFD } & \multicolumn{2}{|c|}{ VDD versus RWD } \\
\hline Compound & $\begin{array}{l}\text { Regression } \\
\text { coefficient } \\
\text { (VDD) }\end{array}$ & Compound & $\begin{array}{l}\text { Regression } \\
\text { coefficient } \\
\text { (VDD) }\end{array}$ & Compound & $\begin{array}{l}\text { Regression } \\
\text { coefficient } \\
\text { (VDD) }\end{array}$ \\
\hline$\alpha$-Terpineol & 0.17 & Geranial & 0.10 & Tryptophan & 0.14 \\
\hline Linalool & 0.16 & B-Ionone & 0.10 & Malate & 0.11 \\
\hline B-Ionone & 0.15 & Neral & 0.10 & Nerylacetone & 0.01 \\
\hline $\begin{array}{l}\text { 3-Methylbutanoic } \\
\text { acid }\end{array}$ & 0.12 & $\alpha$-Terpineol & 0.09 & 3-Ethylbenzaldehyde, & -0.06 \\
\hline Acetate & 0.12 & Tryptophan & 0.09 & $\begin{array}{l}\text { 6-Methyl-5-hepten-2- } \\
\text { one }\end{array}$ & -0.08 \\
\hline 2-Isobutylthiazole & 0.08 & Linalool & 0.08 & Geranial & -0.08 \\
\hline Phenylacetaldehyde & 0.03 & 2-Isobutylthiazole & 0.08 & Neral & -0.08 \\
\hline Valine & 0.02 & $\begin{array}{l}\text { 3-Methylbutanoic } \\
\text { acid }\end{array}$ & 0.07 & $\alpha$-Terpineol & -0.11 \\
\hline Glutamate & 0.01 & AMP & 0.07 & Linalool & -0.12 \\
\hline Asparagine & -0.004 & Nerylacetone & 0.07 & B-Ionone & -0.16 \\
\hline Glucose & -0.01 & Citrate & 0.07 & & \\
\hline Aspartate & -0.04 & Malate & 0.06 & & \\
\hline Isoleucine & -0.06 & Nonanoic acid & -0.07 & & \\
\hline UMP & -0.11 & & & & \\
\hline \multicolumn{2}{|c|}{ DD versus ATFD } & \multicolumn{2}{|c|}{ DD versus RWD } & \multicolumn{2}{|c|}{ ATFD versus RWD } \\
\hline Compound & $\begin{array}{l}\text { Regression } \\
\text { coefficient } \\
\text { (DD) }\end{array}$ & Compound & $\begin{array}{l}\text { Regression } \\
\text { coefficient } \\
\text { (DD) }\end{array}$ & Compound & $\begin{array}{l}\text { Regression } \\
\text { coefficient } \\
\text { (ATFD) }\end{array}$ \\
\hline AMP & 0.16 & AMP & 0.09 & Nonanoic acid & 0.07 \\
\hline Citrate & 0.15 & 3-Ethylbenzaldehyde & -0.08 & $\begin{array}{l}\text { 6-Methyl-5-hepten-2- } \\
\text { one }\end{array}$ & -0.06 \\
\hline$\alpha$-Terpineol & 0.13 & 2-Isobutylthiazole & -0.10 & Nerylacetone & -0.07 \\
\hline Geranial & 0.08 & $\begin{array}{l}\text { 3-Methylbutanoic } \\
\text { acid }\end{array}$ & -0.11 & AMP & -0.07 \\
\hline Neral & 0.07 & $\alpha$-Terpineol & -0.13 & Neral & -0.08 \\
\hline Fructose & 0.05 & Linalool & -0.13 & Geranial & -0.08 \\
\hline Glucose & 0.05 & B-Ionone & -0.13 & Citrate & -0.09 \\
\hline Tryptophan & 0.04 & & & 2-Isobutylthiazole & -0.09 \\
\hline Isoleucine & 0.03 & & & Linalool & -0.09 \\
\hline Asparagine & 0.03 & & & $\begin{array}{l}\text { 3-Methylbutanoic } \\
\text { acid }\end{array}$ & -0.09 \\
\hline Aspartate & 0.03 & & & B-Ionone & -0.10 \\
\hline Valine & 0.03 & & & $\alpha$-Terpineol & -0.10 \\
\hline Glutamate & 0.02 & & & & \\
\hline Acetate & -0.15 & & & & \\
\hline
\end{tabular}


Comparing the impacts of VDD and ATFD on product quality, eight volatiles and five non-volatiles were selected as markers (Table 6-1). Most compounds (twelve) had positive regression coefficients, indicating they were more abundant in the VDD class. Similar results were observed when comparing ATFD with DD or RWD. The comparison between DD and ATFD showed that thirteen of the fourteen markers (three volatiles and eleven non-volatiles) were in higher concentration in DD dried powders (Table 6-1). Regarding ATFD versus RWD, eleven of the thirteen markers (eleven volatiles and two non-volatiles) were more retained in RWD (Table 6-1). These findings show that ATFD retained less flavour compounds than the others, under the applied drying conditions. This may be due to the thermal damage induced by the fast blade rotation. Therefore, more optimization of the processing parameters, i.e. feed moisture content and blade rotation speed, etc., is necessary in order to produce tomato powders of higher quality.

When comparing RWD with VDD, ten markers (eight volatiles and two nonvolatiles) were selected, while seven of them had negative regression coefficients in VDD. Similarly, in the comparison of RWD and DD, six of the seven markers had a negative coefficient in DD. In both comparisons, all the discriminative volatiles (except nerylacetone) were detected in high levels in RWD (Table 6-1). The reason could be attributed to the low operating temperatures $\left(<95{ }^{\circ} \mathrm{C}\right)$ applied in RWD, resulting in less release of volatiles from tomato puree. The more abundant volatiles might contribute to higher aroma retention in RWD processed products. Specifically, for VDD compared to RWD, a lower concentration of 6-methyl-5-hepten-2-one in VDD could also be related to the absence of oxygen in VDD. 6-methyl-5-hepten-2-one is regarded as a marker compound for lycopene degradation as it forms when lycopene is oxidized ${ }^{42,43}$. This was also consistent with the observation that VDD dried powders had higher $\mathrm{a}^{*}$ values than RWD.

Concluding, RWD processing has the best potential to produce powders with a high level of volatile compounds (i.e. retained aromas), followed by VDD. Although DD processing led to lower levels of volatiles compared to RWD and VDD, it produced powders with more non-volatiles, known to contribute 
to overall taste of tomato. ATFD processed powders contained lowest amount of (non)-volatiles compared to other conductive drying technologies, making ATFD probably less suitable for drying of tomato products.

\subsubsection{Changes of discriminative compounds during drying processes}

To further substantiate differences between the drying methods, Figure 6-7 shows the individual plots of several discriminative markers. The concentrations of these markers were also compared to the original tomato puree (as a reference) to visualise how they changed after drying. It can be observed that phenylacetaldehyde and 6-methyl-5-hepten-2-one had higher concentration in the tomato powders. Especially, formation of phenylacetaldehyde was more pronounced for VDD at high temperature, probably because more Strecker/Maillard reactions occurred. Formation of 6methyl-5-hepten-2-one in VDD and ATFD dried powders was less than RWD and DD, which is related to less oxidation of lycopene in a low oxygen environment. Differently, the concentration of B-ionone decreased during drying probably due to its low boiling point ${ }^{44}$. RWD dried powders had the highest $\beta$-ionone level practically similar to the reference, due to its mild operating conditions. Again, all the dried powders, except those obtained from $\mathrm{DD}$ at $100{ }^{\circ} \mathrm{C}$ and $0.82 \mathrm{w} / \mathrm{w}$, contained less glutamate (known as a marker for umami taste) compared to the reference. One possible reason could be that glutamate converted into pyroglutamic acid during thermal processing, which contributes to a more bitter and undesirable sour taste of the product ${ }^{1}$. 

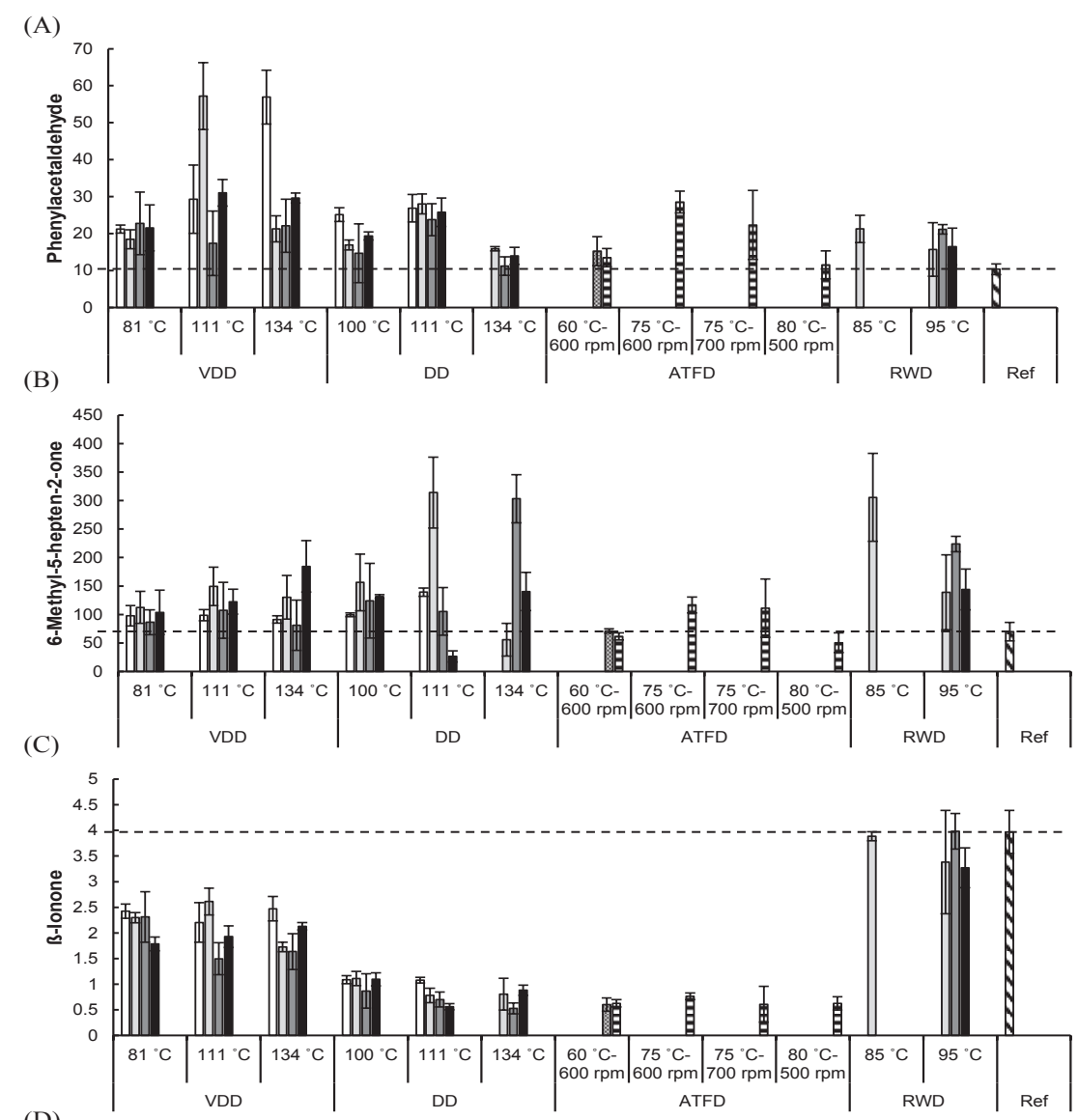

(D)

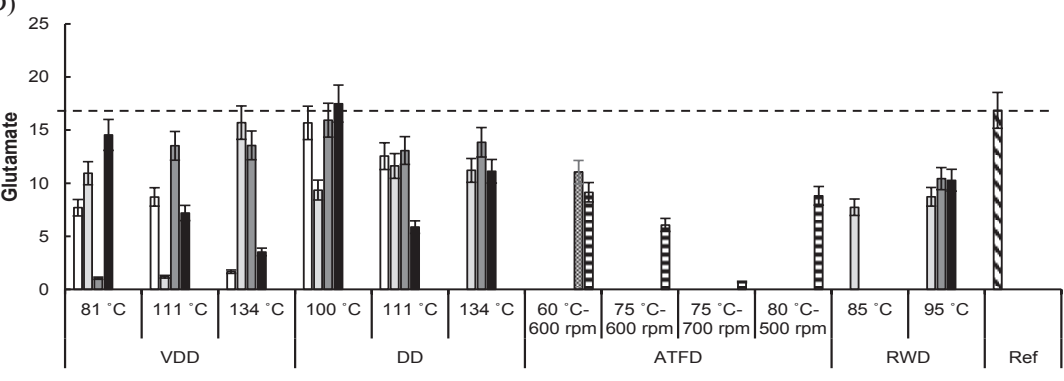

Figure 6-7 Discriminative components (A) phenylacetaldehyde, (B) 6-methyl-5hepten-2-one, (C) B-ionone and (D) glutamate of reconstituted tomato powders dried from puree of varying initial feed moisture contents at different drying conditions: 0.75 $\mathrm{w} / \mathrm{w}$ (white bars); $0.80 \mathrm{w} / \mathrm{w}$ (light grey bars); $0.81 \mathrm{w} / \mathrm{w}$ (dark grey bars); $0.82 \mathrm{w} / \mathrm{w}$ (black bars); $0.86 \mathrm{w} / \mathrm{w}$ (bars with dots) and $0.93 \mathrm{w} / \mathrm{w}$ (bars with lines). The Y-axis of volatiles indicates the peak area $\times 10^{5}$. The error bars represent the standard deviation of the experimental data $(\mathrm{n}=3)$. The $\mathrm{Y}$-axis of non-volatiles indicates the concentration in $\mathrm{mg} / \mathrm{g}$. The error bars represent the standard deviation of the experimental data $(\mathrm{n}=2)$. 


\subsection{Conclusions}

Tomato puree was dried into powders applying four conductive drying methods and the organoleptic quality (colour and flavour) of the resulting powder was compared. Operation of RWD and ATFD was more challenging than DD and VDD because more optimization of the processing conditions, i.e. feed moisture content, drying temperature and blade rotation speed (for ATFD), was needed.

The drying methods strongly affected the final powder morphology of the dried products. DD and RWD produced smooth thin flakes, while VDD dried products were sausage-like after collection, due to the high temperature in the vacuum chamber. The products from ATFD were fractured into small particles because of the blade rotation. All samples were milled afterwards to produce powder.

All the drying methods resulted in a change in colour when comparing the reconstituted tomato puree and the original tomato puree. The colour changes were most obvious for ATFD and RWD, due to the high local shear and long drying time, respectively. In addition to colour, the different technologies also led to different volatile and non-volatile profiles in the powders that might be related to perceived flavour quality. In general, RWD resulted in a higher level of discriminative volatiles, due to the lower operation temperature. Comparing to DD, discriminative volatiles were more abundant in VDD, while discriminative non-volatiles especially amino acids were less. Under the applied conditions, ATFD dried powders had a lower level of flavour compounds. However, since the ATFD is operated under vacuum and at lower drying temperature, we had expected to prepare tomato powders with more flavour compounds. Possibly, further process optimization, i.e. feed moisture content and blade rotation speed, etc., might improve ATFD processing.

Choice of technology depends on the specific requirements on product quality and costs involved. RWD has potential for making powders with high retention of volatiles, with amongst other aromas. However, RWD is a relative slow process for drying of concentrated tomato puree, and thus has limitations with 
respect to capacity and scale-up. Following RWD, VDD can be an alternative to retain aromas during drying. Nevertheless, also its high capital costs need to be concerned. Although DD dried products contain less volatiles, they have higher concentration of certain non-volatile compounds, i.e. amino acids, which contributes to the taste. ATFD is probably less suitable for sticky materials like tomato, while it can be applied to products with limited sticky behaviour, such as spinach juice ${ }^{12}$. The results in the present work may be considered a starting point for selecting conductive drying technologies for the production of tomato powders and even other vegetable powders of desired quality. Sensory analysis of processed powders combined with corresponding volatile and non-volatile profiles is recommended to achieve more detailed information about how powder flavour quality is perceived by consumers.

\section{Acknowledgements}

This work was supported by the Institute of Sustainable Process Technology (ISPT). Partners in this project are Bodec, Danone, ECN and Unilever. We would like to thank Hans van den Broek and Almeida Rivera Cristhian from Unilever, Ron van Heijningen from Andritz, Paul Craenen from Bodec and Domien De Paepe from ILVO for their support during the pilot-scale experiments. 


\section{References}

[1]. Qiu, J., Vuist, J.-E., Boom, R. M. and Schutyser, M. A. I. (2018). Formation and degradation kinetics of organic acids during heating and drying of concentrated tomato juice. LWT - Food Science and Technology, 87(C), 112121.

[2]. Gahler, S., Otto, K. and Böhm, V. (2003). Alterations of vitamin C, total phenolics, and antioxidant capacity as affected by processing tomatoes to different products. Journal of Agricultural and Food Chemistry, 51(27), 79627968.

[3]. Sahni, E. K. and Chaudhuri, B. (2012). Contact drying: A review of experimental and mechanistic modeling approaches. International Journal of Pharmaceutics, 434(1), 334-348.

[4]. Devahastin, S. and Mujumdar, A. S. (2006). Indirect dryers. Handbook of Industrial Drying, Fourth Edition (pp. 137-149). Boca Raton: CRC Press.

[5]. Fudym, O., Carrère-Gée, C., Lecomte, D. and Ladevie, B. (2003). Drying kinetics and heat flux in thin-layer conductive drying. International Communications in Heat and Mass Transfer, 30(3), 333-347.

[6]. Nindo, C. and Tang, J. (2007). Refractance window dehydration technology: a novel contact drying method. Drying Technology, 25(1), 37-48.

[7]. Pawar, S. B., Patil, R., Mujumdar, A. and Thorat, B. (2011). Mathematical modeling of agitated thin-film dryer. Drying Technology, 29(6), 719-728.

[8]. Trystram, G. and Vasseur, J. (1992). The modeling and simulation of a drum-drying process. International Chemical Engineering, 32, 689-689.

[9]. Kalogianni, E., Xynogalos, V., Karapantsios, T. and Kostoglou, M. (2002). Effect of feed concentration on the production of pregelatinized starch in a double drum dryer. LWT-Food Science and Technology, 35(8), 703-714.

[10]. Rodriguez, G., Vasseur, J. and Courtois, F. (1996). Design and control of drum dryers for the food industry. Part 1 . Set-up of a moisture sensor and an inductive heater. Journal of Food Engineering, 28(3), 271-282.

[11]. Daud, W. R. W. (2006). Drum dryers. Handbook of Industrial Drying, Fourth Edition. Boca Raton: CRC Press. 
[12]. Qiu, J., Boom, R. and Schutyser, M. (2018). Agitated thin-film drying of foods. Drying Technology, 1-10.

[13]. Zotarelli, M. F., Carciofi, B. A. M. and Laurindo, J. B. (2015). Effect of process variables on the drying rate of mango pulp by Refractance Window. Food Research International, 69, 410-417.

[14]. Abonyi, B., Feng, H., Tang, J., Edwards, C., Chew, B., Mattinson, D. and Fellman, J. (2002). Quality retention in strawberry and carrot purees dried with Refractance Window ${ }^{\text {TM }}$ system. Journal of Food Science, 67(3), 10511056.

[15]. Raghavi, L., Moses, J. and Anandharamakrishnan, C. (2018). Refractance window drying of foods: A review. Journal of Food Engineering, 222, 267-275.

[16]. Azizi, D., Jafari, S. M., Mirzaei, H. and Dehnad, D. (2017). The influence of refractance window drying on qualitative properties of kiwifruit slices. International Journal of Food Engineering, 13(2).

[17]. Moses, J., Norton, T., Alagusundaram, K. and Tiwari, B. (2014). Novel drying techniques for the food industry. Food Engineering Reviews, 6(3), 4355.

[18]. Caparino, O. A., Tang, J., Nindo, C. I., Sablani, S. S., Powers, J. R. and Fellman, J. K. (2012). Effect of drying methods on the physical properties and microstructures of mango (Philippine 'Carabao' var.) powder. Journal of Food Engineering, 111(1), 135-148.

[19]. Nindo, C. I., Sun, T., Wang, S. W., Tang, J. and Powers, J. R. (2003). Evaluation of drying technologies for retention of physical quality and antioxidants in asparagus (Asparagus officinalis, L.). LWT - Food Science and Technology, 36(5), 507-516.

[20]. Malmendal, A., Amoresano, C., Trotta, R., Lauri, I., De Tito, S., Novellino, E. and Randazzo, A. (2011). NMR spectrometers as "magnetic tongues": prediction of sensory descriptors in canned tomatoes. Journal of Agricultural and Food Chemistry, 59(20), 10831-10838.

[21]. Yilmaz, E. (2001). The chemistry of fresh tomato flavor. Turkish Journal of Agriculture and Forestry, 25(3), 149-155. 
[22]. Petro-Turza, M. (1986). Flavor of tomato and tomato products. Food Reviews International, 2(3), 309-351.

[23]. Rambla, J. L., Alfaro, C., Medina, A., Zarzo, M., Primo, J. and Granell, A. (2015). Tomato fruit volatile profiles are highly dependent on sample processing and capturing methods. Metabolomics, 11(6), 1708-1720.

[24]. Kazeniac, S. and Hall, R. (1970). Flavor chemistry of tomato volatiles. Journal of Food Science, 35(5), 519-530.

[25]. Qiu, J., Khalloufi, S., Martynenko, A., Van Dalen, G., Schutyser, M. and Almeida-Rivera, C. (2015). Porosity, bulk density, and volume reduction during drying: review of measurement methods and coefficient determinations. Drying Technology, 33(14), 1681-1699.

[26]. Aganovic, K., Grauwet, T., Kebede, B. T., Toepfl, S., Heinz, V., Hendrickx, M. and Van Loey, A. (2014). Impact of different large scale pasteurisation technologies and refrigerated storage on the headspace fingerprint of tomato juice. Innovative Food Science \& Emerging Technologies, $26,431-444$.

[27]. Vervoort, L., Grauwet, T., Kebede, B. T., Van der Plancken, I., Timmermans, R., Hendrickx, M. and Van Loey, A. (2012). Headspace fingerprinting as an untargeted approach to compare novel and traditional processing technologies: A case-study on orange juice pasteurisation. Food Chemistry, 134(4), 2303-2312.

[28]. Koutidou, M., Grauwet, T., Van Loey, A. and Acharya, P. (2017). Impact of processing on odour-active compounds of a mixed tomato-onion puree. Food Chemistry, 228, 14-25.

[29]. Kim, J. (2009). Review of nucleate pool boiling bubble heat transfer mechanisms. International Journal of Multiphase Flow, 35(12), 1067-1076.

[30]. Qiu, J., Kloosterboer, K., Guo, Y., Boom, R. M. and Schutyser, M. A. I. (2019). Conductive thin film drying kinetics relevant to drum drying. Journal of Food Engineering, 242, 68-75.

[31]. Kitson, J. and MacGregor, D. (1982). Drying fruit purées on an improved pilot plant drum-drier. International Journal of Food Science \& Technology, 17(2), 285-288. 
[32]. Shi, J. and Maguer, M. L. (2000). Lycopene in tomatoes: chemical and physical properties affected by food processing. Critical reviews in food science and nutrition, 40(1), 1-42.

[33]. Goula, A. M. and Adamopoulos, K. G. (2005). Stability of lycopene during spray drying of tomato pulp. LWT-Food Science and Technology, 38(5), 479-487.

[34]. Krumbein, A., Peters, P. and Brückner, B. (2004). Flavour compounds and a quantitative descriptive analysis of tomatoes (Lycopersicon esculentum Mill.) of different cultivars in short-term storage. Postharvest Biology and Technology, 32(1), 15-28.

[35]. Xu, Y. and Barringer, S. (2009). Effect of temperature on lipid-related volatile production in tomato puree. Journal of Agricultural and Food Chemistry, 57(19), 9108-9113.

[36]. Buttery, R. G., Teranishi, R., Ling, L. C. and Turnbaugh, J. G. (1990). Quantitative and sensory studies on tomato paste volatiles. Journal of Agricultural and Food Chemistry, 38(1), 336-340.

[37]. Sieso, V. and Crouzet, J. (1977). Tomato volatile components: Effect of processing. Food Chemistry, 2(4), 241-252.

[38]. Goodman, C., Fawcett, S. and Barringer, S. (2002). Flavor, viscosity, and color analyses of hot and cold break tomato juices. Journal of Food Science, 67(1), 404-408.

[39]. Hu, Q., Shen, P., Bai, S., Dong, M., Liang, Z., Chen, Z., . . Li, P. (2018). Metabolite-related antidepressant action of diterpene ginkgolides in the prefrontal cortex. Neuropsychiatric Disease and Treatment, 14, 999.

[40]. Jeyaprakash, S., Frank, D. and Driscoll, R. (2016). Influence of heat pump drying on tomato flavor. Drying Technology, 34(14), 1709-1718.

[41]. Granvogl, M., Beksan, E. and Schieberle, P. (2012). New insights into the formation of aroma-active Strecker aldehydes from 3-oxazolines as transient intermediates. Journal of Agricultural and food Chemistry, 60(25), 6312-6322. 
[42]. Thakur, B. R., Singh, R. K. and Nelson, P. E. (1996). Quality attributes of processed tomato products: A review. Food Reviews International, 12(3), 375-401.

[43]. Cremer, D. R. and Eichner, K. (2000). Formation of volatile compounds during heating of spice paprika (capsicum a nnuum) powder. Journal of Agricultural and Food Chemistry, 48(6), 2454-2460.

[44]. Narain, N., Galvao, M. d. S., de Santana, K. L. and da Silveira Moreira, J. d. J. (2010). Volatile compounds in tomato-based dried products. Drying Technology, 28(2), 232-239. 
Supplementary data 6-1 Drying conditions of each experiments

\begin{tabular}{|c|c|c|c|c|c|c|}
\hline \multirow[b]{2}{*}{ No. } & \multicolumn{6}{|c|}{ Drying conditions } \\
\hline & $\begin{array}{l}\text { Temperature } \\
\left({ }^{\circ} \mathrm{C}\right)\end{array}$ & $\begin{array}{l}\text { Initial solid } \\
\text { content } \\
\text { (w/w) }\end{array}$ & $\begin{array}{l}\text { Rotor } \\
\text { speed } \\
(\mathrm{rpm})\end{array}$ & $\begin{array}{l}\text { Film } \\
\text { thickness } \\
(\mathrm{mm})\end{array}$ & $\begin{array}{l}\text { Vacuum } \\
\text { (mbar) }\end{array}$ & $\begin{array}{l}\text { Residence } \\
\text { time } \\
\text { (s) }\end{array}$ \\
\hline \multicolumn{7}{|c|}{ Vacuum drum drying (VDD) } \\
\hline 1 & 81.3 & 0.25 & \multirow{12}{*}{ - } & \multirow{12}{*}{$0.1^{\text {a }}$} & \multirow{12}{*}{60} & \multirow{12}{*}{$\sim 17$} \\
\hline 2 & 111.4 & 0.25 & & & & \\
\hline 3 & 133.5 & 0.25 & & & & \\
\hline 4 & 81.3 & 0.20 & & & & \\
\hline 5 & 111.4 & 0.20 & & & & \\
\hline 6 & 133.5 & 0.20 & & & & \\
\hline 7 & 81.3 & 0.19 & & & & \\
\hline 8 & 111.4 & 0.19 & & & & \\
\hline 9 & 133.5 & 0.19 & & & & \\
\hline 10 & 81.3 & 0.18 & & & & \\
\hline 11 & 111.4 & 0.18 & & & & \\
\hline 12 & 133.5 & 0.18 & & & & \\
\hline \multicolumn{7}{|c|}{ Drum drying (DD) } \\
\hline 13 & 99.6 & 0.25 & \multirow{13}{*}{-} & \multirow{13}{*}{$0.1^{\text {a }}$} & \multirow{13}{*}{-} & \multirow{13}{*}{$\sim 28$} \\
\hline 14 & 111.4 & 0.25 & & & & \\
\hline 15 & 99.6 & 0.20 & & & & \\
\hline 16 & 111.4 & 0.20 & & & & \\
\hline 17 & 133.5 & 0.20 & & & & \\
\hline 18 & 99.6 & 0.19 & & & & \\
\hline 19 & 111.4 & 0.19 & & & & \\
\hline 20 & 133.5 & 0.19 & & & & \\
\hline 21 & 143.6 & 0.19 & & & & \\
\hline 22 & 99.6 & 0.18 & & & & \\
\hline 23 & 111.4 & 0.18 & & & & \\
\hline 24 & 133.5 & 0.18 & & & & \\
\hline 25 & 143.6 & 0.18 & & & & \\
\hline \multicolumn{7}{|c|}{ Agitated thin film drying (ATFD) } \\
\hline 26 & 60 & 0.14 & 600 & \multirow{5}{*}{$1 \mathrm{~b}$} & \multirow{5}{*}{50} & \multirow{5}{*}{-} \\
\hline 27 & 60 & 0.07 & 600 & & & \\
\hline 28 & 75 & 0.07 & 600 & & & \\
\hline 29 & 75 & 0.07 & 700 & & & \\
\hline 30 & 80 & 0.07 & 500 & & & \\
\hline \multicolumn{7}{|c|}{ Refractance window drying (RWD) } \\
\hline 31 & 85 & 0.20 & \multirow{4}{*}{-} & \multirow{4}{*}{$1.5^{c}$} & \multirow{4}{*}{-} & \multirow{4}{*}{$\sim 1800$} \\
\hline 32 & 95 & 0.20 & & & & \\
\hline 33 & 95 & 0.19 & & & & \\
\hline 34 & 95 & 0.18 & & & & \\
\hline \multicolumn{7}{|c|}{$\begin{array}{l}\text { a: Estimated from the gap between two drums. } \\
\text { b: Estimated from the gap between the blade tips and the inner surface of the heating jacket. } \\
\text { c: Controlled by the applicator. }\end{array}$} \\
\hline
\end{tabular}


Supplementary data 6-2 Detected key volatile and non-volatile compounds, which contribute to tomato flavour.

\begin{tabular}{ll}
\hline Volatile compounds & Non-volatile compounds \\
\hline 3-Methylbutanoic acid & Asparagine \\
Nonanoic acid & Aspartate \\
Benzaldehyde & Glutamate \\
Phenylacetaldehyde & Isoleucine \\
3-Ethylbenzaldehyde & Phenylalanine \\
Neral & Tryptophan \\
Geranial & Tyrosine \\
Linalool & Valine \\
$\alpha$-Terpineol & Fructose \\
6-Methyl-5-hepten-2-one & Glucose \\
Nerylacetone & Sucrose \\
B-Ionone & Acetate \\
2-Isobutylthiazole & Citrate \\
4-Methylbenzaldehyde & Malate \\
& AMP \\
& UMP \\
\hline
\end{tabular}

Supplementary data 6-3 Performance of the PLS-DA models of the pairwise comparison of the drying technologies.

\begin{tabular}{llllll}
\hline PLS-DA & Number of Latent variables & $\mathrm{r}^{2} \mathrm{X}$ & $\mathrm{r}^{2} \mathrm{Y}$ & $\mathrm{Q}^{2}$ & P-Values $^{\mathrm{a}}$ \\
\hline VDD versus DD & 2 & 0.51 & 0.90 & 0.81 & $<0.001$ \\
VDD versus ATFD & 1 & 0.31 & 0.94 & 0.88 & $<0.001$ \\
VDD versus $\mathrm{RWD}$ & 2 & 0.42 & 0.82 & 0.79 & $<0.001$ \\
DD versus ATFD & 2 & 0.58 & 0.88 & 0.74 & $<0.001$ \\
DD versus $\mathrm{RWD}$ & 2 & 0.60 & 0.94 & 0.88 & $<0.001$ \\
ATFD versus $\mathrm{RWD}$ & 2 & 0.71 & 0.96 & 0.89 & $<0.001$ \\
\hline
\end{tabular}

a: Significance of the model determined from a permutation test using 999 iterations. 


\section{CHAPTER 7}

\section{General discussion}




\subsection{Introduction}

Throughout the years, different conductive dryers have been developed and applied for drying of foods. Although conductive drying is inherently more energy efficient than convective drying, its practical application to drying of foods is still limited due to the relatively harsh conditions during the process that may negatively affect the product quality. More recently, mild conductive drying approaches have been developed, often operating at lower (vapour) pressure and hence allowing the use of lower temperatures. However, the exact principle of conductive drying is still relatively poorly understood. Therefore, the aim of this thesis is to obtain better insights on the principle of conductive drying of foods and to translate insights generated to operation of different mild conductive drying technologies. This objective relies on the hypothesis that a lower drying temperature and faster drying to lower moisture content during conductive drying lead to higher product quality. Therefore, it may be expected that the conductive drying processes, namely vacuum drum drying (VDD), agitated thin film drying (ATFD), and refractance window drying (RWD) provide milder drying conditions and thus higher product quality compared to regular drum drying (DD). RWD may be less mild than VDD and ATFD, since the residence time is very long.

In this chapter we first summarise the main findings of the thesis. We extend the comparison of conductive drying technologies to drying of milk and report on a primary techno-economic assessment of conductive drying technologies. Subsequently, we discuss guidelines how to select the optimal conductive drying method for a specific product. Finally, this chapter concludes with an outlook towards needs for future research.

\subsection{Discussion of main findings}

Thermal processing, such as drying, induces changes in food quality. In this thesis, tomato juice was used as a model food to evaluate the impact of thermal processing on quality. In Chapter 2, we studied the influence of heating and drying on tomato taste by monitoring the presence of important tomato taste markers, citric, malic, ascorbic and pyroglutamic acids (PCA). The levels of 
these four organic acids were experimentally assessed by isothermal treatment of concentrated tomato juice at varying moisture content, temperature and time combinations. Both citric and malic acids were not affected by heating, only increasing in concentration due to the reduction in volume by drying. In contrast, ascorbic acid was significantly degraded and PCA was formed during heating. The degradation rate of ascorbic acid and the formation rate of PCA depend on both temperature and moisture content. Increase of the temperature accelerates both reactions. At a lower moisture content the ascorbic acid degradation rate decreases, while the PCA formation rate increases. Subsequently, the reaction kinetics were successfully described using an Arrhenius-type equation. These kinetic models were combined with a dryer model to assess the effect of co- and counter-current air drying on the presence of ascorbic acid and PCA in tomato.

Drum drying is a widely used conductive drying method for pasty and/or viscous food materials. Assessing the conductive drying kinetics on-line during drum drying is challenging since the mass and temperature profiles are difficult to monitor. Therefore, in Chapter 3, the drying kinetics of conductive drying was studied by drying a stagnant thin film of maltodextrin DE12 and native potato starch suspensions with a custom-built experimental system that allows on-line monitoring of mass and temperatures. During drying of films that were thicker than $1 \mathrm{~mm}$, three distinct periods could be identified: heating (period 1), boiling (period 2) and conductive drying (period 3). During the boiling period, the drying rate remains constant while large bubbles formed that greatly hinder the heat transfer. The degree of bubble formation depends on the properties of the product that is dried: larger bubbles were observed with starch suspensions than with maltodextrin, due to its higher viscosity and elasticity. Increased solid content also leads to larger bubbles and hence slower drying in period 2. During the conductive drying period (period 3), drying gradually slows. The drying rate during this period depends on the initial amount of dry solids per surface area because this determines the final thickness of the semimoist layer that is dried during period 3 into a completely dry film. During drying of starch suspensions with high initial solid contents (40\%), a thin film 
was required to avoid accumulation of vapour below the film (vapour blanketing), which was detrimental to the heat transfer and led to less homogeneous drying.

In Chapter 4, a heat-transfer governed model is presented to describe the drying process in the lab-scale conductive thin film dryer that was used in Chapter 3. The model considered the three distinct periods (e.g. heating, boiling and conductive drying periods) of the drying process. The input parameters of the model are the boiling temperature and rate of heat transfer, measured as the temperatures and evaporation rate during the boiling period. Based on this, the model determines the decrease in moisture content over time during all three stages of the drying process. The model calculations described the experimental data in Chapter 3 well. An overall heat transfer coefficient was calculated to describe the heat transfer during the conductive drying in period 3. This overall heat transfer coefficient and the conductive drying model (period 3 only) were used to predict the course of drum drying of maltodextrin. Moisture content profiles during drum drying were calculated and optimal drying times for different drying conditions were suggested. The predicted drying times were comparable to reported literature values.

In Chapter 5, agitated thin film drying (ATFD) was studied. A laboratory-scale ATFD was developed and applied for drying different food formulations, to create a better understanding of ATFD drying behaviour and how this is influenced by process parameters and product properties. ATFD could be applied to specific products such as spinach leaf juice, sucrose solutions and whey protein isolate (WPI) solutions. However, drying of tomato juice and bell pepper juice gave poor results, due to their high concentrations of glucose and fructose. We conclude that ATFD is suitable for materials that are not too sticky during drying, and have fast crystallisation kinetics or transform into a brittle solid matrix. Spinach leaf juice was selected as a model suspension to investigate the influence of drying parameters, being the heating temperature, feeding rate and blade rotation speed. The wall temperature and feed rate greatly affect the specific drying rate and the absolute drying rate, respectively. In contrast, the blade rotation speed had only limited effect, but it is crucial for 
fragmentation of the dried material into powder particles. The limited effect of blade rotation on drying suggests that the process is limited by heat transfer through the wall, which falsifies an existing model for ATFD based on penetration theory.

Different conductive drying methods affect the product quality (e.g. during drying of tomato puree) in a different way. In Chapter 6, we studied the influence of the choice of conductive drying process on the organoleptic quality of tomato powders (colour and flavour) by carrying out pilot-scale experiments with a vacuum drum dryer (VDD), a regular drum dryer (DD), an agitated thin film dryer (ATFD) and a refractance window dryer (RWD). The flavour quality of the resulting powders was evaluated by quantitatively determining the presence of a range of volatile and non-volatile components, which contribute to the aroma and taste characteristics. The drying methods, especially RWD and ATFD, induced colour differences between the reconstituted tomato puree and the original tomato puree. The colour change during RWD is related to chemical reactions during the longer drying time, while for ATFD it is due to heat dissipation from the fast rotating blades. Drying strongly affected the volatile and non-volatile profiles of the powders. These profiles were analysed by advanced statistical analysis (principal component analysis (PCA) and partial least square discriminant analysis (PLS-DA)). The results showed that RWD (before VDD) leads to high retention of volatiles in powders that may be related to a different driving force for evaporation during RWD. In contrast, products dried with drum drying had less volatiles, but retained higher levels of specific non-volatile compounds (i.e. amino acids) that can contribute to taste perception. ATFD processed powders have a lower level of discriminant volatiles and non-volatiles, probably because it is less suitable for sticky materials like tomato puree (as discussed in Chapter 5).

\subsection{Application of conductive drying on dairy products}

As mentioned before, conductive drying was successfully used for drying of tomato puree and the quality of the resulting powders was compared (Chapter 6). However, it was observed that drying behaviour is very product dependent. 
Therefore, in order to render the conclusions more generic, in addition to a comparison for drying of tomato puree also a comparison for drying of reconstituted milk was carried out with the four different conductive drying technologies.

We carried out pilot-scale drying of reconstituted skim milk and whole milk concentrates $(0.25 \mathrm{~kg}$ dry matter/ $\mathrm{kg}$ total) with RWD, ATFD and regular and vacuum drum drying (the same dryers as used in Chapter 6). The reconstituted milk was prepared from spray dried skim milk powder (SMP) and whole milk powder (WMP). The compositions of the SMP and WMP are shown in Table 7-1.

Table 7-1 The concentrations of different compositions in the skim milk powders (SMP) and whole milk powders (WMP).

\begin{tabular}{ccc}
\hline $\begin{array}{c}\text { Compositions } \\
(\mathrm{kg} / \mathrm{kg} \text { total })^{\mathrm{a}}\end{array}$ & Skim milk powder & Whole milk powder \\
\hline Moisture & $0.035 \pm 0.007$ & $0.033 \pm 0.018$ \\
Total solids & $0.965 \pm 0.007$ & $0.968 \pm 0.018$ \\
Fat & $0.009 \pm 0.005$ & $0.273 \pm 0.018$ \\
Protein & $0.355 \pm 0.021$ & $0.255 \pm 0.021$ \\
Lactose & $0.508 \pm 0.018$ & $0.385 \pm 0.035$ \\
Minerals & $0.084 \pm 0.003$ & $0.060 \pm 0.007$ \\
\hline
\end{tabular}

a: Each value is expressed as mean $\pm \mathrm{SD}(\mathrm{n}=2)$.

Figure 7-1 shows the morphology of milk powders dried by different drying methods. Similar to tomato powders (Chapter 6), DD and RWD produced flake-like samples, while VDD dried sheets that rolled into a sausage shape. At the end of ATFD, fractured particles were collected directly.

The type of reconstituted milk may lead to a visually different final product. For DD and VDD, there was no obvious visual difference between the SM and WM products, however for RWD, the SM flakes were transparent while the WM flakes were opaque. This visual difference might be attributed to the high fat content in the WM flakes (Table 7-1), which has been observed before $\mathbf{1}$.

Scanning electron microscopy (SEM) shows the detailed morphology of the products (Figure 7-1). The DD, VDD and RWD powders consist of small 
flake-like particles with a smooth surface, while the ATFD dried products consist of densely agglomerated particles with small regular hexagon lactose crystals (indicated in the SEM pictures). The fat could be observed in the WM particles as dark spots, which are indicated in the SEM pictures with a black circle.

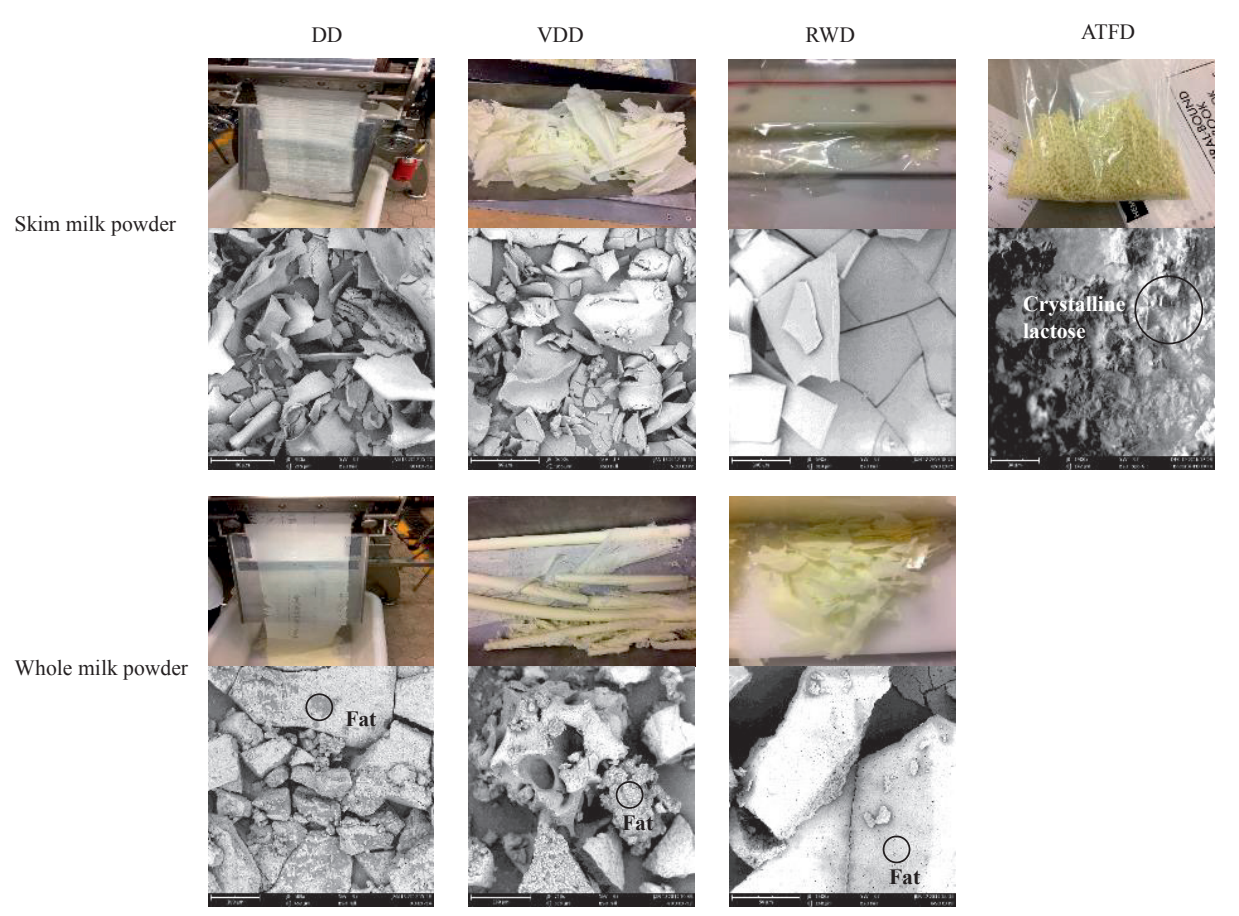

Figure 7-1 Visual and scanning electron microscopy (SEM) images of skim milk powder and whole milk powders prepared by regular drum drying (DD), vacuum drum drying (VDD), refractance window drying (RWD) and agitated thin film drying (ATFD).

The operation of ATFD for WM was challenging and no significant amount of product was obtained. This is probably due to the presence of high levels of free fat leading to the formation of sticky lumps during ATFD drying, which accumulate inside the dryer ${ }^{2}$. The WM powders from conductive dryers had very high free fat concentrations compared to spray dried WM (Figure 7-2). Moreover, similar to the ATFD dried SM (Figure 7-1), lactose may crystallise during ATFD drying of WM, which also contributes to larger amounts of free fat and thus the formation of sticky lumps ${ }^{3}$. 


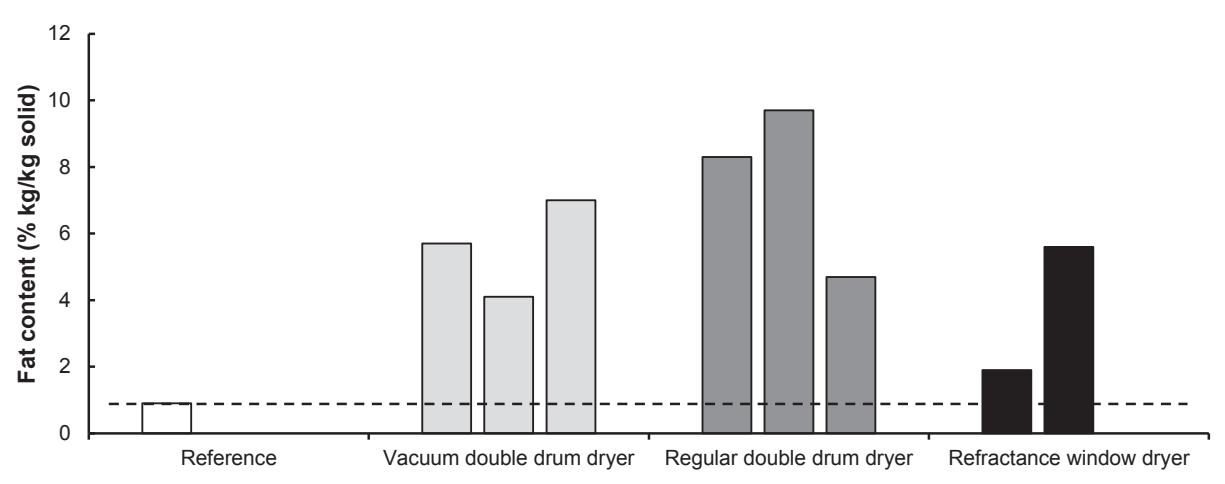

Figure 7-2 Free fat concentrations of the reference (spray dried whole milk powder) and whole milk powders prepared by different conductive drying technologies.

An important functional property for milk powder is its solubility. We followed an empirical method to assess solubility of milk powder, according to the GEA Niro analytical method A $5 \mathrm{~b}^{4} .10 \pm 0.1 \mathrm{~g}$ of SMP or $13 \pm 0.1 \mathrm{~g}$ WMP is dissolved and stirred in $250 \pm 1.0 \mathrm{~mL}$ of deionized water at $40 \pm 0.1{ }^{\circ} \mathrm{C}$ for $\sim 15$ s. The reconstituted suspensions were then poured through a $0.6 \mathrm{~mm}$ sieve, which retained the undissolved powder (Figure 7-3).

Except for ATFD, all other conductive drying methods produced SMP with high solubility, comparable to spray dried SMP. The poor solubility of ATFD processed SMP may be related to the very dense powder particles that it gives, as shown in Figure 7-1. In contrast to the SMP, the WMP prepared by conductive drying was less soluble compared to spray dried WMP, mainly because of the higher levels of free fat (Figure 7-2) ${ }^{\mathbf{5}, \boldsymbol{6}}$.

To conclude, DD, VDD and RWD could produce SMP with the desired solubility and thus could offer an alternative to spray drying. Conductive drying of WM would only be an option if the higher free fat would not be negative, and thus good solubility would not be required for their final application. 


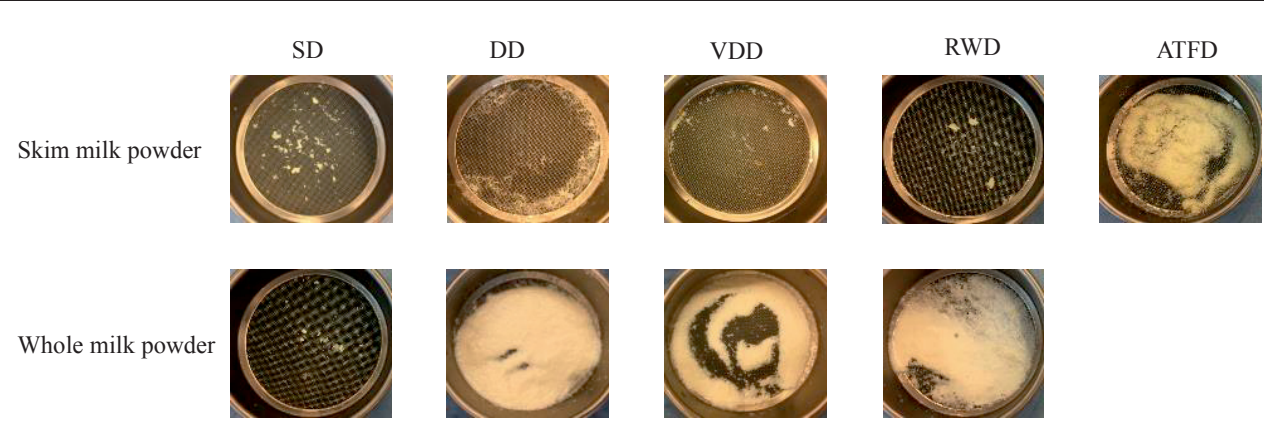

Figure 7-3 Solubility of skim milk powder and whole milk powders prepared by spray drying (SD), regular drum drying (DD), vacuum drum drying (VDD), refractance window drying (RWD) and agitated thin film drying (ATFD).

\subsection{Energy and economic evaluation on conductive drying compared to spray drying}

Conductive drying has been reported as being more energy efficient than convective drying, such as spray drying ${ }^{7,8}$. However, this has not yet been specified in the energy consumption and economic costs for conductive drying of foods. Availability of such data can help food industries to implement more efficient technology on a large scale. Therefore, in the framework of the overall research project on thin film drying, the Energy Research Centre of the Netherlands (ECN) carried out a first techno-economic assessment for the different conductive drying technologies ${ }^{9}$. The conductive drying methods considered in the assessment were vacuum drum drying (VDD), refractance window drying (RWD) and agitated thin film drying (ATFD). Regular drum drying (DD) was considered not comparable due to its higher operating temperature. Spray drying was a reference technology in the assessment.

\subsubsection{Comparison of energy consumption}

The energy use and efficiency of the conductive dryers were calculated using a generic model. Figure 7-4 shows a schematic representation of the calculations with the employed boundary conditions. The operating conditions for each drying method (e.g. mass flow, capacity, feedstock, etc.) were defined based on expert input and were used in the energy calculations (Table 7-2). Specifically, the efficiencies for the production of electricity and heat from the power plant, 
the hot water boiler, the steam boiler and the air heater were taken as $45 \%$, $95 \%, 95 \%$, and $85 \%$, respectively. The energy consumption was compared on the basis of energy use per ton water removed (GJ/ton water evaporated).

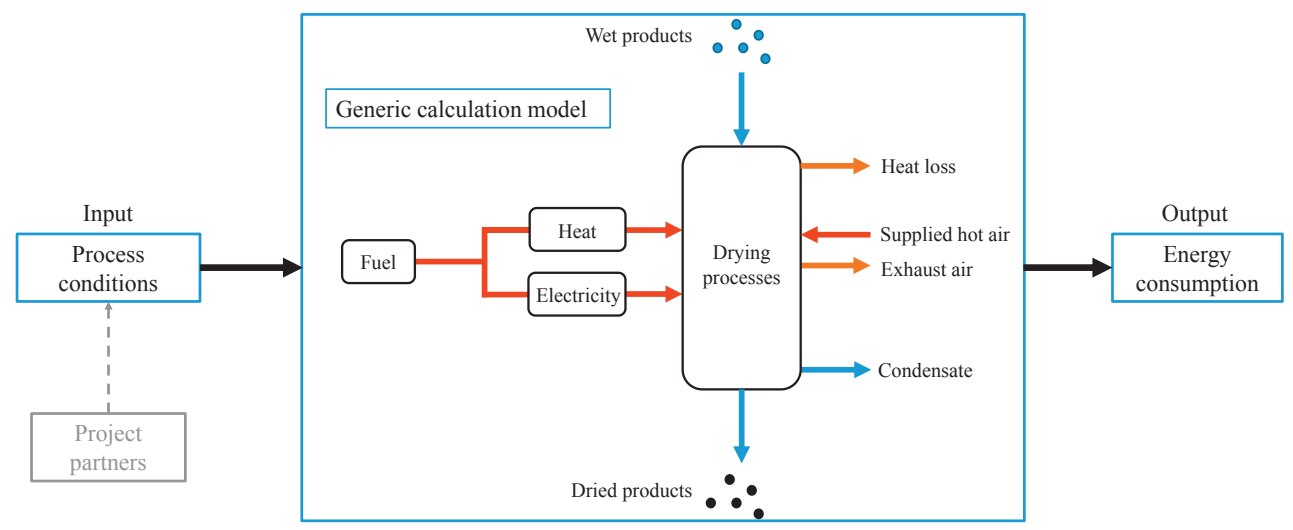

Figure 7-4 Schematic representation of the calculations for the reviewed drying processes. 
GENERAL DISCUSSION

Table 7-2 Inputs used for the calculations of the energy consumptions

\begin{tabular}{llll}
\hline & Vacuum drum drying & Agitated thin film drying & Refractance window drying \\
\hline Drying capacity $\left[\mathrm{kg} \mathrm{H} \mathrm{H}_{2} \mathrm{O} / \mathrm{h}\right]$ & 500 & 500 & 500 \\
Process pressure $[\mathrm{mbar}]$ & 50 & 50 & 1000 \\
Feedstock input & & & 20 \\
$\quad$ Temperature $\left[{ }^{\circ} \mathrm{C}\right]$ & 20 & 20 & 20
\end{tabular}

Product output

$\begin{array}{llll}\text { Temperature }\left[{ }^{\circ} \mathrm{C}\right] & 60 & 60 & 60 \\ \text { Solid content }[\mathrm{w} / \mathrm{w}] & 90 & 90 & 90 \\ \text { ng surface }\left[\mathrm{m}^{2}\right] & 41 & 21 & 32\end{array}$

Supply air

Temperature $\left[{ }^{\circ} \mathrm{C}\right]$

Humidity $\left[\mathrm{g} \mathrm{H}_{2} \mathrm{O} / \mathrm{kg}\right.$ ]

10

Infiltration air

$\begin{array}{lll}\text { Mass }[\mathrm{kg} / \mathrm{h}] & 0.25 & 0.25 \\ \text { Humidity }\left[\mathrm{g} \mathrm{H}{ }_{2} \mathrm{O} / \mathrm{kg}\right] & 10 & 10 \\ \text { Temperature }\left[{ }^{\circ} \mathrm{C}\right] & 25 & 25\end{array}$

Exhaust air

Temperature $\left[{ }^{\circ} \mathrm{C}\right]$

27

Humidity [g H $\left.\mathrm{g}_{2} \mathrm{O} / \mathrm{kg}\right]$

21

Exfiltration air

Humidity $\left[\mathrm{g} \mathrm{H}_{2} \mathrm{O} / \mathrm{kg}\right] \quad 33$

Hot water/steam system

$\begin{array}{llll}\text { Pressure }[\mathrm{bar}] & 2 & 2 & 1 \\ \text { Inlet temperature }\left[{ }^{\circ} \mathrm{C}\right] & 120 & 120 & 95 \\ \text { Outlet temperature }\left[{ }^{\circ} \mathrm{C}\right] & 100 & 100 & \text { t.b.c. }\end{array}$

Electric power

Total power $\left[\mathrm{kW} / \mathrm{m}^{2}\right]$

Vacuum pump $[\mathrm{kW}] \quad$ t.b.c.

Drive power $\left[\mathrm{kW} / \mathrm{m}^{2}\right] \quad 1.8$

Pumps, fans $[\mathrm{kW}] \quad$ t.b.c.

Conveyor belt $[\mathrm{kW}]$

Heat loss [\% of Fuel supply] 5

5

5

t.b.c.: To be calculated 
Figure 7-5 shows the calculated energy consumptions of the drying processes. All conductive dryers consume less energy for heating (which is energy used for the water boiler, the steam boiler, etc.) than spray drying. If we compare the conductive dryers, the energy demands of VDD and ATFD are comparable and lower than that of RWD. In contrast, conductive dryers have higher electricity demand (used for drive power, the pump, etc.) than spray dryers. VDD has the highest electricity use, followed by ATFD and then RWD. Regarding the total energy consumption, spray drying has the highest total energy use, while VDD consumes more energy than ATFD and RWD.

The heat used for water evaporation is divided by the overall use of energy, to calculate the thermal efficiencies for spray drying, VDD, ATFD and RWD, which are $46 \%, 53 \%, 63 \%$ and $63 \%$, respectively.

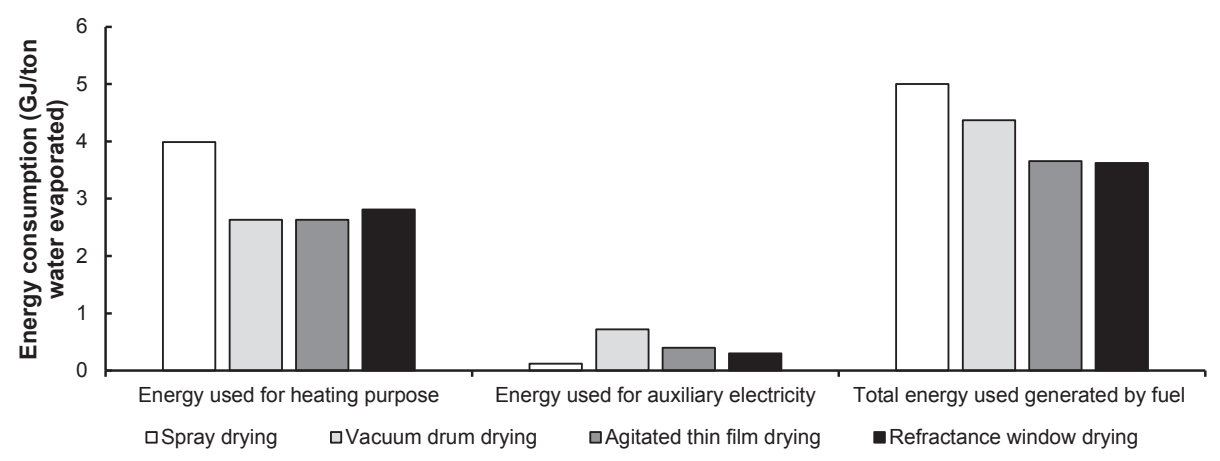

Figure 7-5 Calculated energy consumptions for different drying processes.

\subsubsection{Capital expenditures (CAPEX)}

The capital expenditures (CAPEX) were estimated from price quotes given by equipment manufacturers and from experiences by industrial partners (Figure 7-6). For similar drying capacity, all conductive dryers have lower investment costs than the spray dryer. The investment costs for the ATFD and RWD are comparable, while VDD is slightly more expensive. Except RWD, all drying technologies benefit from economy of scale. The cost price of RWD is linearly related to the scale (Figure 7-6), because scale-up of RWD is mainly by modular build-up of separate individual modules according to the RWD manufacturer (GW-dryer, USA). 


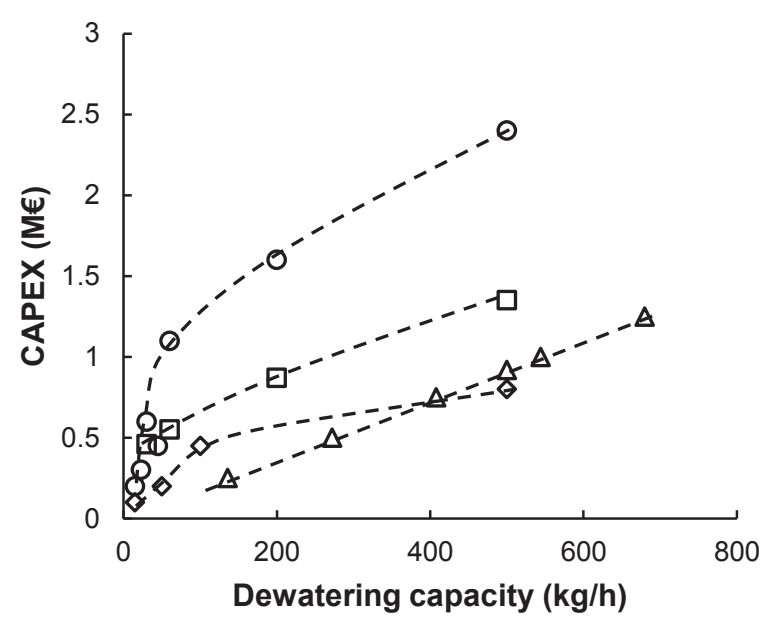

Figure 7-6 Estimated CAPEX for different drying processes at different dewatering capacities: spray drying $(\odot)$, vacuum drum drying $(\square)$, agitated thin film drying $(\diamond)$, and refractance window drying $(\Delta)$.

\subsubsection{Operating expenditures (OPEX)}

The operating expenditures (OPEX) are the recurring costs necessary to operate the drying facilities. It can be subdivided into personnel, maintenance and energy costs. Only the costs of maintenance and energy were considered here since there is limited information about personnel costs of conductive drying processes. The assumptions used for the calculations are shown in Table $7-3$.

Table 7-3 Assumptions used for OPEX calculations.

\begin{tabular}{cc}
\hline Category & Assumptions \\
\hline Gas price & $7 € / \mathrm{GJ}$ \\
Electricity price & $40 € / \mathrm{MWh}$ \\
Operating hours & $7000 \mathrm{~h} /$ year \\
Dewatering capacity & $500 \mathrm{~kg} / \mathrm{h}$ \\
Maintenance & $3 \%$ of investment costs \\
\hline
\end{tabular}

Figure 7-7 summarises the OPEX of the reviewed drying processes at a dewatering capacity of $500 \mathrm{~kg} / \mathrm{h}$. As expected, the total costs of the conductive drying technologies are lower compared to that of spray drying, mainly due to the lower energy consumption (natural gas and electricity). The natural gas 
costs for all conductive dryers are comparable. The maintenance costs of spray dryers are highest. If we compare the OPEX of each conductive dryer, VDD has a higher OPEX than ATFD and RWD, due to its higher demand of electricity and maintenance cost. It should be mentioned that the calculations are very sensitive to the assumed energy prices, which will be certainly vary in time.

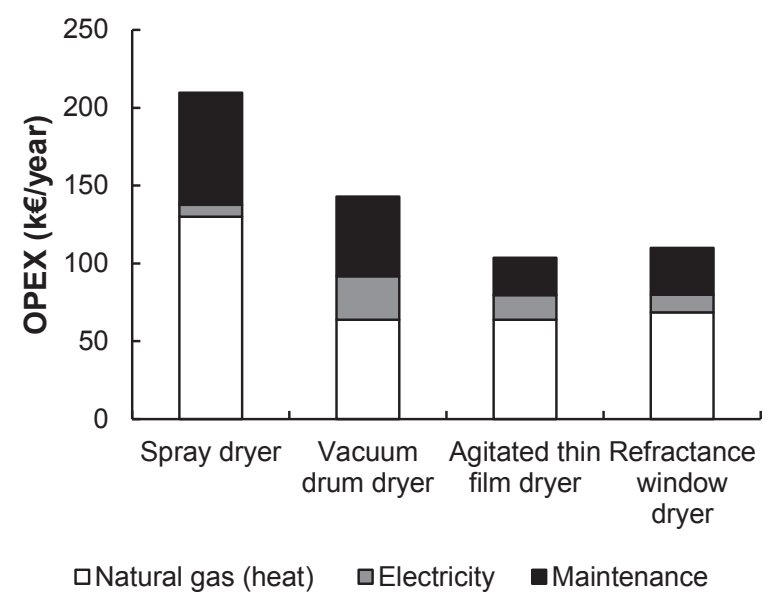

Figure 7-7 Estimated OPEX for different drying processes at a dewatering capacity of $500 \mathrm{~kg} / \mathrm{h}$.

To conclude, the energy assessment shows that conductive drying may reduce the total energy consumption between $7 \%$ and $17 \%$ compared to spray drying, contributing to a reduction in OPEX for conductive drying. At the mentioned dewatering capacity of $500 \mathrm{~kg} / \mathrm{h}$, a yearly reduction of OPEX can be expected between 77 and $106 \mathrm{k} €$ for the evaluated conductive dryers, which represents approximately $37 \%$ to $50 \%$ of the OPEX of the spray dryer. In addition, reductions in CAPEX are also expected for the conductive drying, as the spray drying requires equipment for redundant feed and atomization, intake air heating and exhaust air handling. Specifically, for the dewatering capacity of $500 \mathrm{~kg} / \mathrm{h}$, the expected CAPEX reductions range from 1.05 to $1.6 \mathrm{M} €$, corresponding to a reduction of $45 \%$ to $65 \%$ comparing to the spraying drying. Although the CAPEX and OPEX of DD were not estimated in this study, they are expected to be lower than those of VDD, as no vacuum is needed. 


\subsection{Selection of conductive drying technologies}

Selection of a drying technology is a complex decision, depending on many aspects, such as costs and technical operation of the dryer and the requirements in terms of product quality. In this section, we conceptually discuss the selection of different conductive drying technologies for tomato powders as an example, based on the above-mentioned techno-economic assessment and the results from Chapter 6 (Figure 7-8).

The first question is the suitability of a technology to dry a specific raw material. ATFD is not very suitable to dry tomato puree, since it contains significant amounts of low molecular weight sugars that lead to formation of sticky lumps during drying (Chapter 5 and Chapter 6). For drying spinach juice concentrate, ATFD may be an interesting choice as it is technically feasible and may give high product quality (Chapter 5).

Other specifications on product quality may steer our choice for a specific drying technology. For a premium tomato powder, RWD could be a preferred option as it can produce powders with both high levels of volatiles and nonvolatiles. However, RWD has limitations in capacity and scale-up and thus would only be suitable for a high-quality, small-volume product. Alternatively, VDD might be used to produce high-aroma powders on larger scales with a small compromise on product quality, while DD is the best option to make powders with more taste retention but will retain less aromas.

Such decisions become clearer when visualised in a decision tree (Figure 7-8). To make such decision trees applicable to a wider range of foods, more expert information and experimental data input is required. 


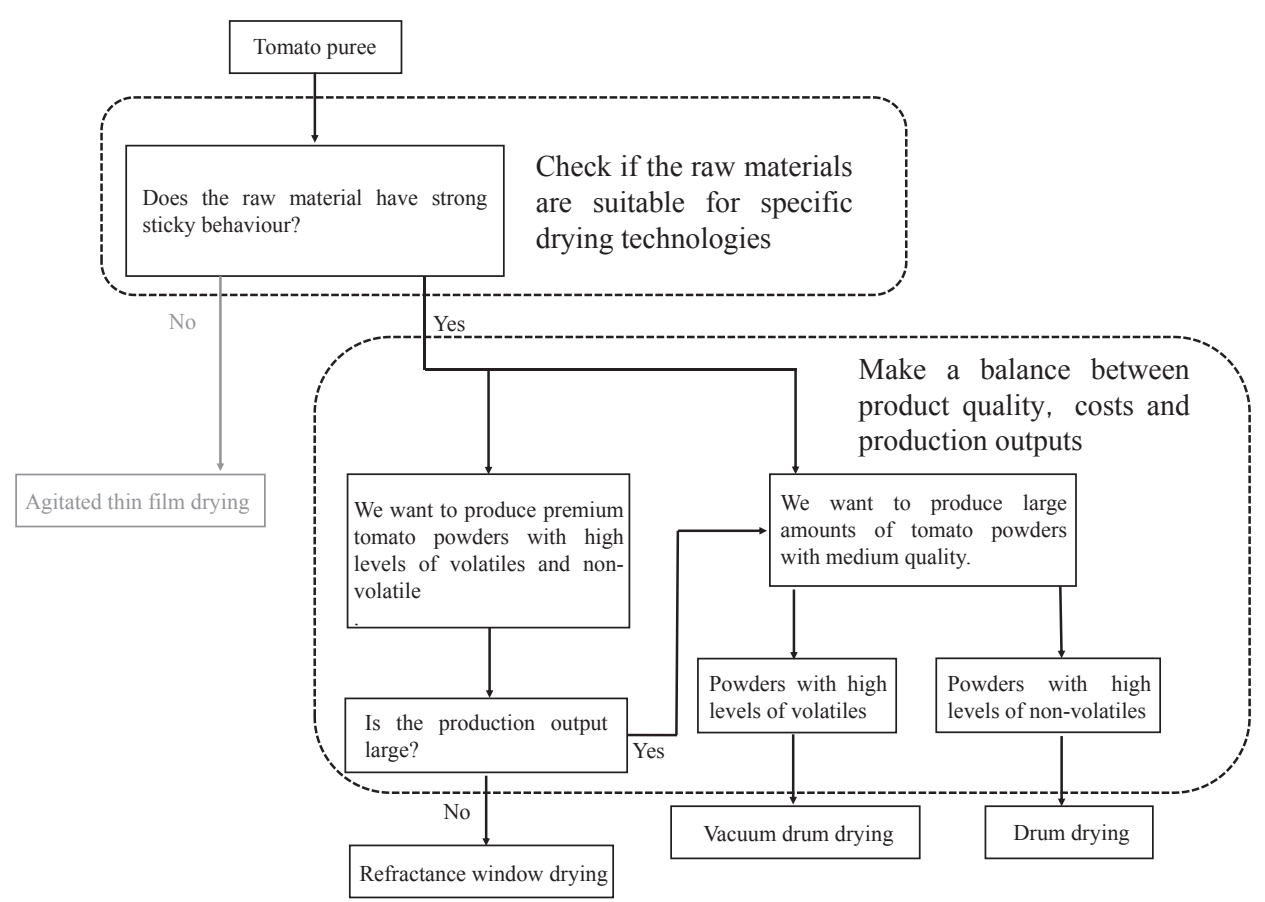

Figure 7-8 A conceptual decision tree for the selection of an appropriate conductive drying methods in this case applied to drying of tomato puree.

\subsection{Outlook for future research}

In Chapter 3, the custom-built experimental conductive dryer was demonstrated to be a reliable tool to better understand the transient drying kinetics. However, this device is operated at constant heat flux, while drum dryers are operated at constant temperature. Although the drying mechanism itself does not change, the difference of heat supply can result in slightly different drying behaviour (e.g. faster conductive drying in period 3 in our labscale apparatus). Therefore, to better mimic real drying processes, the lab-scale dryer could be equipped with fast temperature control to operate at constant pan temperature. In addition to the drying behaviour itself, the influence of material properties and operating conditions on product structure formation during drying could be studied with this equipment, just like the impact of drying on specific quality parameters (e.g. functional properties, protein denaturation, Maillard reactions). 
In Chapter 5, the effect of the material properties on ATFD drying behaviour was qualitatively described for selected products. However, a quantitative description of the drying behaviour during ATFD drying is still missing and is important to further development of this technology. More in-depth investigations should be carried out towards better understanding how material properties (especially composition in relation to rheological properties) change with moisture content, temperature and shear and how these interact with the operation of the ATFD dryer.

One approach would be to construct state diagrams of materials of interest and combine these with measurements on rheological properties of materials with varying moisture content, temperatures and deformation. This then supports the description of the rheological property changes during ATFD drying (going from a liquid, to a paste and a solid).

In this thesis, the effect of the operation conditions on ATFD drying behaviour was experimentally assessed. The next step is to develop a predictive model for ATFD drying that incorporates the rheological changes of the materials. A model is available for the initial stage of ATFD drying (i.e. when the feed is still liquid) ${ }^{\mathbf{1 0}}$, but for the subsequent stages (when the product transforms into a paste and solid) process models still need to be developed. Ultimately, this research could contribute to a more rational assessment of the suitability of a material for ATFD drying.

\subsection{Conclusions}

The work reported in this thesis has provided further insights on the principle of conductive drying of foods, by gaining understanding on the drying behaviour using two custom-built lab-scale dryers. In addition to well defined experiments on the lab-scale, the effect of different conductive dryers on the product quality was investigated by carrying out pilot-scale experiments and subjecting powders to extensive quality analysis. This could be translated into the first set of guidelines for choosing a conductive drying process. 
The work confirmed but also nuanced the hypotheses that were the basis of the research reported in this thesis. Novel insights on conductive drying of foods are obtained and conclusions are drawn on directions for future research to develop energy efficient conductive drying technologies that deliver high quality products. 


\section{Reference}

[1]. Frøst, M. B., Dijksterhuis, G. and Martens, M. (2001). Sensory perception of fat in milk. Food Quality and Preference, 12(5), 327-336.

[2]. Paterson, A. H., Zuo, J. Y., Bronlund, J. E. and Chatterjee, R. (2007). Stickiness curves of high fat dairy powders using the particle gun. International Dairy Journal, 17(8), 998-1005.

[3]. Foster, K. (2002). The prediction of sticking in dairy powders: a thesis presented in partial fulfilment of the requirements for the degree of Doctor of Philosophy in Bioprocess Engineering at Massey University: Massey University.

[4]. GEA, N. R. L. (2009). GEA Niro Analytical Method No. A 5b - Wettability IDF method. Soeborg, Denmark.

[5]. Nijdam, J. J. and Langrish, T. A. G. (2006). The effect of surface composition on the functional properties of milk powders. Journal of Food Engineering, 77(4), 919-925.

[6]. Kosasih, L., Bhandari, B., Prakash, S., Bansal, N. and Gaiani, C. (2016). Physical and functional properties of whole milk powders prepared from concentrate partially acidified with $\mathrm{CO} 2$ at two temperatures. International Dairy Journal, 56, 4-12.

[7]. Daud, W. R. W. (2006). Drum dryers. Handbook of Industrial Drying, Fourth Edition. Boca Raton: CRC Press.

[8]. Devahastin, S. and Mujumdar, A. S. (2006). Indirect dryers. Handbook of Industrial Drying, Fourth Edition (pp. 137-149). Boca Raton: CRC Press.

[9]. Smidt de, R. P., Wemmers, A. K. and Spoelstra, S. (2017). Thin film drying pocesses 'Energy and economic aspects compared to spray drying': Report ECN-E-17-084, Energy Research Centre of the Netherlands (ECN).

[10]. Pawar, S. B., Patil, R., Mujumdar, A. and Thorat, B. (2011). Mathematical modeling of agitated thin-film dryer. Drying Technology, 29(6), 719-728. 
CHAPTER 7 
Drying is one of the most energy-intensive operations in the food industry and has big impact on the quality and properties of foods. This why there is interest in developing more energy efficient, mild drying technologies. The focus of this thesis is on understanding conductive drying processes, which are more energy efficient and may be mild when operated at reduced pressure. Laboratory-scale analyses were carried out to understand the degradation and formation dynamics of product quality parameters and to characterise drying behaviour during conductive drying processes. Additionally, an experimental pilot scale programme was carried out to compare and study the effect of different conductive drying technologies on tomato powder quality.

First, isothermal heat treatment of tomato juice was carried out to experimentally assess the effect of heat and water content on the presence of important tomato taste markers, such as citric acid, maleic acid, ascorbic acid and pyroglutamic acid (PCA) (Chapter 2). The levels of citric and malic acids levels were unaffected, while ascorbic acid was degraded and PCA was formed during thermal processing. The reaction kinetics of ascorbic acid and PCA can be described as first order. Both reactions increase with increasing temperature, while a decrease in moisture content reduces ascorbic acid degradation, but accelerates PCA formation. These coupled effects of temperature and moisture content on the reaction rates were modelled with an Arrhenius-type equation. The developed kinetic models were combined with a process model for a convective tray dryer to assess the changes of ascorbic acid and PCA during co- and countercurrent drying of tomato products.

The transient conductive drying kinetics relevant to drum drying was experimentally assessed with a custom-built experimental system (Chapter 3). Maltodextrin and native potato starch were applied as model systems, and their corresponding drying kinetics were followed by on-line monitoring of mass and temperatures. Three distinct periods were identified: heating (period 1), boiling (period 2) and conductive drying (period 3). During the boiling period, the drying rate remained constant while extensive bubble formation hindered the heat transfer. The degree of bubble formation were dependent on the viscoelastic properties of the formulation: larger bubbles were observed during 
drying of starch suspensions than maltodextrin solutions with the same concentration. During the conductive drying period, the total amount of dry solids per surface area is crucial as it determines the thickness of the semi-moist layer subjected to conductive drying.

Subsequently, the experimental data reported in Chapter 3 were used for model development (Chapter 4). For model calculations we assumed that the processes was heat-transfer governed, considering the three distinct periods of the drying process. As input the model uses the measured temperatures and evaporation rate during the boiling period. As output the model calculates the decrease in moisture content over time during the entire drying process. The model calculations describe the experimental data in Chapter 3 well. With the calculations also the overall heat transfer coefficient for period 3 could be obtained. The heat transfer coefficient and the conductive drying model (period 3 only) were finally used to predict the course of industrial drum drying of maltodextrin solutions. This model predicts the moisture content and temperature profiles during drum drying and can be used to suggest optimal drying times for different drying conditions. This process model can be combined with kinetic models to describe product quality changes during drum drying.

The drying behaviour of various formulations in an agitated thin film dryer (ATFD) was investigated in a laboratory-scale set-up (Chapter 5). Successful drying for the ATFD was only obtained with specific feed materials. Materials that crystallise (e.g. sucrose) or contain insoluble particles (spinach juice) could be dried well, while more sticky materials accumulate inside the drying chamber, which impairs the drying process. The effect of operating parameters was investigated: the wall temperature affects the specific drying rate, while the absolute drying rate is proportional to the feed rate. The blade rotation speed has limited effect on the drying rate, indicating that the process is governed by heat transfer through the wall. In contrast, the mechanical action of the blade was found to be crucial in fragmenting the material into fine powder particles. 
In Chapter 6, pilot-scale experiments were carried out to compare the quality (colour and flavour) of tomato powders prepared by four pilot-scale dryers, namely a vacuum drum dryer (VDD), a drum dryer (DD), an agitated thin film dryer (ATFD) and a refractance window dryer (RWD). VDD and the ATFD are operated at a reduced pressure and DD at atmospheric pressure. RWD relies on conductive drying below the boiling temperature, in which evaporation is driven by the relative humidity difference between product film and air. The drying methods induced colour differences between the reconstituted tomato puree and the original tomato puree, especially for RWD and ATFD. In addition, drying caused significant variance in the volatile and non-volatile profiles of the powders, which might contribute to different aroma and taste characteristics. From advanced statistical analysis (principal component analysis (PCA) and partial least square discriminant analysis (PLS$\mathrm{DA})$ ), it was found that RWD produced powders with high volatile markers, followed by VDD. In contrast, DD dried products had less volatiles, but contained larger amounts of specific non-volatile compounds (i.e. amino acids) that can contribute to taste perception. ATFD processed powders had a lower level of discriminant volatiles and non-volatiles, because ATFD is less suitable for sticky feed materials like tomato puree (Chapter 5).

The results obtained in this thesis are discussed in Chapter 7. In the general discussion, the comparison of the different conductive drying technologies are extended to drying of skim milk and of whole milk. Subsequently, a first techno-economic assessment of different conductive drying technologies is presented. It is concluded that conductive drying technologies show lower energy consumption, operating expenditures and capital expenditure than conventional spray drying. By combining the techno-economic assessment and the results from Chapter 6, guidelines for selecting an appropriate conductive drying method for a (tomato-based) product are formulated. The final technology choice for making a product depends largely on the ability of a process to dry the raw materials to the desired product specifications. Finally, an outlook for future research is provided. 


\section{Acknowledgements}


When I think about the past four years, I realize that doing a doctoral research in Wageningen UR is a wonderful journey. Many great people helped and inspired me, making the past four years colourful and memorable. I would like to take this opportunity to express my deep appreciation for the people who have guided and accompanied me through the four years.

First of all, I am very grateful for all the supervision from my promotors. Maarten, thank you for the extremely helpful supervision and support. I could always receive your quick responses to my manuscripts. Discussions with you were always inspiring. I learned a lot from you, on how to write scientific papers, how to be critical and structured in my thinking, and how to nicely present my research to others. Remko, thank you for your inspiring and challenging discussions during our meetings. Your experience and wisdom helped me a lot in writing and analysing data.

Secondly, I would like to thank the rest staff members in FPE. Marjan and Ilona, thank you for your excellent administrative works. Maurice, thank you for your support of HPLC. Jos and Jarno, thank you also for your valuable assistance in the lab. Martin, thanks for your help with financial matters.

Thirdly, I would like to give my thanks to all my fellow Ph.D. colleagues for the pleasant time we spent together. To all my officemates: Ali, Anja, Evelien, Victor and Wanqing, thank you for your company in the office. I had a wonderful time in our office. Dimitri, thank you for the nice trip in Canada. Also, many thanks to all my drying buddies, Eline, Evelien, Isabel, Jaap, JanEise, Joanna, Lu, Qinghui and Sicong. I enjoyed our discussions in the drying group meeting. Your researches are inspiring and I learned a lot from them.

Also, I would like to thank my colleagues from the Technical Development Studio, who helped me to design and develop my experimental setups. Thank you Eric Karruppannan, Hans de Rooij and Reinoud Hummelen. Every time when I met technical problems with the setup, you always kindly helped me to figure out and solve them. With your help, I could have stable setups doing experiments and finish my $\mathrm{PhD}$ in time. 
In addition, I would like to thank ISPT and all my industrial partners. Thank you Jordan, Parag and Paul, especially for the help during our pilot-plant experiments. Collaboration with you added a lot of values to my $\mathrm{PhD}$ project. I also learned a lot from you during our project meetings. And thank you Hans van den Broek for your hard work during our experiments. I really appreciate for your contributions to the project.

I would like to give my special thanks to all my BSc and MSc students. Chaoyang, Koen, Leoné, Manouk, Remco, Rens, Yang and Yuchan, thank you all for your hard work and input. My special thanks also goes to all my coauthors. Thank you for the nice collaboration we had and your valuable contributions to the manuscripts.

Special thanks goes to my dear paranymphs: Wanqing and Lu. Thanks a lot for your kindness and help. All the best with your research.

Many thanks to all the friends I met in Netherlands. Coen, I am glad to meet you in Rotterdam. We had great time of playing magic and guitar together. I promise to be your guide if you travel to China. 姜博博, 虽然没能一起在瓦村读 博, 但是我们一起度过无忧无虑美好的大学四年还有在瓦村硕士的两年。怀念我们 一起旅行游遍欧洲。感恩王总, 虽然遗憾没能跟王总一起去南美, 但是我们也一起 去了很多有趣的地方。希望以后我们还有机会相约旅行。吴贻璋, 赵熙, 王艺儒, 田北, 张瑞琪, 熊炜, 岳娜, 谷方婕, 陈洋, 韩越, 张春月, 刘法辉, 张露, 王昭 君, 王珏, 刘坤, 彭金峰, 罗琦, 边梦溪, 朱一凡, 周点凡, 蒋亦博, 贾婉清, 彭 郁, 朱思聪, 李岫峰, 裴锐哲, 李京阳, 崔欣悦, 韩碧瑶, 邢沁绘, 王亚, 田灵敏, 张婧妍, 张丽娜, 王玥, 李佳雨, 姜洋, 周思, 季永然, 还有很多很多在瓦村相识 的朋友们, 很高兴能在异国他乡与你们相识。这段时光是我生命里一段美好的回忆。 我会好好珍藏, 愿未来某一天我们还能相遇相聚。

同样感谢国内的小伙伴们, 顾老大, 朱老板, 虽然高中后我们流浪到世界各地, 虽 然我们相聚时间越来越少, 但是我们的友情从未褪色。每次回国最开心的就是跟你 们相聚。我们早已过了当年年少轻狂的年纪, 业已成家立业, 每次相聚总似乎又回 到高中最青春的年纪。特别谢谢顾老大为我设计论文封面。白石, 圆圆, 顾欣, 林 一腾, 张亦文, 吴斌, 郭彦君, 每次回国都能带我吃好喝好。当然还有我的大学室 
友, 臭 C, 可索, 感谢每次回来你们会尽量抽空来从广州来上海与我相聚。我会好 好珍藏我们的友谊和相聚的美好时光。

最后, 感谢爱我的和我爱的家人们。亲爱的爸爸妈妈, 谢谢你们的无条件的支持和 鼓励, 没有你们我也无法取得今天的成就。谢谢爷爷, 奶奶, 外公, 外婆, 舅舅, 印康, 舅妈, 谢谢你们对我我在外求学的支持。

最后的最后, 感谢最特别的人, 羽西。谢谢你在交论文最后阶段对我的鼓励, 支持 和帮助。与你相遇是命运赐予我最美好的礼物。我们以后还有更长的路要一起走, 更多的事要一起做。我会用更多美好的记忆来装饰我们未来的生活。 
About the author 


\section{Curriculum Vitae}

Jun Qiu was born on $26^{\text {th }}$ April, 1989, in Nantong, Jiangsu Province, China. After finishing a 6-years study in the middle and high school affiliated to Nantong No.1 Middle School, he started his bachelor study of Food Science and Technology at South China University of Technology in 2008. In 2012, Jun started his master programme of Food Technology at

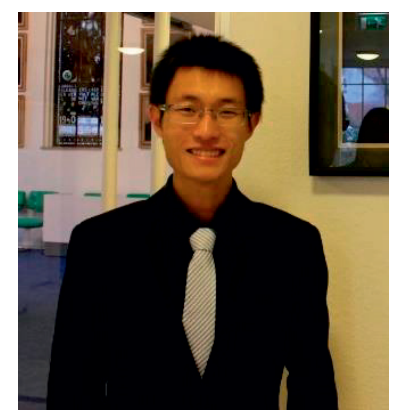
Wageningen University and Research. He finished his MSc thesis at the Laboratory of Food Process Engineering under the supervision of Dr. Jacob Bouman and Dr. Maarten Schutyser studying morphology development of whey protein droplets during single droplet drying. He carried out his MSc internship at R\&D Unilever Vlaardingen under the supervision of Dr. Seddik Khalloufi on modelling volume reduction of food products during drying. After obtaining his MSc degree in 2014, he started his PhD research at the Laboratory of Food Process Engineering under the supervision of Dr. Maarten Schutyser and Prof. dr. Remko Boom. The results of his PhD research are presented in this thesis.

E-mail: ntqiujun@163.com 


\section{List of publication}

Qiu, J., Khalloufi, S., Martynenko, A., Van Dalen, G., Schutyser, M., \& Almeida-Rivera, C. (2015). Porosity, bulk density, and volume reduction during drying: review of measurement methods and coefficient determinations. Drying Technology, 33(14), 1681-1699.

Qiu, J., Vuist, J.-E., Boom, R. M., \& Schutyser, M. A. I. (2018). Formation and degradation kinetics of organic acids during heating and drying of concentrated tomato juice. LWT - Food Science and Technology, 87(C), 112-121.

Qiu, J., Boom, R., \& Schutyser, M. (2018). Agitated thin-film drying of foods. Drying Technology, 1-10.

Qiu, J., Kloosterboer, K., Guo, Y., Boom, R. M., \& Schutyser, M. A. I. (2019). Conductive thin film drying kinetics relevant to drum drying. Journal of food engineering, 242, 68-75.

Qiu, J., Acharya, P., Jacobs. D.M., Boom, R. M., \& Schutyser, M. A. I.. A systematic analysis on tomato powder quality prepared by four conductive drying technologies. Submitted for publication.

Qiu, J., Boom, R. M., \& Schutyser, M. A. I.. Model development for conductive thin film drying process. Submitted for publication. 


\section{Overview of completed training activities}

\section{Discipline specific activities}

\section{Courses}

COMSOL - Multiphysics 2-day Intensive Training (COMSOL, Eindhoven, the Netherlands, 2015).

Advanced Thermodynamics (OSPT, Delft, the Netherlands, 2016).

Advanced Food Analysis ${ }^{2}$ (VLAG, Wageningen, the Netherlands, 2017).

Numerical Methods for Chemical Engineers (OSPT, Eindhoven, the Netherlands, 2017).

International School on Modelling and Simulation in Food and Bio Process MSFS2017 (COST, Seiano-Vico Equense, Italy, 2017).

\section{Conferences and meetings}

A Joint Event on Intensified Separation and Intensified Drying (ECN, Petten, the Netherlands, 2015).

Rockwell Automation: A Joint Event (NWGD, Ede, the Netherlands, 2015).

5th European Drying Conference ${ }^{1}$ (MKE, Budapest, Hungary, 2015).

Program Autumn Session PIN-NL-NWGD (Intensifying-Drying) (NWGD, Helmond, the Netherlands, 2015).

NWGD Symposium 2015 (NWGD, Wageningen, the Netherlands, 2015).

NWGD Symposium 2016 (NWGD, Wageningen, the Netherlands, 2016).

6th European Drying Conference ${ }^{1}$ (University of Liège, Liège, Belgium, 2017).

NWGD Symposium 2017 (NWGD, Wageningen, the Netherlands, 2017).

International Drying Symposium ${ }^{1}$ (IDS, València, Spain, 2018). 
NWGD Symposium $2018^{1,2}$ (NWGD, Wageningen, the Netherlands, 2018).

\section{$\underline{\text { General courses }}$}

PhD Workshop Carousel (WGS, Wageningen, the Netherlands, 2015).

Presenting with Impact (WGS, Wageningen, the Netherlands, 2015).

VLAG PhD Week (VLAG, Baarlo, the Netherlands, 2015).

PhD Workshop Carousel (WGS, Wageningen, the Netherlands, 2016).

Chemometrics (VLAG, Wageningen, the Netherlands, 2016).

Scientific Writing (WGS, Wageningen, the Netherlands, 2017).

Career Perspectives (WGS, Wageningen, the Netherlands, 2018).

\section{Optional activities}

Preparation of research proposal (FPE, Wageningen, the Netherlands, 2015).

PhD study tour to Switzerland and Germany ${ }^{1,2}$ (FPE, 2016).

PhD study tour to Canada ${ }^{1,2}$ (FPE, 2018).

Weekly group meetings ${ }^{1}$ (FPE, Wageningen, the Netherlands, 2015-2019).

Teaching: Mathematical Concepts for food technology $(2015,2016,2017)$.

${ }^{1}$ : Oral presentation; ${ }^{2}$ : Poster presentation;

COST: European Cooperation in Science and Technology;

ECN: Energy Research Centre of the Netherlands;

FPE: Food Process Engineering;

MKE: Magyar Kémikusok Egyesulete;

NWGD: Nederlandse Werkgroep Drogen;

OPST: Dutch Research School in Process Technology;

VLAG: Graduate School for Nutrition, Food Technology, Agrobiotechnology and Health Sciences.

WGS: Wageningen Graduate Schools 
The work described in this thesis was carried out in the framework of the Institute of Sustainable Process Technology (ISPT) under the project 'DR-2003': Thin Film Drying.

Financial support from Wageningen University \& Research for printing this thesis is gratefully acknowledged.

Cover design by Yipeng Gu and Jun Qiu

This thesis was printed by Digiforce \|| ProefschriftMaken.

Jun Qiu, April 2019 


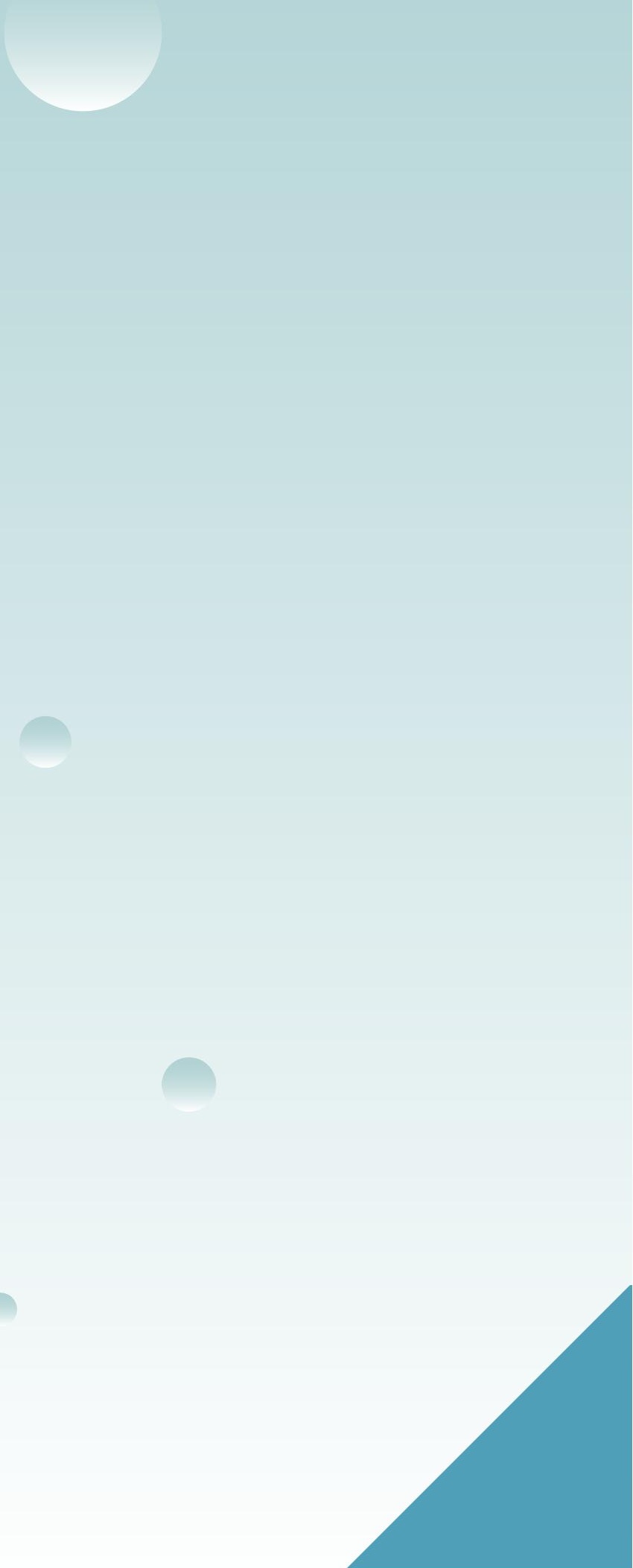